University of Louisville

ThinkIR: The University of Louisville's Institutional Repository

Electronic Theses and Dissertations

8-2017

\title{
A cross-sectional exploration of household financial reactions and homebuyer awareness of registered sex offenders in a rural, suburban, and urban county.
}

John Charles Navarro

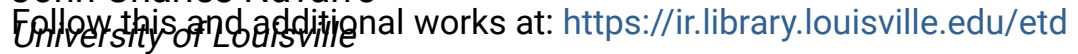

Part of the Agency Commons, Applied Statistics Commons, Behavioral Economics Commons, Criminal Law Commons, Criminal Procedure Commons, Criminology Commons, Criminology and Criminal Justice Commons, Demography, Population, and Ecology Commons, Design of Experiments and Sample Surveys Commons, Econometrics Commons, Economic Policy Commons, Finance Commons, Geographic Information Sciences Commons, Health Economics Commons, Health Law and Policy Commons, Home Economics Commons, Housing Law Commons, Human Ecology Commons, Labor Economics Commons, Law and Economics Commons, Law and Society Commons, Legal Ethics and Professional Responsibility Commons, Multivariate Analysis Commons, Other Economics Commons, Property Law and Real Estate Commons, Public Economics Commons, Public Policy Commons, Quantitative, Qualitative, Comparative, and Historical Methodologies Commons, Real Estate Commons, Regional Sociology Commons, Rural Sociology Commons, Social Statistics Commons, Sociology of Culture Commons, Spatial Science Commons, Statistical Methodology Commons, Urban Studies Commons, and the Urban Studies and Planning Commons

\section{Recommended Citation}

Navarro, John Charles, "A cross-sectional exploration of household financial reactions and homebuyer awareness of registered sex offenders in a rural, suburban, and urban county." (2017). Electronic Theses and Dissertations. Paper 2768.

https://doi.org/10.18297/etd/2768

This Doctoral Dissertation is brought to you for free and open access by ThinkIR: The University of Louisville's Institutional Repository. It has been accepted for inclusion in Electronic Theses and Dissertations by an authorized administrator of ThinkIR: The University of Louisville's Institutional Repository. This title appears here courtesy of the author, who has retained all other copyrights. For more information, please contact thinkir@louisville.edu. 


\title{
A CROSS-SECTIONAL EXPLORATION OF HOUSEHOLD FINANCIAL REACTIONS AND HOMEBUYER AWARENESS OF REGISTERED SEX OFFENDERS IN A RURAL, SUBURBAN, AND URBAN COUNTY
}

\author{
By \\ John Charles Navarro \\ B.S., Illinois State University, 2011 \\ M.S., Illinois State University, 2014

\begin{abstract}
A Dissertation
Submitted to the Faculty of the

for the Degree of

Doctor of Philosophy

In Criminal Justice

Department of Criminal Justice

University of Louisville

Louisville, Kentucky
\end{abstract} \\ College of Arts and Sciences of the University of Louisville \\ to Partial Fulfillment of the Requirements
}

August 2017 
Copyright 2017 by John Charles Navarro

All rights reserved 



\section{A CROSS-SECTIONAL EXPLORATION OF HOUSEHOLD FINANCIAL REACTIONS AND HOMEBUYER AWARENESS OF REGISTERED SEX OFFENDERS IN A RURAL, SUBURBAN, AND URBAN COUNTY \\ By \\ John Charles Navarro \\ B.S., Illinois State University, 2011 \\ M.S., Illinois State University, 2014 \\ A Dissertation Approved on}

June 30, 2017

by the following Dissertation Committee:

\begin{tabular}{|c|}
\hline $\begin{array}{c}\text { Dissertation Director } \\
\text { Kirstin M. Swartz }\end{array}$ \\
\hline Jill L. Adelson \\
\hline George E. Higgins \\
\hline Justin Nix \\
\hline
\end{tabular}




\section{DEDICATION}

This dissertation is dedicated to my babcia, Dr. Jaqwellyn Schneider (A.K.A. Dr. Jacqueline Schneider), Dr. Cara Rabe-Hemp, Dr. Edward L. Wells, and the women staff (Ginger, Kam, Karen, Kim, Jen, and Sandy) of the second floor of Brigman Hall for being there. These selfless individuals deserve more than a mere dedication as their

efforts are beyond gratitude, although a career that is an exhibition of their efforts is one way of expressing my gratefulness. 


\section{ACKNOWLEDGEMENTS}

For the public, commendations must be addressed, Illinois county assessor's units, and Jefferson County for their participatory efforts. Without their data contributions, this project would not have been achieved.

Keeping in line with contributions, survey design and methodologies must be thanked to several entities and persons. The advice of Drs Justin Nix and Ralph Weisheit escorted construction of the survey format and delivery. The manufacturing of surveys was kept within their timelines because of the assistance of Drs. Cara Rabe-Hemp and kooky Jaqwellyn Schneider, and the two daughters (Ashley and Morgan) of Morgan Sponholtz, Office Depot, Terri Schneider, and The Woollens.

Burdensome were the spatial analyses. Drs. Jason Ingram and Matthew Ruther undertook conversations with me regarding incessant statistical inquiries for which I am rich with gratefulness.

Yearning for a strong dissertation committee, Drs. Kristin M. Swartz, Jill L. Adelson, George E. Higgins, and Justin Nix fulfilled their obligations. My project was notably tumultuous, but each person endured, especially Dr. Kristin Swartz, whose durability, encouragement, and optimism will not be forgotten.

Underneath my devotion to the completion of my dissertation was Miss Audrey,

often referred to as my grandmother, and the women staff belonging to the University of Louisville's second floor of Brigman Hall. 


\section{ABSTRACT}

\section{A CROSS-SECTIONAL EXPLORATION OF HOUSEHOLD FINANCIAL REACTIONS AND HOMEBUYER AWARENESS OF REGISTERED SEX OFFENDERS IN A RURAL, SUBURBAN, AND URBAN COUNTY}

John C. Navarro

June 30, 2017

As stigmatized persons, registered sex offenders betoken instability in communities. Depressed home sale values are associated with the presence of registered sex offenders even though the public is largely unaware of the presence of registered sex offenders. Using a spatial multilevel approach, the current study examines the role registered sex offenders influence sale values of homes sold in 2015 for three U.S. counties (rural, suburban, and urban) located in Illinois and Kentucky within the social disorganization framework. Homebuyers were surveyed to examine whether awareness of local registered sex offenders and the homebuyer's community type operate as moderators between home selling prices and the distance to the nearest registered sex offender. Registered sex offenders were not associated with home sale values after accounting for neighborhood characteristics. Urban homebuyers were most likely to be aware of local registered sex offenders. The homebuyers' proximity to the nearest registered sex offenders is not related to the awareness of nearby registered sex offenders. Non-urban and urban homebuyers who are aware tend to reside further from registered sex offenders and buy higher priced homes, whereas unaware homebuyers seemingly buy homes without the consideration of nearby registered sex offenders. The importance of neighborhood characteristics in a spatial multilevel framework and the effects of sex 
offender policies are highlighted. 


\section{TABLE OF CONTENTS}

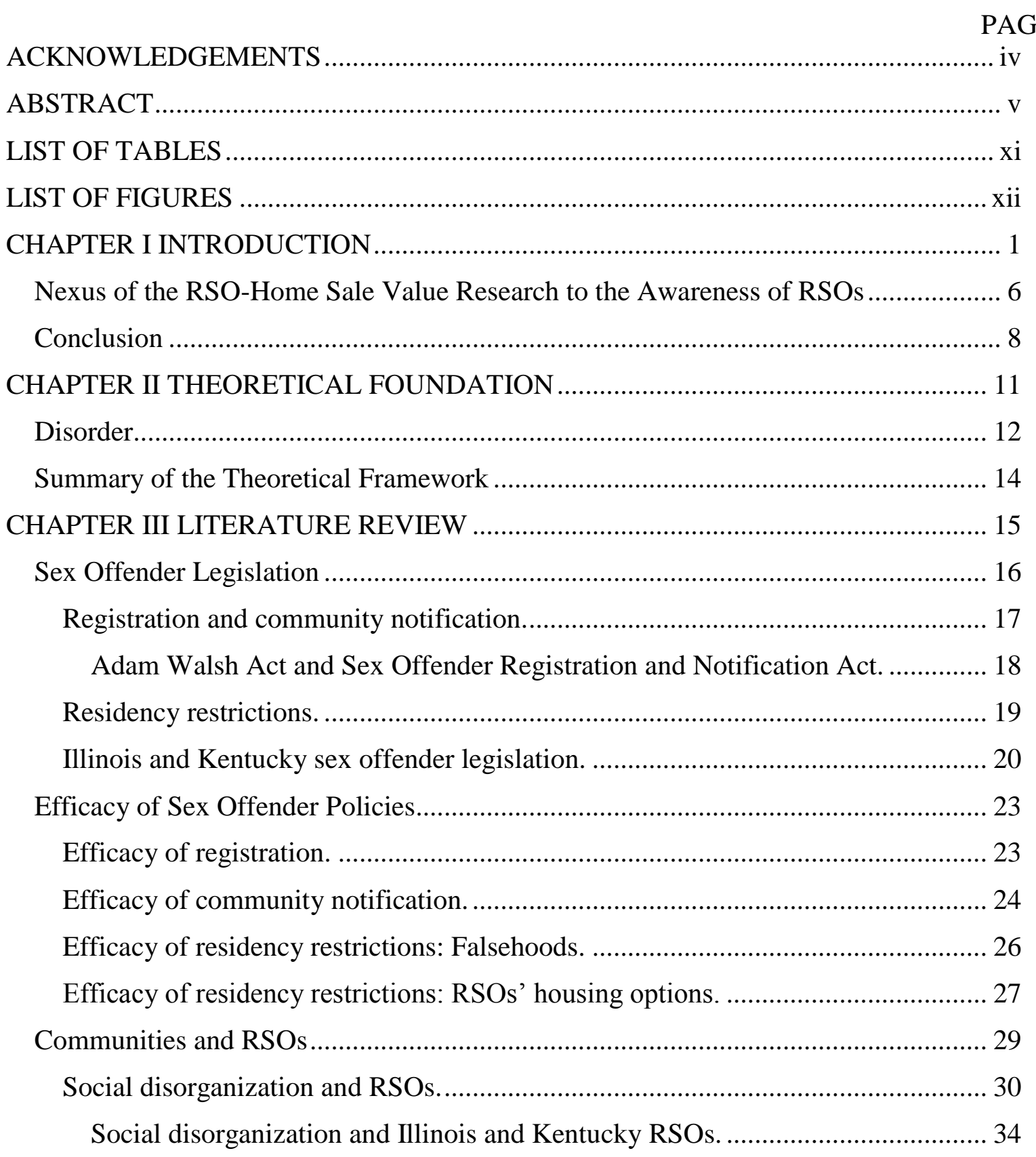




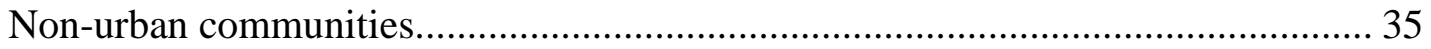

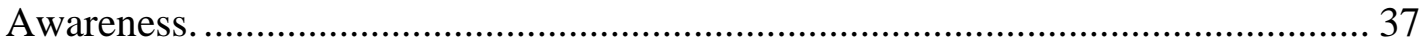

Access to public information of RSOs.............................................................. 39

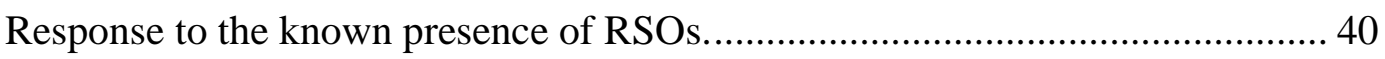

The fear of sexual victimization. ........................................................... 40

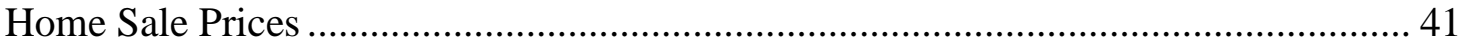

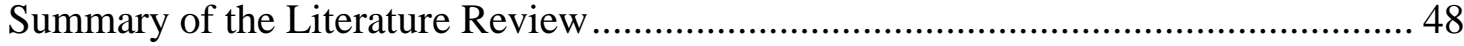

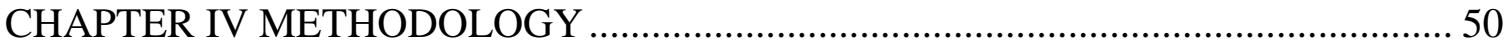

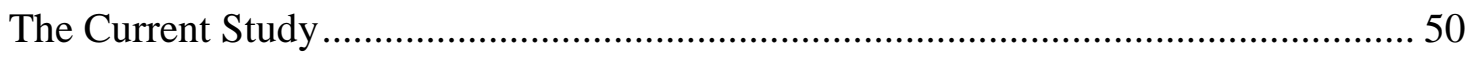

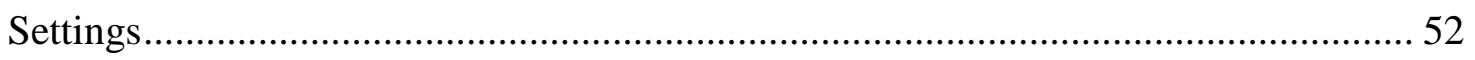

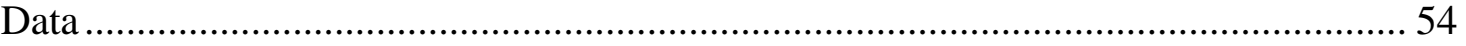

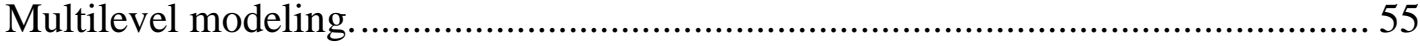

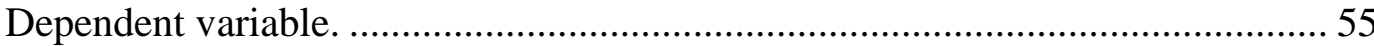

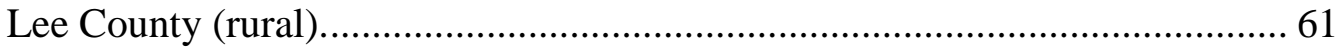

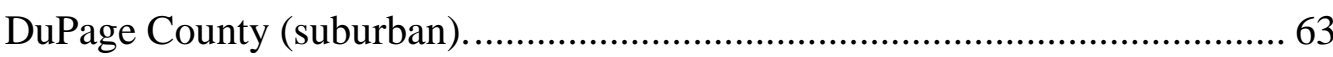

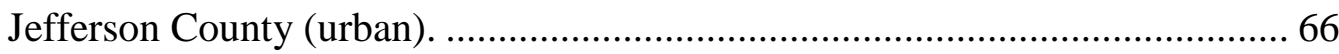

Primary independent variable: The distance to the nearest RSO....................... 68

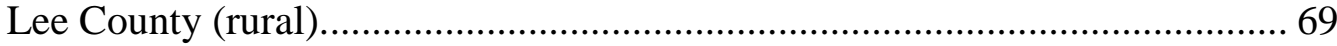

DuPage County (suburban)............................................................... 70

Jefferson County (urban). ................................................................ 70

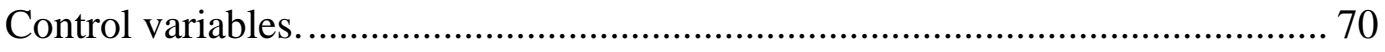

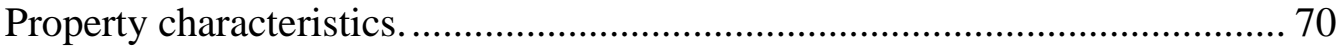

Neighborhood characteristics............................................................... 71

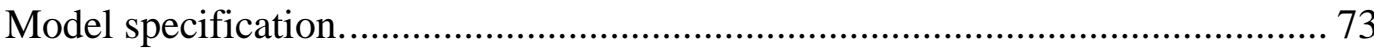

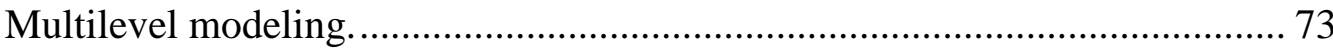

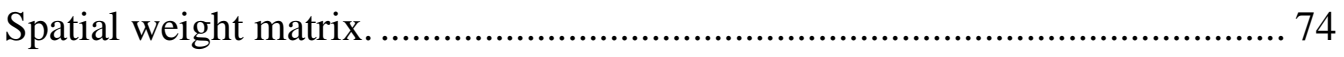

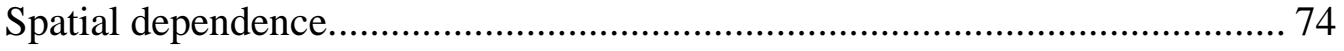

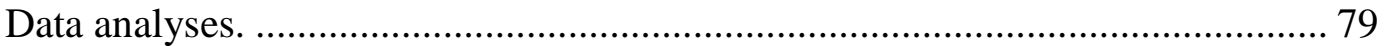

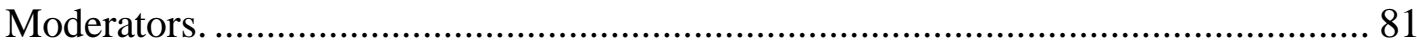

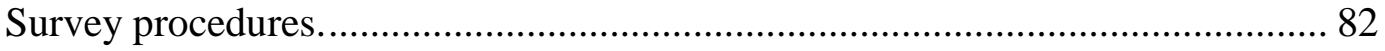

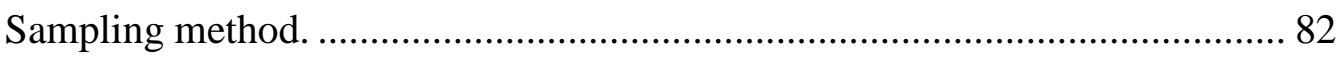


Homebuyer survey process........................................................... 83

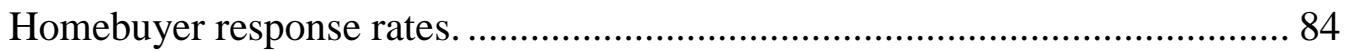

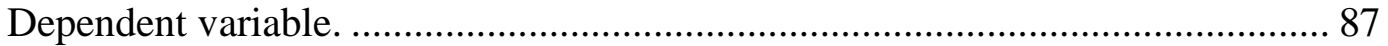

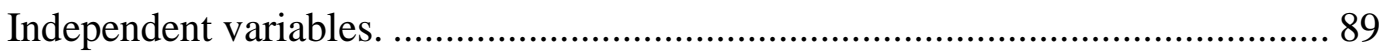

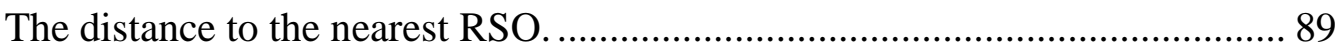

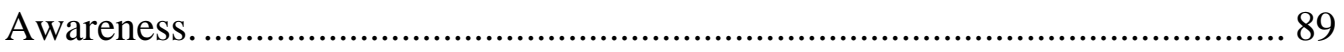

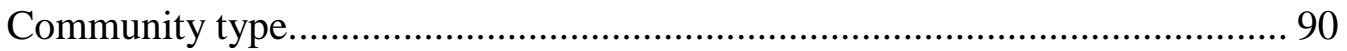

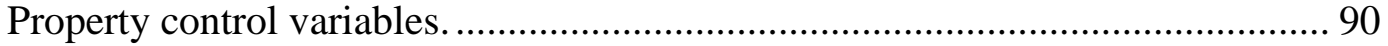

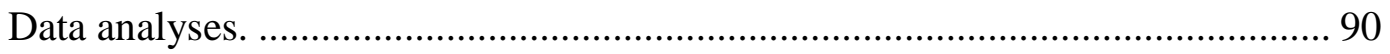

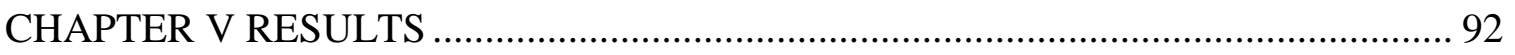

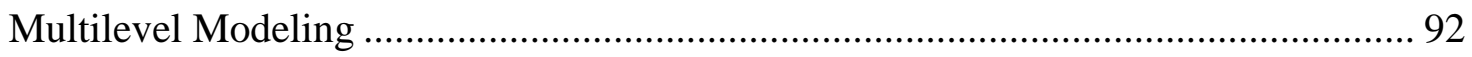

Unconditional model (one-way ANOVA with random effects model)................... 92

Level-1 models (random coefficients models). .................................................... 94

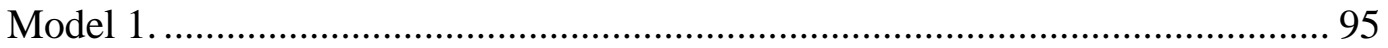

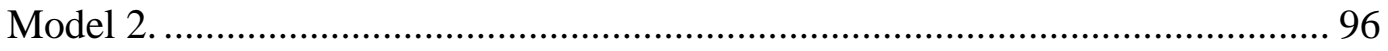

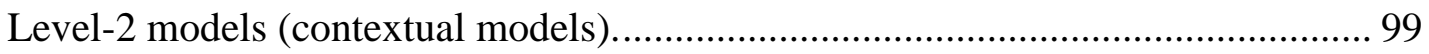

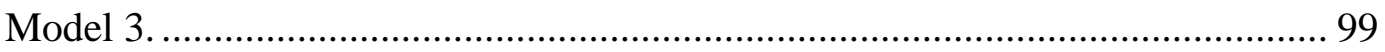

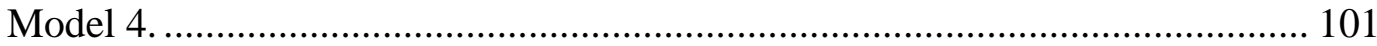

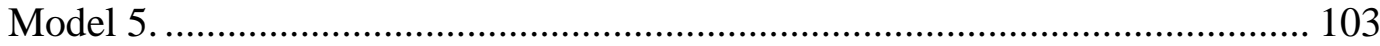

Final model. ....................................................................................... 108

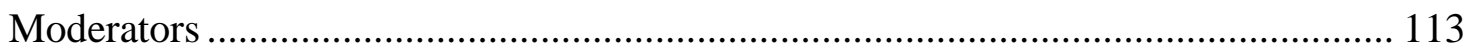

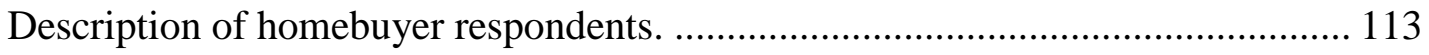

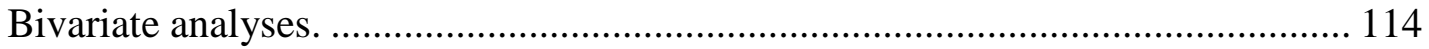

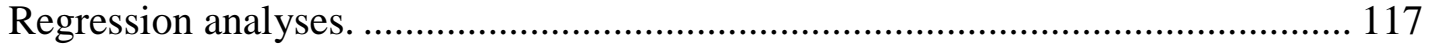

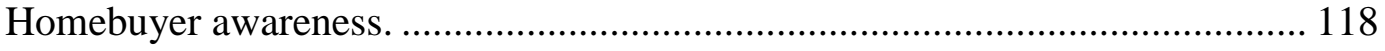

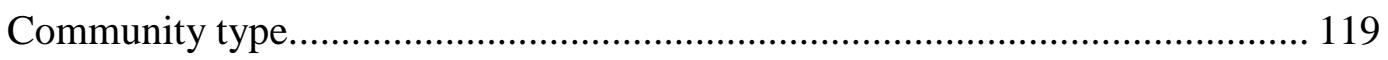

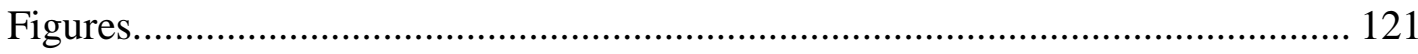

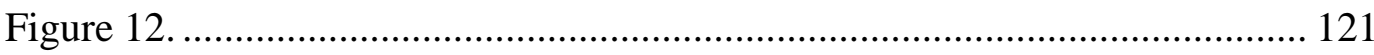

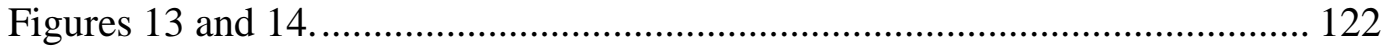

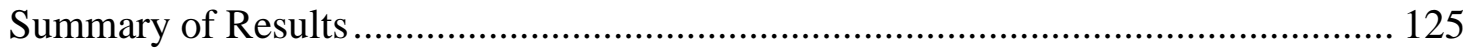

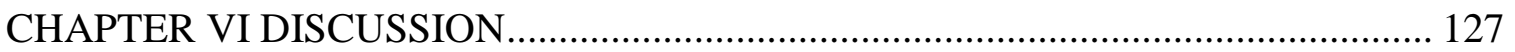

Policy Implications and Recommendations................................................ 134 


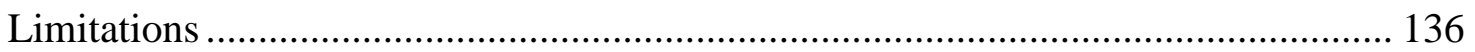

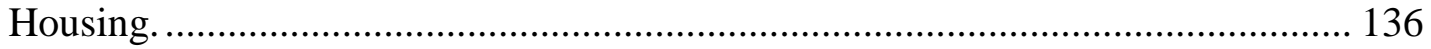

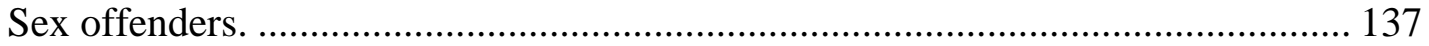

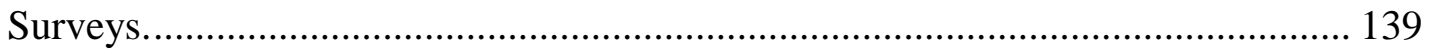

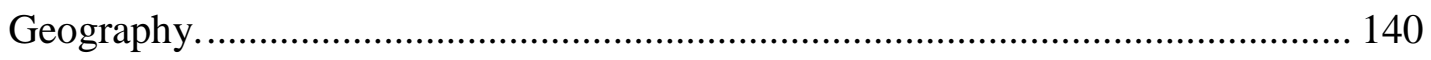

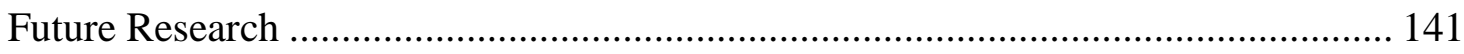

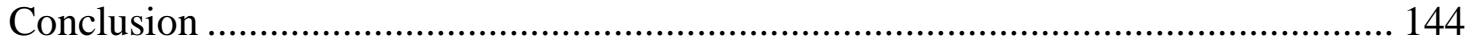

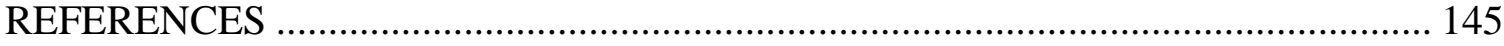

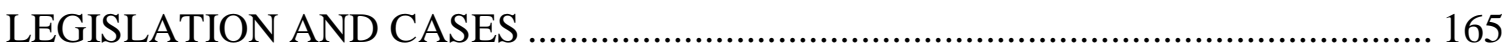

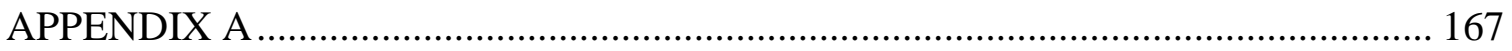

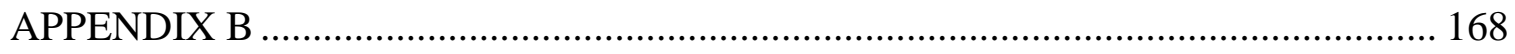

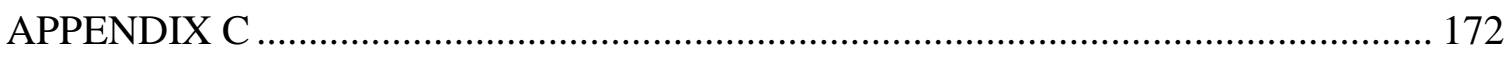

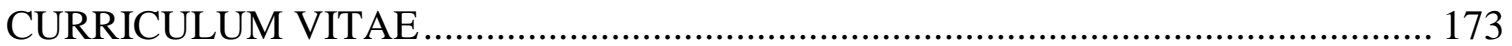




\section{LIST OF TABLES}

TABLE

1. Unfavorable Neighborhood Characteristics Associated With RSOs Identified by Studies 31

2. Multilevel Descriptive Statistics for All Variables 61

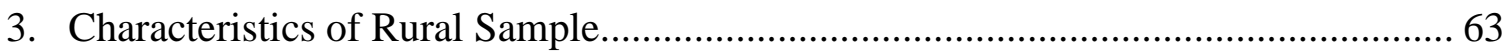

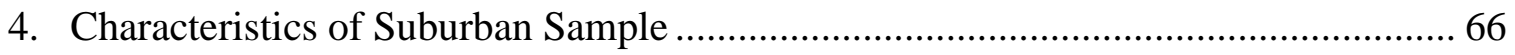

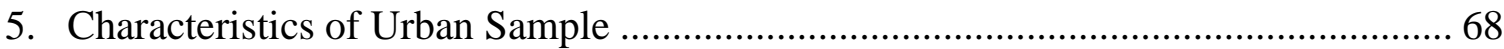

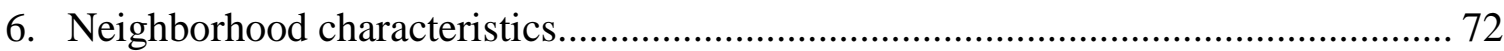

7. Descriptives of Sampling Method per Wave and Waves Combined........................... 85

8. Characteristics of Non-Urban Homebuyer Respondents and Urban Homebuyer Respondents within 1,000 Feet of the Nearest RSO ................................................. 88

9. Unconditional Model of Home Sale Values ................................................................. 94

10. Random Coefficients Models With Level-1 Property and Residential Characteristics

11. Contextual Models With Level-1 (Property/Residential-Level) and Level-2 (Neighborhood-Level) Control Characteristics 105

12. Final Model With Level-1 (Residential-Level) and Level-2 (Neighborhood-Level) Control Characteristics 109

13. Model Fit Comparisons. 112

14. Descriptives and Cross Tabulations of Non-Urban and Urban Respondents Awareness of RSOs Within 1,000 Feet of Their Property..... 114

15. Correlations $(\mathrm{N}=277)$ 116

16. OLS Regressions of Home Selling Prices with Property Characteristics as Controls, Distance to the Nearest RSO, and Moderators ( $\mathrm{N}=277)$. 120 17. Summary of Hypotheses and Findings 126 


\section{LIST OF FIGURES}

FIGURE

1. An illustration of the current study's data.....

2. Calculated means of home selling prices and median household values across census block groups (or neighborhoods) in Lee County, Illinois.

3. Calculated means of home selling prices and median household values across census block groups (or neighborhoods) in DuPage County, Illinois 66

4. Calculated means of home selling prices and median household values across census block groups (or neighborhoods) in Jefferson County, Kentucky

5. Locations of sold homes and RSOs across block groups in Lee County, Illinois ...... 70

6. Locations of sold homes and RSOs across block groups in DuPage County, Illinois 73

7. Locations of sold homes and RSOs across block groups in Jefferson County, Kentucky 75

8. Queen's contiguity.....

9. LISA cluster map of the weighted average of sold homes' selling prices (logged) in Lee County, Illinois

10. LISA cluster map of the weighted average of sold homes' selling prices (logged) in DuPage County, Illinois 86

11. LISA cluster map of the weighted average of sold homes' selling prices (logged) in Jefferson County, Kentucky.

12. Scatter plot of community type moderating the relationship between home selling prices and the centered distance to the nearest RSO.

13. Scatter plot of non-urban homebuyers (classified by awareness) and its relationship between home selling prices and the centered distance to the nearest RSO 
14. Scatter plot of non-urban homebuyers (classified by awareness) and its relationship between home selling prices and the centered distance to the nearest RSO............. 130 


\section{CHAPTER I}

\section{INTRODUCTION}

Stigmatized persons are those whose characteristics are blemished by various undesirable traits, such as imprisonment, a mental disorder, or unemployment (Goffman, 1963). Persons who do not possess these traits,- - otherwise referred to as "normals"view individuals who have experienced the undesirable features or traits above as social pariahs. Henceforth, a social pariah is fitted into a preconceived notion of being a traditional social deviant. One such sect of stigmatized persons includes criminal offenders given their linkage as being social deviants, especially registered sex offenders (RSOs). In support of this argument, offenders who have committed sex crimes experience stigma that is above and beyond those without the sex offender label (Hipp, Turner, \& Jannetta, 2010; Rade, Desmarais, \& Mitchell, 2016; see Tewksbury, 2012; Tewksbury \& Lees, 2006). Some registered sex offenders have self-imposed an isolated lifestyle that is then exacerbated by the stigma associated with their sex offender status (Burchfield \& Mingus, 2008).

Stigmatized individuals and "normals" might find themselves mixed in the same social situation either physically or socially (e.g., conversation, gathering). "Normals" (or the public, assuming that they are without a sexual conviction history) hold a greater negative attitude toward RSOs than ex-offenders without sexual convictions (Rade et al., 
2016). Correspondently, RSOs have reported feelings of inferiority and ostracism when among the general populace (Burchfield \& Mingus, 2008; Evans \& Cubellis, 2015; Levenson \& Cotter, 2005; Levenson, D’Amora, \& Hern, 2007b; Mustaine \& Tewksbury, 2011a; see Tewksbury, 2012; Tewksbury \& Lees, 2006; Tewksbury \& Mustaine, 2010; Zevitz \& Farkas, 2000b). Feelings of contempt against RSOs by the public parallel with Goffman's (1963) thesis of the reactions expressed by "normals" to the presence of stigmatized persons.

Under these circumstances, "normals" can engage in acts of discrimination. Several acts of (legal) discrimination enforced upon RSOs have been propelled by sex offender legislation, which these laws are reviewed in the present study to convey the stigmas associated with being a RSO. These legal acts of discrimination prompted a variety of adverse effects (better known as collateral consequences) for RSOs. Primary among the collateral consequences faced by convicted sex offenders is their relegation into socially disadvantaged communities (Burchfield \& Mingus, 2008; Clark \& Duwe, 2015; Craun, 2010; Gordon, 2013; Hipp et al., 2010; Huebner et al., 2013; Hughes \& Burchfield, 2008; Hughes \& Kadleck, 2008; Mustaine \& Tewksbury, 2008; Mustaine, Tewksbury, \& Stengel, 2006b; Mustaine \& Tewksbury, 2011b; see also Yeh, 2015; Sloas, Steele, \& Hare, 2012; Socia, 2011, 2012a, 2016; Socia, Levenson, Ackerman, \& Harris, 2015; Socia \& Stamatel, 2012; Suresh, Mustaine, Tewksbury, \& Higgins, 2010; Tewksbury \& Mustaine, 2006, 2008; Tewksbury, Mustaine, \& Rolfe, 2016). Another act of discrimination included banishment into the outskirts of the main metropolitan cities (Berenson \& Appelbaum, 2011; Chajewski \& Mercado, 2009; see Huebner et al., 2013; see also Socia, 2011, 2012a; Zandbergen \& Hart, 2006). As a consequence of legal 
discrimination like residency restrictions housing options for RSOs are severely limited (Barnes, Dukes, Tewksbury, \& De Troye, 2009; Berenson \& Appelbaum, 2011;

Burchfield \& Mingus, 2008; Chajewski \& Mercado, 2009; Clark \& Duwe, 2015; Duwe, Donnay, \& Tewksbury, 2008; Huebner et al., 2013; Socia, 2011, 2012a, 2016; Socia et al., 2015; Tewksbury \& Mustaine, 2010; Zandbergen \& Hart, 2006; Zevitz \& Farkas, 2000b). Given these acts of discrimination, it is apparent that mainstream society rejects RSOs as there is a desire to keep RSOs outside the consciousness of the public.

To explain the socio-ecological interactions between an environment and persons within said environment Clifford Shaw and Henry D. McKay’s social disorganization theory is most apt for the present study's objectives. Shaw and McKay (1942) argued that neighborhoods ${ }^{1}$ that contain greater rates of the "negative" indicators like high rates of poverty, minorities, and population turnover be considered socially disorganized (or disadvantaged) areas, and in turn, susceptible to criminality. Paralleling with the theory's foundation, the presence of RSOs have been associated with communities that contained high rates of concentrated disadvantage (Clark \& Duwe, 2015; Hipp et al., 2010; Huebner et al., 2013; Hughes \& Burchfield, 2008; Hughes \& Kadleck, 2008; Mustaine \& Tewksbury, 2011b; Socia, 2011, 2012a, 2016), racial/ethnic heterogeneity (Clark \& Duwe, 2015; Craun, 2010; Hipp et al., 2010; Hughes \& Burchfield, 2008; Hughes \& Kadleck, 2008; Mustaine \& Tewksbury, 2011b; Socia, 2011, 2012a, 2016; Socia \& Stamatel, 2012), and residential instability (Clark \& Duwe, 2015; Hipp et al., 2010;

\footnotetext{
${ }^{1}$ Hereafter, the present study will utilize the terms community and neighborhood to describe two different concepts. Community is in reference to a broader social network of people, and, at times, a larger geographic boundary; whereas, neighborhoods are smaller social-geographic networks of people, with a greater emphasis on a geographic vicinity (The Minnesota Governor's Council on Developmental Disabilities, 2016). Some overlap between these two terms may occur, as the present study will also honor the terms used by the scholars cited.
} 
Hughes \& Burchfield, 2008; Hughes \& Kadleck, 2008; Mustaine \& Tewksbury, 2011b; Socia, 2011, 2012a, 2016). The sex offender literature has suggested that RSOs are relegated (away from affluent communities and) into disadvantaged communities that already have the adversity to overcome systemic socio-ecological issues (Clark \& Duwe, 2015; Hughes \& Burchfield, 2008; Hughes \& Kadleck, 2008; Mustaine \& Tewksbury, 2011b; Mustaine, Tewksbury, \& Stengel, 2006a, 2006b; see Burchfield \& Mingus, 2008). In contrast to disadvantaged communities, affluent communities inherently contain the meaningful social resources to push out RSOs who are linked as disruptors of the socialecological homeostasis of communities (Clark \& Duwe, 2015; Hughes \& Burchfield, 2008; Hughes \& Kadleck, 2008).

Social disorganization theory also laid the foundation for neighborhood disorder (also known as incivilities) and dichotomized as a physical or social disorder (Ross \& Mirowsky, 1999). As an outcome of social disorganization, the presence of disorder can compromise the strength of a community's physical and social fabric (Abdullah, Marzbali, Woolley, \& Bahauddin, \& Maliki, 2014; Austin, Furr, \& Spine, 2002; BruntonSmith \& Sturgis, 2011; Kubrin \& Weitzer, 2003; Perkins \& Taylor, 1996; Ross \& Mirowsky, 1999; Skogan, 1990; Skogan \& Maxfield, 1981). The presence of these incivilities can influence local residents' perceived risk of victimization based on the degree of criminality in their environment. Residents are reasonably accurate in gauging objective (observational forms of) disorder (Perkins \& Taylor, 1996), but the (objective) disorder is in the eye of the beholder (Gau \& Pratt, 2008). It can be argued that a local RSO be an objective form of disorder because RSOs in communities indicated social disorganization (see Gordon, 2013). Because like disorder, concentrations of RSOs can 
promote additional layers of disadvantage in already vulnerable communities (Burchfield \& Mingus, 2008). Gordon (2013) argued that a greater number of RSOs should be considered as a form of social disorder. In support of her logic, concentrations of RSOs have yielded concerns by residents' of additional RSOs relocating into the neighborhood (Zevitz, 2004) and (increased) fears of victimization (Beck \& Travis, 2004; Brown, Deakin, \& Spencer, 2008; Craun \& Theriot, 2009; Kernsmith, Craun, \& Foster, 2009; Levenson, Brannon, Fortney, \& Baker, 2007a; Zevitz, 2004; Zevitz \& Farkas, 2000a). Therefore, it would not be difficult to fathom that the areas around RSO residences' are less appealing areas to be inhabited by the public, thereby resulting in depressed housing values to make residences surrounding RSOs more financially attractive to the public.

Financial reactions via home values may be suggestive of an avoidance of RSOs by the public. Real estate markets in various jurisdictions have been compromised in the form of depressed home selling prices as a consequence of the presence of RSOs (Bian, Brastow, Waller, Stoll, \& Wentland, 2013; Caudill, Affuso, \& Yang, 2014; Larsen, Lowrey, \& Coleman, 2003; Linden \& Rockoff, 2008; Navarro \& Rabe-Hemp, 2017; Pope, 2008; Wentland, Waller, \& Brastow, 2014; Yeh, 2015)—referred to as the RSOhome sale value research in the present study. However, existent within each of these publications are methodological issues that were not assessed. Issues included not partitioning clustered data (i.e., homes nested within neighborhoods) and not accounting for neighborhood characteristics, or for spatial dependence (things closer to one another are more strongly related) and autocorrelation (observations correlated with one another in a spatial dimension). Because previous researchers had not accounted for these methodological issues, the relationships so far suggested in the RSO-home sale research 
may be based on spurious conclusions. The primary focus of the present study is to address the methodological issues so far present in the RSO-home sale value scholarship to ascertain whether the conclusion that RSOs are associated with (depressed) home selling prices is valid.

Environmental surroundings of RSOs is another crucial element to be addressed. A body of literature has also shown that not all environments RSOs inhabited are socially disorganized (Burchfield \& Mingus, 2008; Craun, 2010; Huebner et al., 2013; Mustaine et al., 2006a, 2006b; Socia \& Stamatel, 2012; Tewksbury \& Mustaine, 2006; Tewksbury, Mustaine, \& Stengel, 2007). Mixed results may be due to not exploring individual effects of neighborhood characteristics but rather creating neighborhood characteristics to align with the structural dimensions of social disorganization (e.g., concentrated disadvantage), using of larger units of analysis (e.g., census tracts), or the setting explored (e.g., rural). Thus, the present study includes the effects of neighborhood characteristics (e.g., femaleheaded households) with census block groups as proxies for neighborhoods in settings that are explicitly defined as rural, suburban, and urban (see Ingram \& Franco, 2014) to reduce specification error related to the presence of RSOs.

\section{Nexus of the RSO-Home Sale Value Research to the Awareness of RSOs}

In line with Goffman's (1963) thesis of stigma, RSOs socially operate in either a public (discredited) or anonymous venue (discreditable). Sex offender policies encouraged the creation and development of sex offender registries, a tool that aligns with what Goffman has coined as symbols of stigma. These registries manage and transmit personally identifying information of RSOs that was designed to empower residents to inform themselves about local RSOs (Levenson et al., 2007a; Mustaine \& 
Tewksbury, 2013). Publicly accessible registries became acts of (legal) discrimination against RSOs, with sex offender registries now available online to all jurisdictions. With Goffman's logic, a RSO whose identity is known by nearby community members (e.g., homebuyers) is viewed as a discredited person (see Evans \& Cubellis, 2015). Once the presence of the offender is known it creates unease in the surrounding areas (Anderson \& Sample, 2008; Beck \& Travis, 2004; Brown et al., 2008; Caputo \& Brodsky, 2004; Craun \& Theriot, 2009; Kernsmith, Craun et al., 2009; Levenson et al., 2007a; Lieb \& Nunlist, 2008; Phillips, 1998; Zevitz, 2004; Zevitz \& Farkas, 2000a).

Paradoxically, these acts of discrimination have socially isolated RSOs because their information is broadcasted and induced fear among the general population (Tewksbury, 2012; Zevitz, 2004). These legislative responses are considered antitherapeutic. Forced social isolation of stigmatized persons - in this case, RSOs—are unhealthy tactics considering offenders have begun their reentry into a society already socially handicapped (Goffman, 1963; Huebner et al., 2013; Hughes \& Burchfield, 2008; Zevitz \& Farkas, 2000b). Because of their celebrated public identity coupled with public misperceptions, RSOs may identify themselves as so discredited that they may recidivate because the outcome is no worse than their current state of being (Goffman, 1963; see Evans \& Cubellis, 2015; see also Prescott \& Rockoff, 2011).

Different from the discredited (e.g., visible deformity), the discreditable are persons whose identities are not readily known by the public (Goffman, 1963). One of the primary issues of sex offender registration and notification laws is the assumption held by policymakers that community members have capitalized on the public release of information concerning where RSOs live (Agan \& Prescott, 2014). Sex offender laws 
were intended to empower community members, thereby, encourage the transmission of the whereabouts of local RSOs. However, that notion is far from the truth. The general populace has not actively utilized the tools (like accessing online sex offender registries) meant to facilitate information about RSOs, and, for the most part, unaware of RSOs in their environments (Anderson, Evans, \& Sample, 2009; Anderson \& Sample, 2008; Beck \& Travis, 2006; Burchfield, 2012; Craun, 2010; Kernsmith, Comartin, Craun, \& Kernsmith, 2009; Kernsmith, Craun, et al., 2009; Lieb \& Nunlist, 2008; Phillips, 1998; Zevitz, 2004). Additionally, awareness of local RSOs may vary by community types, as rural residents are more likely to be aware of local RSOs than urban residents (Phillips, 1998) with the awareness of RSOs in suburban areas left unexplored. It is quite trivial that the RSO-home sale value literature has suggested offenders are associated with depressed home sale values when a sizeable portion of community members is unaware of the presence of RSOs. The present study will disentangle the relationship between RSOs-depressed home sale values across contexts with a more suitable analytical strategy, multilevel modeling (HLM 7.01; Raudenbush, Bryk, \& Congdon, 2013), and will account for spatial dependence, with an ancillary focus to fill the gap of homebuyer awareness of local RSOs across different types of communities.

\section{Conclusion}

Altogether, the present study has two primary objectives. The main aim of this quantitative-based dissertation is to add clarity to and strengthen the RSO-home sale value literature by detailing the variation explained by property and neighborhood characteristics alongside the presence of RSOs in communities with the use of rigorous appropriate analytical methods. From a methodological and theoretical perspective, the 
incorporation of spatial effects (via Arc Geographic Information Systems [GIS] and GeoDa) must be considered among contemporary social disorganization researchers (Kubrin \& Weitzer, 2003) to assess and to reduce the influence of nearby home selling prices. Further, because the observations occur at two different levels of analysis with residential characteristics—includes the distance to the nearest RSO variable—nested within neighborhoods (i.e., home sale value within neighborhoods is more related to other homes in the same neighborhood than to homes in other neighborhoods), multilevel modeling can account for the hierarchical nature of the data. In other words, by using multilevel modeling in the current study, I will be able to disentangle the effects of residential and neighborhood characteristics on home selling prices. Additionally, multilevel modeling is considered the most appropriate tool for analysis to describe the real estate market (Brown \& Uyar, 2004). A secondary goal is to strengthen the confidence in the current state of the sex offender literature by surveying homebuyers in non-urban (collapsed rural and suburban) and urban communities and their awareness of RSOs in two contiguous U.S. states. Whereas the primary goal is oriented at addressing methodological approaches, the second goal is primarily directed at addressing the policy implications that call into question the integrity and purpose of the sex offender legislation.

Thus, the primary and secondary data collected for the present study addresses two fundamental questions that resulted from the theoretical framework. Is the presence of a RSO related to home sale values? Specifically, is the presence of the nearest RSO associated with home sale values when controlling for property characteristics in a level1 model, and whether the distance to the nearest RSO is a variable associated with home 
sale values when neighborhood characteristics (together with spatial dependence) are included in a two-level model?

The second primary question is to assess the moderating relationships of homebuyer awareness and their community type between home sale values and the distance to local RSOs. How do rural homebuyers compare to suburban and urban homebuyers regarding their awareness of RSOs in their community? Additionally, does awareness of local RSOs and the type of community moderate the relationship between home sale values and the distance to the nearest RSO, after controlling for the property characteristics of sold homes?

These questions resulted in five hypotheses. It is hypothesized that sold homes financially reacted to the nearby presence of RSOs when only property characteristics are accounted for in the multilevel model, but when neighborhood characteristics are accounted for in the two-level model, the relationship will become non-significant. It is also hypothesized that non-urban homebuyers would be more aware of local RSOs than urban homebuyers, with homebuyer awareness and homebuyer community type functioning as moderators between home sale values and the distance to the nearest RSO. 


\section{CHAPTER II}

\section{THEORETICAL FOUNDATION}

Shaw and McKay (1942) based social disorganization theory on the humanecological interactions across a spatial distribution in an urban environment. ${ }^{2}$ They stated that the ecological conditions of neighborhoods are much more influential on crime rates than the behaviors (or the characteristics) of persons in the area. According to Shaw and McKay (1942), criminality was encapsulated by three structural dimensions of communities: economic status (high percentages of poverty), ethnic heterogeneity (high percentages of minorities), and residential mobility (high rates of population turnover).

Nearly five decades later, Sampson and Groves (1989) extended the original model of social disorganization by highlighting the importance as well as the complexities of social networks within communities. Sampson and Groves (1989) emphasized a systemic model of social disorganization, which valued the multifaceted social networks within a locality that in turn influenced a community's ability to engage

\footnotetext{
${ }^{2}$ Important to note are the other Chicago School theorists (i.e., Edwin Sutherland and Robert E. Park \& Ernest Burgess) who had inspired Shaw and McKay's social disorganization theory. In brief, Park and Burgess (1925) stated that urban cities are ecological environments in a constant state of change primarily due to competition for resources, and ultimately, crime. To explain this social phenomenon, these two theorists illustrated the concentric zone model, which included five rings, and each ring contained a spatial distribution of various social structures and different uses of the land (e.g., central business district, the zone of transition). The term social disorganization originated from Sutherland's (1939) work that discussed how (criminal) values among Western societies could be adopted by neighboring inhabitants, in which the process resulted in social problems like criminality.
} 
in social control. These included additions of independent aspects—exogenous—of a community like family disruption (e.g., high percentages of single-family households) and urbanization (e.g., high population density) into the systemic model of social disorganization theory. These exogenous aspects linked how social behaviors of a community are dependent—intervening (i.e., local friendship networks, organizational participation, unsupervised teens) —on the overall organizational structure of the community. Community features like friendship networks, organizational participation, and unsupervised teen groups had substantially explained as to why communities contained aspects of social disorganization (that ultimately led to crime and delinquency). Sampson and Groves' (1989) efforts allowed for the broadening of the social disorganization framework to include social characteristics that define communities, and re-acknowledged the significance of Shaw and McKay's (1942) scholarly work as it could be generalized to other cultures. The present study will use several of these variables as an outline to ascertain how they operate in different community types within a multilevel framework.

\section{Disorder}

Disorder within a community is one outcome of social disorganization.

Encompassing both the physical and social aspects of an environment (Perkins \& Taylor, 1996), it enables for Gordon (2013) to argue that clusters of RSOs should be considered as markers of social disorganization within neighborhoods. Signs of social disorder are extensions of a lack of formal and informal social $\operatorname{control}^{3}$ within a community and

\footnotetext{
${ }^{3}$ Informal social control gauges indicators of neighborhoods likelihood to exercise personal action to address an issue (Sampson et al., 1997; Sampson \& Raudenbush, 1999). Formal social control is in reference to structured entities responsible for criminal justice issues (Kruttschnitt, Uggen, \& Shelton, 2000; Kubrin \& Weitzer, 2003; Mustaine \& Tewksbury, 2011a).
} 
demonstrated by social behaviors that create a sense of danger such as drinking and panhandling (Kelling \& Wilson, 1982; Ross \& Mirowsky, 1999). Interrelated to social disorder, the presence of physical disorder is an indicator of the physical deterioration of a neighborhood, like abandoned or dilapidated buildings and graffiti. These physical and social conditions of disorder are not only visually indicative of a severe neglect of the community but also emblematic of an underlying breakdown of localized behavioral norms established by formal and informal social control measures (Skogan \& Maxfield, 1981). Regardless whether a stigmatized person like a RSO is known, such elements of disorder are present in the environments they typically reside. Items of physical disorder like vacant lots and litter are frequently present in the neighborhoods RSOs, which simultaneously contained a lack of formal community structures (e.g., police station) and a strong notion of informal social control (e.g., neighborhood watch groups) (Tewksbury \& Mustaine, 2006).

The physical and social conditions of a neighborhood influence residents' feelings of control in their neighborhood (Austin et al., 2002; Kelling \& Wilson, 1982). Located on the other end of disorder, a lack of order is represented by an absence of visual cues of a state of peace and control, with indicators of social and physical disorder are placed onto this continuum (Ross \& Mirowsky, 1999). Likewise, residents of an urban community reported a sense of losing control over the community in response to the placement of a RSO (Zevitz, 2004). These urban residents stated concerns that the newly placed RSO would disrupt the social environment of the community and inevitably the physical environment. Residents believed that the placement of a RSO in their community would be interpreted as an open invitation to other RSOs. Comparable to the 
effects of disorder, a relocated RSO who was the focus of Zevitz's (2004) study encouraged adverse social behaviors like despair, hopelessness, and withdrawal from the community among these urban residents.

\section{Summary of the Theoretical Framework}

Social disorganization theory is a fitting theoretical outline for the present study for two key reasons. First, social disorganization theory caters to the hierarchical and spatial nature of the present study, in which homes and neighborhoods are simultaneously

considered. Second, the social disorganization processes align with the effects associated with the presence of a RSO or several RSOs in communities. Overall, the theoretical framework with the backing of the sex offender literature embraces the culture of neighborhood dynamics. 


\section{CHAPTER III}

\section{LITERATURE REVIEW}

A review of the literature is crucial to unraveling the socio-ecological effects stimulated by symbolic legislative mandates enforced upon RSOs that have also unintentionally harmed communities. Sex offender legislation is regarded as one of the most far-reaching pieces of law that have been enforced onto a subset of criminal offenders, designed to protect vulnerable populations from (potential) sex offenders (Letourneau, Levenson, Bandyopadhyay, Sinha, \& Armstrong, 2010; Maguire \& Singer, 2011; Meloy, Miller, \& Curtis, 2008; Nobles, Levenson, \& Youstin, 2012). However, the supposed claims of sex offender registration and community notification are incongruous with the scholarly literature, which has suggested that the efficacies of these legislative procedures are questionable (Agan \& Prescott, 2014; Letourneau et al., 2010; Prescott \& Rockoff, 2011; Sperber, Lowenkamp, Carter, \& Allman, 2010; Tewksbury \& Jennings, 2010; Zevitz, 2006; The Council of State Governments [CSG], 2010). Residency restrictions are ineffective in their stated agenda, and negatively reinforced the misconception of stranger danger (Chajewski \& Mercado, 2009; Colombino, Mercado, Levenson, \& Jeglic, 2011; Duwe et al., 2008; Maguire \& Singer, 2011; Nobles et al., 2012; Prescott \& Rockoff, 2011; Socia, 2012b; Sperber et al., 2010). These legal provisions mandated upon RSOs have not achieved their purported claims, and 
discriminatory acts against RSOs reinforced by sex offender policies have encouraged their relocations into disadvantaged, vulnerable, and/or rural communities (Chajewski \& Mercado, 2009; Clark \& Duwe, 2015; Hipp et al., 2010; Mustaine et al., 2006a, 2006b; Sloas et al., 2012; Socia, 2012a; Tewksbury et al., 2016).

Due to the stigmatizing nature of the sex offender label, it comes to no surprise that residents are unwilling to reside near RSOs given that depressed home sale values were associated with nearby RSOs (Bian et al., 2013; Caudill et al., 2014; Larsen et al., 2003; Linden \& Rockoff, 2008; Navarro \& Rabe-Hemp, 2017; Pope, 2008; Wentland et al., 2014; Yeh, 2015). At the same time, community members are grossly unaware of the presence of RSOs within their communities (Anderson \& Sample, 2008; Burchfield, 2012; Craun, 2010; Kernsmith, Comartin, et al., 2009; Lieb \& Nunlist, 2008; Phillips, 1998; see Beck \& Travis, 2006). To understand the contradiction between the offenders' association with depressed home sale values and a lack of residents' awareness of local RSOs Illinois and Kentucky are the settings selected for the current study.

\section{Sex Offender Legislation}

A review of the key legislative pieces of sex offender laws is necessary to understand the ongoing controversy regarding implementation and the fundamental links between RSOs and communities. A defensive cultural zeitgeist against sex offenders and resulted in a number of outcomes primarily rooted from moral panic and in turn sex

offender legislation. A series of famous cases that involved persons who committed sex crimes against children promoted the protection of vulnerable individuals from sex offenders, which compelled policymakers to respond rapidly to appease their constituents (Sample \& Kadleck, 2008). 
Registration and community notification. Federal sex offender policies included mandatory registration (Jacob Wetterling Act of 1994) ${ }^{4}$ and community notification laws (Megan's Law of 1996), ${ }^{5}$ and state-based residency restrictions. The Wetterling Act established the practice of sex offender registries and centralized the listings of persons convicted of sexual crimes together with personally identifying information that was made available for law enforcement purposes. Soon after, Megan's Law amended the Wetterling Act, which had previously warehoused confidential information of persons convicted of sexual offenses, and subsequently made these registries accessible for the public to exercise their right to inform themselves about the identities and residences of these convicts (Zevitz, 2004).

Community notification focuses on the dissemination of information to notify the public of RSOs in their communities. All 50 U.S. states employ various methods of notification regarding the distribution of RSO information (Mustaine \& Tewksbury, 2013; Zevitz, 2004). Some U.S. states exercise passive notification laws where community members must seek and obtain information of RSOs via in-person contacts, mail, telephone, or a website (Beck \& Travis, 2006). A form of passive notification is online websites, which are ubiquitous to all jurisdictions (Levenson et al., 2007a; Mustaine \& Tewksbury, 2013). In contrast, (pro)active notification laws actively inform the public about RSOs via community meetings, media releases by law enforcement, and

\footnotetext{
${ }^{4}$ Jacob Wetterling was an 11-year-old resident of Minnesota who was abducted, raped, and murdered by Danny Heinrich in 1989. The murder of Jacob remained unsolved until September 2016 when his remains were uncovered, followed by Heinrich's confession to Wetterling's murder (Unze \& Marohn, 2016). The Jacob Wetterling Act can be accessed here: https://www.gpo.gov/fdsys/pkg/BILLS103hr3355enr/pdf/BILLS-103hr3355enr.pdf

${ }^{5}$ The rape and murder of Megan Kanka, seven-year-old New Jersey resident, by Jesse Timmendequas (a convicted sex offender) in 1994 prompted the immediate passage of Megan's Law. The Kanka family cited that had they known their neighbor was a RSO that Megan's death would have never occurred. Megan's Law can be accessed here: http://uscode.house.gov/statutes/p1/104/145.pdf
} 
visits by probation officers to community members (Beck \& Travis, 2006; Zevitz, 2004; Zevitz \& Farkas, 2000a). Regardless of these notification methods, some jurisdictions will supersede these procedures and actively inform community members of RSOs if the offender is determined to be at high risk for recidivism (Anderson et al., 2009; Zevitz, 2004).

Adam Walsh Act and Sex Offender Registration and Notification Act.Ten years following the passage of Megan's Law, the Adam Walsh Act (AWA) ${ }^{6}$ of 2006 built upon the eponymous federal laws discussed above (Office of Justice Programs [OJP], 2016). The most significant contribution of the (seven-titled) AWA was Title I, the Sex Offender Registration and Notification Act (SORNA). The aims of SORNA were to unite the wide-ranging registration and notification provisions U.S. states had by standardizing sex offender registries with the establishment of a National Sex Offender Registry.

The passage of AWA/SORNA established a new baseline for who is to be considered a "sex offender" with the implementation of a three-tier taxonomy based on the severity of the convicted offenses that corresponded with minimum registration lengths (OJP, 2016). The most "dangerous" offenders, Tier III offenders are required to register with law enforcement for life because of their convicted crimes (e.g., aggravated sexual abuse, kidnapping of a minor). Tier II offenders can be upgraded to Tier III because of subsequent crimes cited in the AWA/SORNA provisions. Persons who committed crimes against minors (e.g., sex trafficking, distribution/production of child pornography) are labeled as Tier II offenders and required a 25-year registration. Tier I

\footnotetext{
${ }^{6}$ Adam Walsh (the son of John and Reve Walsh) was a six-year-old boy abducted at a mall and subsequently murdered by Otis O'Toole in North Hollywood, Florida on July $27^{\text {th }}, 1981$. The Adam Walsh Act/SORN can be accessed here: https://www.gpo.gov/fdsys/pkg/PLAW-109publ248/html/PLAW109publ248.htm
} 
offenders, or the "catch-all" classification, are legally mandated to register for 15 years (but ten years for persons with clean criminal records). Regardless of the existence of this taxonomy, U.S. states are not required to replicate the AWA/SORNA tier classification.

Unlike community notification and sex offender registries, not all U.S. states have adopted the AWA/SORNA standards. Reasons for noncompliance focused on three issues: (1) registration requirements for juvenile sex offenders, (2) a constitutional violation of ex-post facto laws (because AWA/SORNA required retroactive registration), and (3) a prohibitive cost policy as the costs of implementation were greater than the ten percent financial penalty on law enforcement-oriented grant money (CSG, 2010). Because lawmakers of their respective U.S. states are in disagreement with the implementation of AWA/SORNA, only 20 U.S. states are compliant with the features called for by AWA/SORNA as of 2016.

Residency restrictions. The passage of these federal statutes (especially Megan's Law) stimulated the establishment of residency restrictions though not yet federally adopted (Meloy et al., 2008). These geographic restrictions made their first appearance in 1995 as state mandated policies in Delaware and Florida. At least 30 U.S. states (and hundreds of municipalities) impose residency restrictions on RSOs (Leipnik et al., 2016; Meloy et al., 2008).

There is considerable variation among the jurisdictions that practice residency restrictions. RSOs must legally reside a certain distance (i.e., 500 to 3,000 feet) away from proscribed venues (e.g., daycares, parks, schools) frequently visited by vulnerable populations (e.g., children) (Leipnik et al., 2016; Meloy et al., 2008; Zandbergen \& Hart, 2009). Distances are measured "as the crow flies"; in other words, the distance between 
two named points on a map (i.e., the distance between the RSO residence and restricted zone) (Leipnik et al., 2016; Meloy et al., 2008).

Not all persons convicted of sexual crimes are subjected to these zonal provisions (Leipnik et al., 2016). Some jurisdictions-like Illinois (720 ILCS § 5/11-9.4-1; 730 ILCS $§ 150 / 8$ ) — enforce geographic restrictions to certain classes of RSOs (i.e., child RSO, sexual predator) who are classified by convicted crimes, and state assessments of risk-level by prior criminal offenses and risk factors. Illinois also exercises loitering laws (also referred to as child safety zones) (720 ILCS $\S 5 / 11-9.4-1)$, which are akin to residency restriction laws. These zonal provisions prohibit RSOs from loitering within 300 to 500 feet (varies by jurisdiction) of areas children tended to congregate (Colombino et al., 2011). However, loitering restrictions are not commonly implemented by jurisdictions even though they are the preferred alternative to residency restrictions because they are less punitive. ${ }^{7}$

Illinois and Kentucky sex offender legislation. The sex offender provisions of Illinois and Kentucky — the U.S. states under study — are reviewed to compare and contrast their implementation onto RSOs. In terms of similarity, Illinois and Kentucky have adopted passive notification policies whereby community members are responsible to for notifying themselves about local RSOs, and neither U.S. state complies with the AWA/SORNA standards. Differences between Illinois and Kentucky included registration classifications of RSOs, and in turn, affected how their respective residency restrictions were applied.

\footnotetext{
${ }^{7}$ As of 2016, Indiana and North Carolina overturned their child safety zonal provisions as the courts decided these mandates are unconstitutionally vague in terms of when and what venues RSOs cannot be nearby (Sullum, 2016).
} 
Illinois registration was enacted in 1994, with sex offender information transferred into an online database in 1999 (730 ILCS $\S 152 /)$. RSOs in the state of Illinois are classified into four categories (sex offender, sexual predator, sexually dangerous person, sexually violent person) (730 ILCS $\S 150 / 2)$, with the most common classifications being (general) sex offenders and sexual predators. ${ }^{8}$ Sexually dangerous persons are offenders with a mental disorder that contribute to their propensity to commit sexual acts against minors (725 ILCS $§ ~ 205 / 1.01)$. Sexually violent persons are also offenders diagnosed with a mental disorder, but their mental instabilities are determined severe enough by a trained psychiatrist that these offenders will be a greater likelihood to reoffend (725 ILCS $\S 207 / 5)$. A sexual predator includes individuals who attempted or committed certain offenses (e.g., child pornography), coupled with being convicted of subsequent sexual offenses (730 ILCS $\S 150 / 2$ ). These three sex offender classifications above are lifetime registrants (730 ILCS $\S 150 / 7$ ) with 90-day verifications (730 ILCS $\S$ 150/5-10; 730 ILCS $§ 150 / 6)$. In contrast, offenders who do not fit the three sex offender categories are (general) sex offenders who must annually register for ten years (730 ILCS $\S 150 / 5-10)$. These subsets of RSOs also differ in residency restriction sanctions. Illinois enacted their first statewide residency restriction in 2000 and prohibited RSOs with underage victims (less than 18 years old) from residing within 500 feet of

\footnotetext{
${ }^{8}$ The term (general) sex offenders are the "catch-all" classification for persons convicted of sexual crimes, with additional classifications for others who fit into certain legal definitions of sex offenders. The present study's dataset of Illinois sex offenders $(2015 ; N=27,829)$ primarily consists of sexual predators $(58.6 \%)$, with one-third (34.7\%) classified as general sex offenders, and around one percent were sexually violent persons $(1.3 \%)$ or sexually dangerous persons $(0.4 \%)$. The remaining five percent $(n=1,394)$ comprised RSOs who were non-compliant $(n=782)$, classified as child murderers $(n=322)$, or maintained unknown locations $(n=290)$. The removal of offenders who were non-compliant, child murderers, or maintained unknown locations maintained the same distribution of sex offender classification. Nearly two-thirds $(61.7 \%)$ are sexual predators, over one-third (36.5\%) classified as general sex offenders, and about one percent classified as sexually violent persons $(1.38 \%)$ or sexually dangerous persons $(0.4 \%)$.
} 
schools that persons under the age of 18 attend (730 ILCS $\S 150 / 8$ ). Public parks, youth centers, and/or the victim's residence subsequently added in 2006 as proscribed areas (720 ILCS $\S 5 / 11-9.3$ ). Illinois also exercises loitering restrictions that mandate RSOs with child victims — victim under 18 years old ${ }^{9}$ - (but not RSOs with adult victims) and sexual predators not to be within 500 feet of public parks (720 ILCS $\S 5 / 11-9.4-1$ ).

Like Illinois, Kentucky is a passive notification state and is not compliant with the AWA standards (OJP, 2016). Kentucky enacted its registration provisions for RSOs in 1994 (KRS $§ 17.500$ ) with Internet notification accessible to the public since April 2000

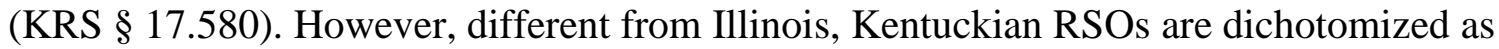
either lifetime or 20-year registrants (moderate-risk) (KRS $\S 17.520) .{ }^{10} \mathrm{RSOs}$ with lifetime registration include: crimes that involved minors (aged 18 or under; e.g., kidnapping), maintained previous (felonious/sexual) convictions that involved a minor, maintained convictions of rape or sodomy in the first degree, classified as a sexually violent predator (an offender who is subjected to involuntary civil commitment), or a RSO (regardless of a lesser registration period) who has moved from another state into Kentucky. All other remaining convicted sex offenders are classified as 20-year registrants. Addresses for 20-year registrants are verified annually by employees of the Justice and Public Safety Cabinet, compared to the stricter 90-day address verification imposed onto lifetime registrants (KRS $§ 17.510)$. Unlike Illinois, every RSO (regardless of offense or tier level) in the state of Kentucky (since 2006) must abide by a longer

\footnotetext{
${ }^{9}$ Colloquially referred to as Romeo and Juliet laws, close-in-age exemptions are not practiced in Illinois or Kentucky. Because there are no close-in-age exemptions in Illinois, two persons under 17 years old or persons one or two years apart in age (e.g., 16 and 17/18) can engage in consensual, sexual relations and be criminally pursued for statutory rape.

${ }^{10}$ RSOs were once classified as ten-year (low-risk) registrants, but this classification scheme is now defunct.
} 
residency restriction of 1,000 feet, and barred from daycare facilities, public playgrounds, and schools (KRS § 17.545). But, certain RSOs do not have any residency restrictions because Kentucky's residency restriction cannot be applied retroactively due to constitutional rights (Commonwealth v. Baker, 2009).

\section{Efficacy of Sex Offender Policies}

Given the overview of the sex offender registration, community notification, and residency restrictions, next to be discussed are as to why these policies are controversial. Sex offender policies were enacted without much evidence to support their purported effectiveness, and have failed to live up to their stated premises because they are misguided and counterproductive (Barnes et al., 2009; Berenson \& Appelbaum, 2011; Burchfield \& Mingus, 2008, 2014; Colombino et al., 2011; CSG, 2010; Duwe et al., 2008; Letourneau et al., 2010; Maguire \& Singer, 2011; Meloy et al., 2008; Nobles et al., 2012; Socia, 2011, 2012a, 2012b; Sperber et al., 2010; Tewksbury \& Jennings, 2010; Zevitz, 2006). Regardless of the unintended repercussions that arise from the passage of these sex offender laws, policymakers and public officials agreed that they had successfully addressed and satisfied the public's demand for action against the prevention of future sex offenses (Sample \& Kadleck, 2008).

Efficacy of registration. Registration policies are dubious. For instance, Ohiobased offenders imposed with 10- or 20-year registration sentences were considered more likely to reoffend than RSOs who had received a lifetime registration (Sperber et al., 2010). Additionally, registration standards set forth by the AWA/SORNA in 2006 were viewed as colossal revisions by U.S. states (CSG, 2010). U.S. states were ambivalent to correspond with the most punitive approach against RSOs called for by AWA/SORNA 
that included the reclassification of RSOs into three tiers, which would effectively result in some RSOs to be retroactively registered. For instance, the adoption of AWA/SORNA standards in the state of New Jersey would require a complete revision of the previous regulations to track RSOs (Ragusa-Salerno \& Zgoba, 2012). An insurmountable task for a U.S. state to conduct. AWA/SORNA provisions of registration by sex crime type are an invalid assessment of a RSO risk to reoffend (CSG, 2010). In other words, sex offender classifications do not correlate with recidivism risk. Registration statuses appear to be indiscriminately attached to persons convicted of sex crimes. A concerning conclusion because dependent on how RSOs are classified affects how the community is notified about that the presence of these offenders (Sperber et al., 2010). Thus, RSOs are examined as a whole group in the present study rather than by classifications.

Efficacy of community notification. On the one hand, the sex offender literature has supported the argument for the effectiveness of community notification laws as a deterrent of sexual offenses (Duwe \& Donnay, 2008; Elbogen, Patry, \& Scalora, 2003; Levenson et al., 2007b; Prescott \& Rockoff, 2011). Take for instance Duwe and Donnay's (2008) examination of Minnesotan RSOs that revealed community notification was an effective deterrent because the lowest recidivism rates were consistently yielded by RSOs subjected to these laws. In support of community notification effectiveness, the highest recidivism rates belonged to the group of RSOs who were registrants before the passage of community notification laws. Even RSOs reported that community notification laws were effective procedures that encouraged them to be law-abiding citizens (Elbogen et al., 2003; Levenson et al., 2007b; see Levenson \& Cotter, 2005). There is even evidence that community notification may have also deterred non-RSOs 
(Prescott \& Rockoff, 2011). Even so, it is still uncertain whether community notification wholly achieved their targeted outcome, that is, the reduction of potential, future sexual offenses.

On the other hand, the sex offender discourse has also supported the notion that notification laws are essentially inconsequential on sexual recidivism rates (Agan \& Prescott, 2014; Letourneau et al., 2010; Prescott \& Rockoff, 2011; Tewksbury \& Jennings, 2010; Zevitz, 2006). Zevitz (2006) tracked offenders subjected to notification procedures over a four-and-a-half-year period following their exit from prison to gauge rates of prison return. Results showed notification had no direct effect on the likelihood to return to prison, regardless of the offender's classified risk level (i.e., extensive \& limited notification groups). Meaning that a RSO classified as more dangerous" (i.e., extensive) was equally as likely to return to prison as a RSO labeled as "less dangerous" (i.e., limited notification). Such an outcome inevitably calls into question the legitimacy of the notification labeling procedures (like registration procedures) and its ability to predict "dangerousness," and ultimately recidivism risk.

The literature has consistently demonstrated that RSOs rarely tend to recidivate, and when they do, it is for crimes unconnected to sex offenses (Colombino et al., 2011; Duwe \& Donnay, 2008; Kruttschnitt et al., 2000; Letourneau et al., 2010; Nobles et al., 2012; Zevitz, 2006). Even though community notification influenced a downward direction for sexually related crimes, the same policy had not affected other criminal offenses (Duwe \& Donnay, 2008). Rates of recidivism via non-sexual crimes or general offenses among RSOs were stagnant across all groups of RSOs, regardless of whether these offenders were subjected to community notification laws. Therefore, it appears that 
community notification addressed its stated objectives as non-sexual and general offenses were not the original criminal issues of concern. Nevertheless, an argument could be made that the stringent sex offender policies (of community notification) encouraged recidivism of non-sexual crimes. A sizeable portion of recidivistic RSOs were those who accrued technical violations, and in turn, promote a misconception that RSOs are recidivating via sex offenses, when in fact, it is attributed to technical violations (Hughes \& Burchfield, 2008; McCoppin, 2016; Zevitz, 2006). These technical violations may rise because RSOs are not wholly aware of the extent of the community notification procedures imposed upon them (Elbogen et al., 2003; Levenson et al., 2007b) which may be contributing to the violation, and in turn, unintentional recidivism. The repercussions of these impositions placed onto RSOs explain why the public has continued to hold distorted beliefs about sexual offenders and sexual offending (Levenson et al., 2007a), which cultivated an unwillingness by community members to reside near RSOs and effectively pushed RSOs to the peripheries of communities.

Efficacy of residency restrictions: Falsehoods. Residency restrictions are cited as illusions of safety (Nobles et al., 2012) because residency restrictions do little to prevent victimization for two primary reasons. First, most sex offenses are committed by persons known to the victim rather than strangers. Roughly half of adult male RSOs (49.1\%) knew their victims as acquaintances, with about one-third (32.6\%) of adult victims being family members (Colombino et al., 2011). Comparatively, Duwe et al. (2008) examined sexual reoffenses committed by Minnesotan RSOs and found that not one case would have been stopped by a residency restriction law because two-thirds of the recidivists (65\%) cultivated relationships with persons known to them. Children are 
more likely to experience a sexual victimization by persons known to them than adults are (Maguire \& Singer, 2011). Creating buffer zones of varying distances around the properties of RSOs to assess for fluctuating home selling prices due to "community fear" is moot because RSOs are likely to offend persons known to them who may not be residents of the community.

Second, the evidence does not support that (sexual) contacts/offenses are associated with residency restrictions, and/or conducted between an offender and the victim at the proscribed venues like parks or schools (Colombino et al., 2011; Duwe et al., 2008; Maguire \& Singer, 2011; Meloy et al., 2008). For instance, less than five percent $(4.4 \%)$ of RSOs encountered their victims at these prohibited locations (Colombino et al., 2011). Further, the recidivist sex offenders in Colombino's et al. (2011) sample who directly contacted their victims in a public venue were more likely to victimize an adult (53.5\%) rather than a child (19.0\%). It must also be considered that residency restrictions may promote RSOs to pursue criminal activities outside these geographic boundaries knowing that they are being watched in these prescribed vicinities (see Nobles et al., 2012).

\section{Efficacy of residency restrictions: RSOs' housing options. Residency}

restrictions have complicated the ability for RSOs to obtain appropriate housing (Barnes et al., 2009; Berenson \& Appelbaum, 2011; Burchfield \& Mingus, 2008; Chajewski \& Mercado, 2009; Huebner et al., 2013; Hughes \& Burchfield, 2008; see Tewksbury, 2005; see Tewksbury \& Lees, 2006; Socia, 2011, 2016; Socia et al., 2015; Tewksbury \& Mustaine, 2010; Zandbergen \& Hart, 2006). Housing options are so limited (even when compared to non-RSO parolees) that RSOs have been forced to return to halfway homes, 
jail, or prison because they had not secured suitable housing within the given time parameters-colloquially referred to as "violating at the door" (Mills, 2015; Wolfson, 2015; Zevitz \& Farkas, 2000b). For instance, roughly 1,000 RSOs per year (from 2005 to 2015) were held beyond their sentence in the city of Chicago because of their inability to find appropriate housing exacerbated by residency restrictions (Mills, 2015).

Neighborhoods became increasingly unavailable as the size and coverage of residency restrictions increased in Orange County, Florida (Zandbergen \& Hart, 2006), upstate New York counties (Socia, 2011), and four counties in South Carolina (Barnes et al., 2009). Compared to jurisdictions with longer residency restrictions, neighborhoods with shorter residency restrictions had the most available housing parcels (Barnes et al., 2009; Socia, 2011), but also maintained the least affordable housing (however, see Socia, 2016; Socia, 2011). The phenomenon described above occurs in the state of Illinois.

Hughes and Burchfield (2008) have suggested that residency restrictions have exercised social class discrimination regarding the housing options for RSOs. Even though Illinois imposes shorter residency restrictions compared to other U.S. states (Leipnik et al., 2016; Meloy et al., 2008) housing options for RSOs are still limited (Hughes \& Burchfield, 2008). RSOs were more likely to reside in disadvantaged communities than more affluent areas in Chicago (Hughes \& Burchfield, 2008; see Clark \& Duwe, 2015). At the same time, Chicago's 500-foot residency restriction limited RSOs to reside in disadvantaged areas (with only $32.2 \%$ of the area being available) far more than affluent areas (69.8\% of the land was available) (Hughes \& Burchfield, 2008). That is because prohibited venues were heavily concentrated in disadvantaged communities when compared to affluent communities. Limited space in disadvantaged areas for RSOs 
continued (51.2\% available in disadvantaged areas vs. $73.6 \%$ available in affluent areas) even with the removal of daycares - the most common prohibited venue.

Scholars have discussed that these zoning policies are not overly oppressive to RSOs and the communities they choose to reside in (Berenson \& Appelbaum, 2011; Huebner et al., 2013; Socia, 2016; Socia \& Stamatel, 2012). Although residency restrictions appeared to reduce the number of RSOs near restricted locations-in Michigan and Missouri- it was not evident that RSOs were displaced because of residency restrictions, with exception to RSOs with minor victims (Huebner et al., 2013). Residency restrictions merely caused an inconvenience to RSO housing in over 50 nonmetropolitan counties located in upstate New York. Socia (2012a) found that residency restrictions had a positive effect on RSO concentration initially. After 17 to 24 months, jurisdictions that mandated a 1,000-foot residency restriction or less reverted to a similar magnitude of RSO concentrations to those jurisdictions without residency restrictions. Regardless of the existence of residency restrictions, RSOs continue to violate the law and reside in restricted areas (Barnes et al., 2009; Berenson \& Appelbaum, 2011; Huebner et al., 2013; Hughes \& Burchfield, 2008; McCoppin, 2016; Socia, 2012a; Tewksbury \& Mustaine, 2006). Further substantiating as to why residency restrictions are legally ineffective, and validation as to the current study's methodological approach to discount using buffer zones to explore the RSO-home sale value research in the examined U.S. counties.

\section{Communities and RSOs}

The literature has consistently demonstrated that RSOs tend to reside in unfavorable living conditions (Clark \& Duwe, 2015; Gordon, 2013; Hipp et al., 2010; 
Hughes \& Burchfield, 2008; Hughes \& Kadleck, 2008; Mustaine et al., 2006a, 2006b; Mustaine \& Tewksbury, 2008, 2011b; Socia, 2011, 2012a, 2016; Socia \& Stamatel, 2012; Suresh et al., 2010; Tewksbury \& Mustaine, 2006, 2008; Tewksbury et al., 2016; Tewksbury et al., 2007). Responses by community members to RSOs in their areas have resulted in disapproval of their presence, as evident of depressed home selling prices (Bian et al., 2013; Caudill et al., 2014; Larsen et al., 2003; Linden \& Rockoff, 2008; Navarro \& Rabe-Hemp, 2017; Pope, 2008; Wentland et al., 2014; Yeh, 2015). But surprisingly, also a general unawareness of RSO presence (Anderson \& Sample, 2008; Burchfield, 2012; Craun, 2010; Kernsmith, Comartin, et al., 2009; Lieb \& Nunlist, 2008; Phillips, 1998; see Beck \& Travis, 2006). As discussed below, these conclusions are fraught with issues due to how scholars have approached their methodology, as well as the lack of consideration of the rural-urban distinction across the sex offender literature.

Social disorganization and RSOs. RSOs are relegated into communities that maintain unfavorable housing and population characteristics (see Table 1 for citations). Housing characteristics that parallel in their associations with social disorganization are frequent in the areas RSOs reside. These include high rates of (1) female-headed households, (2) renter-occupied, (3) vacant housing units and (4) residential mobility. Additionally, areas RSOs have placed residence in contained high levels of poverty. Neighborhoods defined by impoverishment are lacking the social resources required to deter RSO migration into their areas (Clark \& Duwe, 2015; Hughes \& Kadleck, 2008). The insertion of these neighborhood household characteristics in a model is important because it can clarify potential spuriousness between home sale and the residences' of RSOs. 
Comparatively, the population characteristics typical in the neighborhoods containing RSOs have not been included in the models of the RSO-home sale value research. Like the housing characteristics common in neighborhoods with RSOs, the absence of these population characteristics may have yielded spurious results that suggested RSOs are associated with depressed home sale values. The sex offender literature has shown that neighborhoods containing RSOs tend to maintain a higher presence of Blacks and Hispanics, and foreign-born persons. Although neighborhoods with RSOs are abundant in racial/ethnic heterogeneity, they lack in individuals with bachelor and/or graduate degrees and children under the age of 18. The inclusion of elderly persons has not yet been heavily considered among sex offender scholars, but Craun $(2010)^{11}$ found that the rate of elderly persons is no more frequent in areas populated by RSOs compared to areas without RSOs.

\section{Table 1}

Unfavorable Neighborhood Characteristics Associated With RSOs Identified by Studies

\begin{tabular}{ll}
\hline Neighborhood characteristics & Citations \\
\hline Housing characteristics $^{\text {Female-headed households }}{ }^{\mathrm{a}}$ & Burchfield \& Mingus, 2008; however, see Mustaine et \\
& al., 2006b; however, see Tewksbury et al., 2007; \\
& Hughes \& Burchfield, 2008; Hughes \& Kadleck, 2008; \\
& Mustaine \& Tewksbury, 2008; Mustaine et al., 2006b; \\
& Navarro \& Rabe-Hemp, 2017 \\
& Clark \& Duwe, 2015; Craun, 2010; Gordon, 2013; \\
& however, see Tewksbury et al., 2007; Huebner et al., \\
& 2013; Hughes \& Burchfield, 2008; Hughes \& Kadleck, \\
& 2008; Mustaine \& Tewksbury, 2008, Mustaine et al., \\
& 2006b; see Agan \& Prescott, 2014; Sloas et al., 2012; \\
& Suresh et al., 2010; Tewksbury et al., 2016 \\
& Barnes et al., 2009; Navarro \& Rabe-Hemp, 2017 \\
&
\end{tabular}

\footnotetext{
${ }^{11}$ Although not operationalized by Craun (2010), it is presumed elderly persons are defined as persons aged 65 years and over.
} 
Residential mobility (operationalized by year[s] at residence $)^{\mathrm{a}}$

Vacant housing units ${ }^{\mathrm{a}}$
However, see Craun, 2010; however, see Mustaine et al., 2006b; Hughes \& Burchfield, 2008; Hughes \& Kadleck, 2008; Mustaine \& Tewksbury, 2008; Tewksbury et al., 2007; Yeh, 2015 Barnes et al., 2009; Gordon, 2013; Navarro \& RabeHemp, 2017; Socia, 2016; Suresh et al., 2010

\begin{tabular}{|c|c|}
\hline \multicolumn{2}{|l|}{ Population characteristics } \\
\hline $\begin{array}{l}\text { Bachelor and/or graduate } \\
\text { degrees }^{\mathrm{b}}\end{array}$ & $\begin{array}{l}\text { However, see Mustaine et al., 2006a; however, see } \\
\text { Tewksbury et al., 2007; Mustaine \& Tewksbury, 2008; } \\
\text { Mustaine et al., 2006b; Yeh, } 2015\end{array}$ \\
\hline Blacks and/or Hispanics ${ }^{\mathrm{a}}$ & $\begin{array}{l}\text { Burchfield \& Mingus, 2008; Craun, 2010; Hipp et al., } \\
\text { 2010; Hughes \& Burchfield, 2008; Hughes \& Kadleck, } \\
\text { 2008; Mustaine \& Tewksbury, 2008; Mustaine et al., } \\
\text { 2006b; see Yeh, 2015; Socia \& Stamatel, 2012; Suresh } \\
\text { et al., 2010; Tewksbury et al., } 2007\end{array}$ \\
\hline Elderly persons $^{c}$ & Craun (2010) \\
\hline Foreign-born persons ${ }^{a}$ & $\begin{array}{l}\text { Burchfield \& Mingus, 2008; Craun, 2010; Hughes \& } \\
\text { Burchfield, 2008; Hughes \& Kadleck, } 2008\end{array}$ \\
\hline $\begin{array}{l}\text { Population under the age of } \\
18 / 19^{\mathrm{b}}\end{array}$ & $\begin{array}{l}\text { However, see Tewksbury et al., 2007; however, see } \\
\text { Mustaine et al., 2006b; Mustaine \& Tewksbury, } 2008\end{array}$ \\
\hline \multicolumn{2}{|l|}{ Structural determinants } \\
\hline Concentrated disadvantage & $\begin{array}{l}\text { Clark \& Duwe, 2015; Hipp et al., 2010; Huebner et al., } \\
\text { 2013; Hughes \& Burchfield, 2008; Hughes \& Kadleck, } \\
\text { 2008; Mustaine \& Tewksbury, 2011b; Socia, 2011, } \\
\text { 2012a, 2016; Socia \& Stamatel, 2012 }\end{array}$ \\
\hline Racial/Ethnic heterogeneity & $\begin{array}{l}\text { Burchfield \& Mingus, 2008; Clark \& Duwe, 2015; } \\
\text { Hipp et al., 2010; Hughes \& Burchfield, 2008; } \\
\text { Mustaine \& Tewksbury, 2011b; Socia, 2011, 2012a, } \\
\text { 2016; Socia \& Stamatel, } 2012\end{array}$ \\
\hline Residential in/stability & $\begin{array}{l}\text { Clark \& Duwe, 2015; Craun, 2010; Hipp et al., 2010; } \\
\text { however, see Burchfield \& Mingus, 2008; Mustaine \& } \\
\text { Tewksbury, 2011b; Socia, 2011, 2012a, 2016; Socia \& } \\
\text { Stamatel, } 2012\end{array}$ \\
\hline
\end{tabular}

Note. ${ }^{\text {a}} \mathrm{High}$ rates found in neighborhoods with RSOs. ${ }^{\mathrm{b}} \mathrm{Low}$ rates found in neighborhoods with RSOs. ${ }^{c}$ Undetermined.

These housing and population characteristics are occasionally merged into dimensions in accordance with the social disorganization theoretical framework. The sex offender literature has consistently indicated that RSOs are typically relocated into areas littered with the three primary structural determinants (concentrated disadvantage, racial/ethnic heterogeneity, residential instability) of the social disorganization theory 
(see Table 1 for citations). However, other existing sex offender discourse has indicated that RSOs are no more likely to be located in "worse" areas than the general populace (Burchfield \& Mingus, 2008; Craun, 2010; Huebner et al., 2013; Mustaine et al., 2006a, 2006b; Socia \& Stamatel, 2012; Tewksbury \& Mustaine, 2006; Tewksbury et al., 2007). For instance, although the census tracts of four urban counties in Florida and Kentucky RSOs resided in were characterized as socially disorganized (Mustaine et al., 2006b), rates of residential stability (defined as residence in the same house for five years) across all four urban counties were essentially no different from the county and national averages (but these findings may be attributed to the residents' financial inability to move). These findings lend support to Tewksbury and Mustaine's (2006) argument that the neighborhoods RSOs have relocated to are relatively downtrodden, but not excessively so.

The inconsistent relationship between social disorganization and RSOs might be due to the methodological approaches utilized. First, expressions of human ecological behaviors in an environment are temperamental dependent on the selected geographic unit (Hipp, 2007). Census tracts may be an ideal geographic unit in some instances, whereas in other cases, census blocks may be an appropriate unit to exploit the structural aspects within a locality. However, the use of larger geographic units like census tracts can obscure neighborhood variation (Coulton, Cook, \& Irwin, 2004). Census block groups (or smaller geographic units) are argued to be the best at capturing household property characteristics, indicators of disorder/incivilities, and neighborhood characteristics (see Cho, Clark, \& Park, 2006; Coulton, et al., 2004; Socia, 2011, 2012a). Second, the construction of housing and population characteristics into the structural 
dimensions of social disorganization theory convolutes the individual effects of each housing and population characteristic. For these reasons, the present study includes neighborhood characteristics (represented by census block group variables) in the multilevel model.

Social disorganization and Illinois and Kentucky RSOs. One of the U.S. counties in the present study_-Dupage County, Illinois—is adjacent to Chicago, which was the birthplace of the social disorganization theory (Park \& Burgess, 1925; Shaw \& McKay, 1942; Sutherland, 1939). Illinois has continued to be a hotbed of human socioecological explorations by scholars who have explored the effects of RSOs to communities (Burchfield \& Mingus, 2008; Hughes \& Burchfield, 2008; Mustaine \& Tewksbury, 2008; Navarro \& Rabe-Hemp, 2017; Socia \& Stamatel, 2012; Suresh et al., 2010). Contiguous to Illinois, Kentucky (and Jefferson County) has been explored quite extensively by Tewksbury and his colleagues (Mustaine \& Tewksbury, 2008; Mustaine et al., 2006a, 2006b; Tewksbury \& Lees, 2006; Tewksbury \& Mustaine, 2008; Tewksbury et al., 2016; Tewksbury et al., 2007; Tewksbury, Mustaine, \& Stengel, 2008), among others (Sloas et al., 2012). Several of these sex offender-based studies mentioned above utilized census tracts as their unit of analysis rather than census block groups to represent neighborhood characteristics of Illinois and Kentucky (Burchfield \& Mingus, 2008; Hughes \& Burchfield, 2008; Mustaine \& Tewksbury, 2008; Mustaine et al., 2006a, 2006b; Suresh et al., 2010; Tewksbury \& Mustaine, 2008; Tewksbury et al., 2007; Tewksbury et al., 2008). Further, it is evident that rural environments with RSOs operate differently within the framework of social disorganization (Sloas et al., 2012; Tewksbury et al., 2007). Therefore, an exploration of RSOs in various contexts like in the present 
study may show that disaggregation by the type of community and the introduction for a barometer of urbanicity is essential.

Non-urban communities. A majority of the sex offender literature has focused on the ecological dynamics associated with the effects of urban-based RSOs. Consequently, the literature is devoid of empirical information with an exclusive focus the effects of rural- and suburban-based RSOs, which is one such gap in the sex offender literature to be addressed by the present study. Scholars have suggested that the social disorganization theory does not align with the social ecology of rural environments (Brunton-Smith \& Sturgis, 2011; Kaylen \& Pridemore, 2013; Ross \& Mirowsky, 1999; see Sloas et al., 2012; see also Tewksbury et al., 2007; Weisheit \& Wells, 2005) given the urban roots of the theory itself (Park \& Burgess, 1925; Shaw \& McKay, 1942;

Sutherland, 1939). However, these conclusions have not deterred scholars from exploring the theory's appropriateness to RSOs in rural areas (Huebner et al., 2013; Navarro \& Rabe-Hemp, 2017; Sloas et al., 2012; Tewksbury et al., 2007).It is essential to explore rural- and suburban-based RSOs as sex offender policies have constrained RSOs away from urban residential locations, with housing options being much more obtainable (based on residency restriction zones) in suburban areas and even more in less dense, rural areas (Berenson \& Appelbaum, 2011; Chajewski \& Mercado, 2009; see Socia, 2011, 2012a; Zandbergen \& Hart, 2006). The primary culprit of this geographic phenomenon that has displaced RSOs in the outskirts of the main city is residency restrictions (Ragusa-Salerno \& Zgoba, 2012). RSOs reported to have become compliant with residency restrictions by simply moving into rural locations, and at the same time, 
reported frustrations with this decision to relocate into the countryside (Huebner et al., 2013; see Socia, 2012a; see also Socia et al., 2015).

Although RSOs are forced into rural areas, it is evident that they are no more socially disorganized than urban areas, if not more socially organized. In Kentucky, rural areas resided in by RSOs were described as much more socially organized than urbanbased RSOs (Sloas et al., 2012). Additionally, clusters of RSOs in rural areas (defined as five or more RSOs in a census tract) were marginally different from those without clusters (Tewksbury et al., 2007). Even so, these rural communities with RSOs are more socially disorganized when compared to national rates of standard living. Specifically, rural environments with clusters contained lower rates of White residents, residential stability, and owner-occupied housing units than those without clusters of RSOs. Similarly, concentrations of rural-based RSOs (defined as two or more RSOs within a 0.1 of a mile zone) in Illinois contained greater rates of renter-occupied and vacant housing units and female-headed households (Navarro \& Rabe-Hemp, 2017). Additional research of rural-based RSOs is important, given that Burchfield and Mingus (2008) suggested that rural-based RSOs in Illinois might have vastly different experiences than those who reside in urban areas.

Although the movement to rural locations diminished RSOs' probabilities in becoming homeless (Socia et al., 2015), non-metropolitan RSOs faced a greater rate of negative experiences, such as the loss of a job or housing, various forms of harassment (Tewksbury, 2005), and further distances from sex offender treatment (as exhibited in Kentucky) (Sloas et al., 2012). Albeit, rural locations may be alluring to RSOs for a different reason, rural areas allowed for greater levels of anonymity that is inherent in 
these environments (Tewksbury et al., 2007). The same logic can also be applied to urban environments as RSOs can blend among the public. However, urban RSOs reported that they felt easily recognized in their settings compared to rural-based RSOs (Tewksbury \& Mustaine, 2010).

The perceptions of a "neighbor" do vary by community types, especially in rural environments (Wentland et al., 2014). Thus, formal structures of notification may not be necessary for rural communities to inform themselves of who is in close proximity to their residence (Anderson et al., 2009) because rural residents may rely on neighbors to transmit knowledge of such offenders in their neighborhoods (Craun, 2010). In support, and in contrast to the belief held by rural-based RSOs (Tewksbury et al., 2007), rural residents are more likely to be cognizant of nearby RSOs than their urban counterparts (Phillips, 1998). Perhaps greater awareness among rural residents is related to the belief that they hold a greater fear of becoming a victim of a sexual offense than urban residents (Brown et al., 2008). But, urban residents have a greater frequency of being in contact with persons in general, thus, presumably at a greater rate of victimization by potential sex offenders (Anderson et al., 2009). Due to this risk of potential victimization, it would be sensible to suspect that urban residents would access the sex offender registry at a greater frequency, and consequently more aware of RSOs than rural residents. Such an outcome should occur if community notification operates as expected.

Awareness. The social behaviors of community members operate as a cyclical process due to the presence of RSOs, which include awareness, access, response, and fear. Community members can vary in their awareness to local RSOs, which is dependent on whether they have the means to access and gain information concerning the presence 
of these offenders. Second, community members can respond in either a proactive or an inactive approach to local RSOs, but, foremost, the most primary response to these stigmatized offenders will likely be feelings associated with fear.

Anywhere from $27 \%$ to $43 \%$ of residents are aware of the presence of local RSOs in their neighborhoods (Anderson \& Sample, 2008; Burchfield, 2012; Kernsmith, Comartin, et al., 2009; Lieb \& Nunlist, 2008; Phillips, 1998). One of the first assessment of community awareness of RSOs occurred in the state of Washington (Phillips, 1998). Results revealed that roughly a third of the residents surveyed were aware of local RSOs. A follow-up study ten years later revealed an increased percentage of respondents (43\%) who were aware of local RSOs (Lieb \& Nunlist, 2008). Regarding Illinois rural and suburban residents, roughly one-third of residents (29\%) were aware of a RSO in their neighborhood (Burchfield, 2012). Though Burchfield's (2012) findings were based on seven neighborhoods in Illinois, and she had not explored how community member awareness of RSOs functions to the distances to local RSOs.

What is known is that in a southeastern U.S. county, awareness of nearby RSOs varied by the homeowners' proximity to the nearest RSO. Homeowners within a tenth of a mile of a RSO were more aware of the offenders' residence (31\%) compared to owners who resided at least a mile (or further) away from the nearest RSO (2\%) (Craun, 2010). Altogether, community members are grossly unaware of RSOs in their areas, with awareness varying by community type and distance to the RSO. Even so, urban resident awareness of RSOs is unknown, with a need to update and expand the sex offender literature of rural and suburban county awareness of RSOs. 
The type of notification procedure practiced by jurisdictions is an influential factor in the awareness of local RSOs (Beck \& Travis, 2006). Active notification, or a more intrusive notification process, contributed to a greater awareness of RSOs, whereas, passive notification procedures resulted in a lower awareness of RSOs. Hamilton County, Ohio residents who were actively notified of nearby RSOs, were three times (77.3\% vs. 25.7\%) more likely to be aware of offenders directly adjacent to their property than residents were from Jefferson County, Kentucky. As Kentucky and Illinois (730 ILCS § $152 /)$ both practice passive notification, it is safe to assume that residents would be equally as aware of local RSOs; thus, these two U.S. states would be good comparisons concerning residential awareness of RSOs.

Access to public information of RSOs. Access to the registry did not guarantee complete awareness of sex offender residences (Kernsmith, Comartin, et al., 2009). About one-half (51\%) of community members who had accessed the registry reported an awareness of an offender being a resident of their community even though nearly all resided near a RSO. Thus, questioning respondents whether they had accessed the registry is an irrelevant pursuit to gauge awareness of RSOs.

The lack of awareness and action to access sex offender registries insinuates a passive acceptance by residents of RSOs relocating into their communities (Mustaine et al., 2006b; see Agan \& Prescott, 2014; see Brown et al., 2008; Zevitz, 2004). Alternatively, as demonstrated in the social disorganization literature that focused on RSOs, RSOs are relegated into communities that are not socially constructed to be the most ideal in allowing their presence to be known (Zevitz, 2004). A growing population of RSOs can cultivate community social disintegration and a perceived sense of a loss of 
control by residents. Inevitably, allowing RSOs the ability to reside anonymously in communities even though their information is exposed in the virtual realm.

Response to the known presence of RSOs. Zevitz's (2004) case study of a community's reaction to the placement of a well-publicized RSO exemplified the unique process stated above. Initially, about one-third (35\%) of community members reported being more anxious and fearful due to the new placement of the RSO in their community, which dropped over a two month period (26\%). At the same time, despair and hopelessness increased over these two months (from seven percent to 20\%). Community members subsequently reported feelings of demoralization after the placement of a RSO in their area, with the primary concern being that their community would be susceptible to subsequent placements of new RSOs, as well as increased crime rates. Becoming a dumping ground for RSOs prompted several community members to consider relocating and/or selling their businesses and homes given that the financial well-being of the area may have been compromised, if not devalued, by the placement of a RSO.

The fear of sexual victimization. The mere presence of a convicted sex offender or offenders inspires increased amounts of anxiety, fear, and concern for general safety among community members (Anderson \& Sample, 2008; Beck \& Travis, 2004; Brown et al., 2008; Caputo \& Brodsky, 2004; Craun \& Theriot, 2009; Kernsmith, Craun, et al., 2009; Levenson et al., 2007a; Lieb \& Nunlist, 2008; Phillips, 1998; Zevitz, 2004; Zevitz \& Farkas, 2000a). Regarding fear, roughly one-third (38\%) of Zevitz and Farkas' (2000a) sample of Wisconsin residents who attended community notification meetings designed to increase sex offender awareness reported an increase in fear. However, a remaining one-third (35\%) of attendees had reported less fear because of community notification 
meetings. Decreased fears by attendees of community notification meetings may be related to their feelings of potential personal and altruistic victimization.

Beck and Travis (2004) differentiated the concept of the fear of victimization into two forms, a personal fear of victimization (i.e., individual's concern about oneself) and an altruistic fear of victimization (i.e., worried about others [e.g., household members] who may become victims of a crime). Residents notified of a nearby RSO reported a substantially higher personal and altruistic fear of a sexual assault when compared to residents not informed (even though they resided in the same neighborhood). In fact, family homes have been associated with greater depressions in the selling prices of family homes (defined as a household with three bedrooms or more) than non-family homes (Bian et al., 2013; Wentland et al., 2014), which suggests an unwillingness of parents to reside nearby RSOs.

\section{Home Sale Prices}

Undesirable features of a community such as criminal activities (Burnell, 1988; Congdon-Hohman, 2013; Ihlanfeldt \& Mayock, 2010; Thaler, 1978; Troy \& Grove, 2008; Yeh, 2015), sex offenses (Yeh, 2015), and nearby RSOs (Bian et al., 2013; Caudill et al., 2014; Larsen et al., 2003; Linden \& Rockoff, 2008; Navarro \& Rabe-Hemp, 2017; Pope, 2008; Wentland et al., 2014; Yeh, 2015) have been associated with reductions in property values. Even more concerning is that depressed home sale values as a consequence of crime and RSOs' presence resulted in decreased overall revenue of the vicinity as a whole (Burnell, 1988; Congdon-Hohman, 2013; Linden \& Rockoff, 2008). For instance, the presence of RSOs potentially resulted in a $\$ 60$ million financial loss on home sale values in Mecklenburg County, North Carolina (Linden \& Rockoff, 2008). 
In brief, case studies by economists of various U.S. jurisdictions have yielded three consistent key findings in the RSO-home sale value literature. First, the presence of a RSO and/or clusters of RSOs are associated with decreased real estate property sale values (Bian et al., 2013; Caudill et al., 2014; Larsen et al., 2003; Linden \& Rockoff, 2008; Navarro \& Rabe-Hemp, 2017; Pope, 2008; Wentland et al., 2014; Yeh, 2015). Second, the effect lessened as the distance between the sold home and the residence of the RSO increased (Caudill et al., 2014; Larsen et al., 2003; Linden \& Rockoff, 2008; Pope, 2008; Wentland et al., 2014). Third, rural, suburban, and urban locations across the U.S. have supported a link between sex offenders and lowered home selling prices (Bian et al., 2013; Caudill et al., 2014; Larsen et al., 2003; Linden \& Rockoff, 2008; Pope, 2008; Navarro \& Rabe-Hemp, 2017; Wentland et al., 2014; Yeh, 2015). But, Ingram and Franco's (2014) urban-rural classification scheme of counties defines each of these explored U.S. counties as metropolitan counties, not as rural- or suburban-based. ${ }^{12}$

With a sample consisting of one year of housing transactions, Larsen et al. (2003) conducted the first empirical assessment of household financial reactions to RSOs in Montgomery County, Ohio. Here, RSOs were dichotomized by their legal status of dangerousness, limited disclosure (classified by Ohio as the most "dangerous"; i.e., proactive notification) and (strictly) passive notification. When compared to houses outside of the examined tenth of a mile, limited-disclosure offenders yielded a greater

\footnotetext{
${ }^{12}$ Beginning with the most urban counties (Ingram \& Franco, 2014), RSO-home sale value scholars have explored large central metro counties (Hillsborough County, Florida; Mecklenburg County, Ohio; and Shelby County, Tennessee), medium metro counties (Lancaster County, Nebraska; Lynchburg City, Virginia; and Montgomery County, Ohio), and a small metro county (McLean County, Illinois) (Bian et al., 2013; Caudill et al., 2014; Larsen et al., 2003; Linden \& Rockoff, 2008; Navarro \& Rabe-Hemp, 2017; Pope, 2008; Wentland et al., 2014; Yeh, 2015).
} 
reduction in the home sale price $(\$ 11,864)$ than the less dangerous passive notification offenders $(\$ 4,208)$.

Using a time-series dataset, Linden and Rockoff (2008) advanced the scholarship with the inclusion of sex offender $(N=174)$ move-in dates. Selected housing properties $(N=9,086)$ were within three-tenths of a mile of a RSO and sold between 1994 and 2004 in Mecklenburg County, North Carolina. Following the arrival of RSOs, sold homes within one-tenth of a mile depressed in value by roughly four percent $(\$ 5,500$; based on median values of sold homes). The greatest financial loss- $11.6 \%$ depression in sale prices_occurred when sold homes were directly adjacent to RSOs’ properties.

Like Linden and Rockoff (2008), no financial association was evident beyond a tenth of a mile to the residences of RSOs in Pope's (2008) analysis of homes sold (from October 1996 to April 2006) in Hillsborough County, Florida. Unlike Larsen et al. (2003), the presence of a more dangerous RSO (termed sexual predator) did not affect selling prices. However, an average reduction of $\$ 3,500$ occurred with home sale values among sold homes within one-tenth of a mile of a RSO (or non-sexual predators). His contribution to the scholarship involved establishing causality with move-out dates of RSOs, which revealed that the departure of the RSO resulted in rebounded housing prices. Home selling prices rebounding after RSOs moved out were not an isolated financial phenomenon in Hillsborough County, but also apparent in the rural, suburban, and urban areas of Lynchburg City, Virginia (Wentland et al., 2014) as well as in Lancaster County, Nebraska (Yeh, 2015).

Wentland et al. (2014) furthered the literature by extending the distances observed up to a mile of sold and unsold properties $(n=12,426, n=7,295)$ between 1999 and 
2009. Their final model (i.e., Heckman correction model), which allowed for reduced selection bias problems, showed reductions of $\$ 11,332$ for homes within one-tenth of a mile of RSOs (and lengthened the time for the home to be on the real estate market). In contrast to prior studies, Wentland et al. (2014) results from their final model showed that depressed home selling prices were associated with RSOs up to one mile, indicating a reduction of $\$ 3,488$ in home selling prices. Wentland et al. (2014) argued that the effect of RSOs' residence persist beyond three-tenths of a mile because the setting explored also included suburban and rural areas, unlike the previous RSO-home sale value studies. The present study will attempt to support Wentland et al. (2014) argument with explorations of the effects of RSOs based in counties defined as rural and suburban. Comparable to the studies above concerning dangerous RSOs, RSOs in Virginia were dichotomized as violent and non-violent, with violent RSOs associated with larger depressed home sale values by $\$ 17,432$ when liquidity was also accounted for in the model.

An extension of Wentland et al. (2014) dataset, Bian et al. (2013) explored the relationship between homes' selling prices and the concentrations of RSOs. Bian and his colleagues hypothesized that neighborhoods experienced a real estate market tipping point that occurred as a consequence of sex offender clusters. A total of 584, 167, 38, and 23 homes in their sample contained (within a quarter mile) the presence of one, two, three, or four RSOs, respectively. Results showed that the presence of one RSO was associated with a five percent $(\$ 8,338)$ depression in home sale value, with the tipping point identified as four RSOs—-16 percent $(\$ 25,099)$. 
Caudill et al. (2014) distinguished themselves from the studies above by weighting the nearest three home sale values respective to the sold home-single-family homes sold from 2008 to 2012 in Shelby County, Tennessee. Results suggested that spatial models are superior due to the ability to reduce spatial dependence and their attenuation in the relationship between home sale values and the nearby presence of RSOs. The hedonic spatial error model showed that selling price of homes within onetenth of a mile and within one mile from the nearest RSO decreased by $14 \%(\$ 8,653.95)$ and $7.4 \%$, respectively; homes within 1,000 feet (Tennessee's residency restriction) to the nearest RSO resulted in a $\$ 6,410.25$ depression in home sale values. Caudill et al. (2014) findings indicate that the inclusion of a spatial term to account for spatial dependence is crucial in the RSO-home sale value research as it reduces the effect of RSOs onto home sale values.

Yeh (2015) furthered the scholarship of the relationship between home sale values and the presence of high-risk RSOs (risk based on recidivism; a majority resided in the city of Lincoln) with examinations of specific neighborhood characteristics. An analysis of homes sold from 1994 to 2006 in Lancaster County, Nebraska experienced no loss in sale value when matched to all high-risk RSOs. But, when RSOs were dichotomized by their mobility (transient \& non-transient), non-transient RSOs (stayed at residence six months or longer) were associated with roughly a four percent depression in selling prices. Transient high-risk RSOs, when compared to non-transient counterparts, were likely to reside in areas with "desirable" traits, which included greater rates of owneroccupied housing units, college graduates, and residential stability. In contrast, nontransient RSOs were more likely to reside in areas with greater percentages of single 
person households, persons below poverty, and unemployment. Such are the neighborhood characteristics to be included in the present study's analysis. In whole, transient RSOs resided in wealthier neighborhoods, and non-transient living (or a lengthier settlement in a neighborhood) resulted in poor living conditions and depressed home sale values, thereby encouraging continuous residential movement. Seemingly, it could be argued that it takes nearly six months for community members to become aware of local RSOs as non-transient RSOs were not associated with depressed selling prices. Nevertheless, it is still unclear how these neighborhood characteristics related to home sale values as a whole when combined with property characteristics.

Different from the previous studies mentioned, Navarro and Rabe-Hemp (2017) explored the association between RSOs and home sale values in a U.S. county described as predominantly rural, McLean County, Illinois. Within a two-tenths mile radius, for each additional foot (in the distance) between the nearest RSO or sexual predatordeemed more dangerous due to previous sexual convictions and/or crime committedand a sold home, home selling prices increased by $\$ 17.03$ and $\$ 15.25$, respectively. Comparative to Bian et al. (2013), the presence of two or more RSOs/sexual predators were identified as the tipping point in a rural landscape. Selling prices reduced by $\$ 12,750$ with a concentration of two or more RSOs and even greater depression of $\$ 17,797$ was associated with a concentration of two or more sexual predators. Here, ruralbased research presented its (geographic) challenges. Census blocks had to be utilized (as opposed to census block groups) as the units of analysis due to the fact convicted sex offenders had residences over a vast land area. As a consequence, the researchers were 
unable to ascertain the distance of one-tenth of a mile given that so few homes contained RSOs within that radius.

Empirical gaps and issues still exist in the RSO-home sale value research. ${ }^{13}$ First, nearby home sale values were not accounted for with exception to Caudill et al. (2014) study possibly leading to spurious results. Second, hedonic regression modeling was the primary methodological approach utilized (Bian et al., 2013; Caudill et al., 2014; Larsen et al., 2003; Linden \& Rockoff, 2008; Pope, 2008; Wentland et al., 2014; Yeh, 2015). However, these hedonic regression models were hindered by not accounting for the hierarchical structure of a geographically clustered sample of sold homes in neighborhoods. For this reason, hedonic regression modeling may not be the most suitable analytical strategy to be employed. Given the hierarchical structure of homes nested in neighborhoods, multilevel modeling is an ideal alternative, considering this statistical approach can disentangle the effects of the hierarchical levels of the outcome variable and will situate sold homes within a specific local context (see Brown \& Uyar, 2004). Third, some of these studies implemented time/year and/or neighborhood fixed effects to reduce potential omitted variable bias. Thereby, disallowing the estimation of observable neighborhood characteristics, and potentially producing imprecise models or spurious results regarding the RSO-home sale value relationship. Fourth, these studies have been based on areas from metropolitan areas (see Ingram \& Franco, 2014), with little consideration of the influence of urbanicity.

\footnotetext{
13 The relationships between RSOs and home selling prices were typically based on a less stringent alpha value of .10 (vs. .05). But, this is considered the norm for statistical significance in the economic literature. It is noteworthy to mention that there is a strong philosophical debate concerning whether the statistical standard for the significance of .05 is arbitrary. Nevertheless, standards for "appropriate" alpha values are a deeply entrenched philosophical debate in empirical studies.
} 


\section{Summary of the Literature Review}

It is evident that the provisions set forth by federal and state jurisdictions are nothing more than a "feel good" set of policies that have conveyed an illusion of safety. Community members supported sex offender policies and reported feelings of security and awareness of sex offender policies (Anderson \& Sample, 2008; Craun, 2010; Lieb \& Nunlist, 2008; Phillips, 1998). However, community members do not engage in preventative or protective procedures likely contributed by their unawareness of local RSOs (Anderson et al., 2009; Anderson \& Sample, 2008; Bandy, 2011; Brown et al., 2008; Burchfield, 2012; Craun, 2010; Kernsmith, Comartin, et al., 2009; Lieb \& Nunlist, 2008; Phillips, 1998; see Beck \& Travis, 2006). Community unawareness of RSOs may be related to the finding scholars have consistently demonstrated in the sex offender literature: RSOs are relegated into disadvantaged communities as a function of sex offender legislation. Unlike advantaged communities, disadvantaged communities do not have the resources to manage and push out undesirable items (like RSOs) in their environments effectively (Clark \& Duwe, 2015; Hughes \& Burchfield, 2008; Hughes \& Kadleck, 2008; Kelling \& Wilson, 1982; Kubrin \& Weitzer, 2003; Sampson \& Groves, 1989; Sampson, Raudenbush, \& Earls, 1997; Socia \& Stamatel, 2012). The presence of RSOs is not an ideal product for a disadvantaged community, nor is the disadvantaged community an ideal setting for a RSO. Community members responded to the placement of RSOs in their communities with plans to relocate in fear of devalued commodities (Zevitz, 2004). With research that endorsed an unwillingness to reside near RSOs as evident by depressed home sale values (Bian et al., 2013; Caudill et al., 2014; Larsen et 
al., 2003; Linden \& Rockoff, 2008; Navarro \& Rabe-Hemp, 2017; Pope, 2008; Wentland et al., 2014; Yeh, 2015).

The heart of the present study is to address and clarify the finding concerning depressed home sale values associated with RSOs together with the awareness of these offenders by types of communities. The primary intent is to advance the RSO-home sale value literature with a stronger methodological approach and contribute to a more robust link between RSOs and depressed home sale values by gauging homebuyer awareness of RSOs. In order to do this, the organizational structure inherent in human ecological environments within the confines of the social disorganization theoretical framework are acknowledged, together with the recognition of the geographic layout of the environment via the concept of spatial dependence. With much of the sex offender literature focused on the effects of RSOs in the urban environments of two contiguous U.S. states, the present study will add to the literature with explorations of the financial effects associated with RSOs and homebuyer awareness of RSOs across community types. 


\section{CHAPTER IV METHODOLOGY}

\section{The Current Study}

Sex offender policies were intended to encourage the public to engage in protective actions against sex offenders and offenses (Anderson et al., 2009; Anderson \& Sample, 2008; Bandy, 2011; Brown et al., 2008; Caputo \& Brodsky, 2004). That is far from the truth, as community members have not exercised their ability to engage in protective behaviors, as most of the public is unaware of nearby RSOs (Anderson \& Sample, 2008; Burchfield, 2012; Craun, 2010; Kernsmith, Comartin, et al., 2009; Lieb \& Nunlist, 2008; Phillips, 1998). At the same time, scholars have suggested that homes have financially reacted via depressed home sale values as residents do not desire to be near RSOs (Bian et al., 2013; Caudill et al., 2014; Larsen et al., 2003; Linden \& Rockoff, 2008; Navarro \& Rabe-Hemp, 2017; Pope, 2008; Wentland et al., 2014; Yeh, 2015). However, taken together, it is perplexing as to how community members are largely unaware of local RSOs; yet, the presence of these RSOs contributed to, or at a minimum, have been shown to empirically be associated with home selling prices across several different types of communities.

The goal of the present study is to unravel the relationships between the presence of RSOs and home selling prices and community awareness of RSOs. RSO-home sale 
value scholars' conclusions may have resulted from less precise models that had not accounted for neighborhood characteristics and spatial dependence. With the use of spatial and multilevel software, the current study examines the relationship between RSOs and home sale values in accompaniment of property and neighborhood characteristics of three U.S. counties classified as rural, suburban, and urban in two contiguous U.S. states, Illinois and Kentucky. Assessments of urban and particularly nonurban communities, like rural and suburban environments, must be conducted to increase the generalizability of the findings resulting from RSOs and home sale values coupled with community awareness of RSOs. It is uncertain whether rural and suburban environments operate similarly (regarding the awareness of nearby RSOs and home selling prices) to urban areas given that, a wealth of empirical and theoretical literature has focused on the latter community landscape. Additionally, non-urban and urban homebuyers from the sample were surveyed to assess whether they were aware of RSOs nearby their purchased property to add clarity to the link between home selling prices and proximity to RSOs.

The five proposed research questions:

1. Is the distance to the nearest RSO associated with home sale values after controlling for property-level characteristics?

2. Is the distance to the nearest RSO associated with home sale values after controlling for both property-level and neighborhood-level characteristics (including spatial dependence)?

3. Are non-urban homebuyers more aware of RSOs within 1,000 feet of their property than urban homebuyers? 
4. Does homebuyer awareness (aware vs. unaware) of RSOs within 1,000 feet of their recently purchased property moderate the relationship between home selling prices and the distance to the nearest RSO, after controlling for the sold homes' property characteristics?

5. Does the homebuyer's type of community (non-urban vs. urban) moderate the relationship between home selling prices and the distance to the nearest RSO within 1,000 feet of their property, after controlling for the sold homes' property characteristics?

\section{Settings}

The present study contains data from three U.S. counties (one suburban and one rural county in Ilinois ${ }^{14}$ and one urban county in Kentucky. ${ }^{15}$ Located in the northwest region of Illinois is a rural environment with 38,950 inhabitants across 1,044.29 square miles, Lee County (U.S. Census Bureau, 2016c). ${ }^{16}$ Adjacent to the west side of Cook

\footnotetext{
${ }^{14}$ Of the 102 counties in Illinois, 62 were classified as rural (micropolitan $[n=24]$ and noncore $[n=38]$ ), 13 as small and 10 were medium metro areas, 16 suburban counties, and one urban county (or large central areas [i.e., Cook County]). An exploration of Cook County, Illinois is unfeasible for the present project because of its enormity. Therefore the selection of a more reasonably sized urban county in Kentucky was selected. Further, given the enormity of Cook County, Illinois, even a comprehensive methodological study of a RSO-home sale value exploration would probably yield spurious conclusions likely associated with the complexities of social interactions of the great number of neighborhoods of Chicago.

${ }^{15}$ The present study adopts the 2013 National Center for Health Statistics (NCHS) urban-rural classification scheme that lays on a six-part continuum (Ingram \& Franco, 2014). According to the NCHS, beginning from most urban to most rural, the first following four counties are described as metropolitan areas (large central metro [similar to large cities], large fringe metro [similiar to suburbs], medium metro [populations between 250,000 to 999,999 inhabitants], and small metro [populations less than 250,000 inhabitants]). The last two counties of the six-part NCHS urban-rural continuum described nonmetropolitan areas (micropolitan [urban cluster with 10,000 to 49,000 inhabitants] or noncore [remaining nonmetropolitan counties not considered as micropolitan counties]).

${ }^{16}$ As a disclaimer, it must be understood that definitions for rural environments are quite ambiguous, arbitrary, and controversial. Lee County, Illinois was selected based on the following described criteria. First, the rural county must have been identified as a nonmetropolitan county (micropolitan or noncore), in which 62 (of the 102 Illinois counties) were considered rural by Ingram and Franco's 2013 NCHS (2014) report. Second, the rural county must have a minimum of 50 compliant RSOs listed as residents, which reduced the sample to 18 rural counties (eliminated 44 rural counties). Of the remaining 18 rural counties, 16 of those county assessor's offices' reported that household property data would be impossible to
} 
County, Illinois - Chicago — the present study's suburban county is the second most populous county (916,924 inhabitants) in the state of Illinois: DuPage County, Illinois (U.S. Census Bureau, 2016a). ${ }^{17}$ The suburban county spreads out over 327.50 square miles that consist of 2,799.8 inhabitants per square mile, which is a population per square mile considerably higher than previous RSO-home sale value literature. Like DuPage County, Jefferson County, Kentucky is much denser in population than the counties previously explored in the RSO-home sale value research. A merged city-county, Jefferson County is home to 763,623 residents across 380.42 square miles or $1,948.1$ persons per square mile (U.S. Census Bureau, 2016b). ${ }^{18}$ Geographically, this urban county is located on the Ohio River adjacent to the borders with Indiana — is coterminous with the city of Louisville and is the largest county by population size in the state.

retrieve. The selection of Lee County resulted in that it contained a greater sample size of homes sold in 2015.

${ }^{17}$ The National Center for Education Statistics (NCES) (2016) defines a large suburban area as a "[t]erritory outside a principal city (primary population and economic center of a Metropolitan Statistical Area - defined as an area that has a population of one million or more) and inside an urbanized area with a population of 250,000 or more". DuPage County corresponds with the NCES' (2016) definition with an estimated population of 933,736 inhabitants in 2015 (U.S. Census Bureau, 2016a). In accompaniment with the NCES definition of suburban areas, the NCHS (Ingram \& Franco, 2014) dichotomized "large metropolitan areas ( 1 million or more population) into two categories: large 'central' metro (akin to inner cities) and large 'fringe' metro (akin to suburbs)". With this logic, the NCHS urban-rural county classification scheme classifies DuPage County as a large "fringe" metro.

${ }^{18}$ Unlike DuPage County, Jefferson County maintains a principal city—Louisville, Kentucky (Ingram \& Franco, 2014; NCES, 2016), and for that reason, Jefferson County is considered urban even though its population is lower than DuPage County. 


\section{Data}

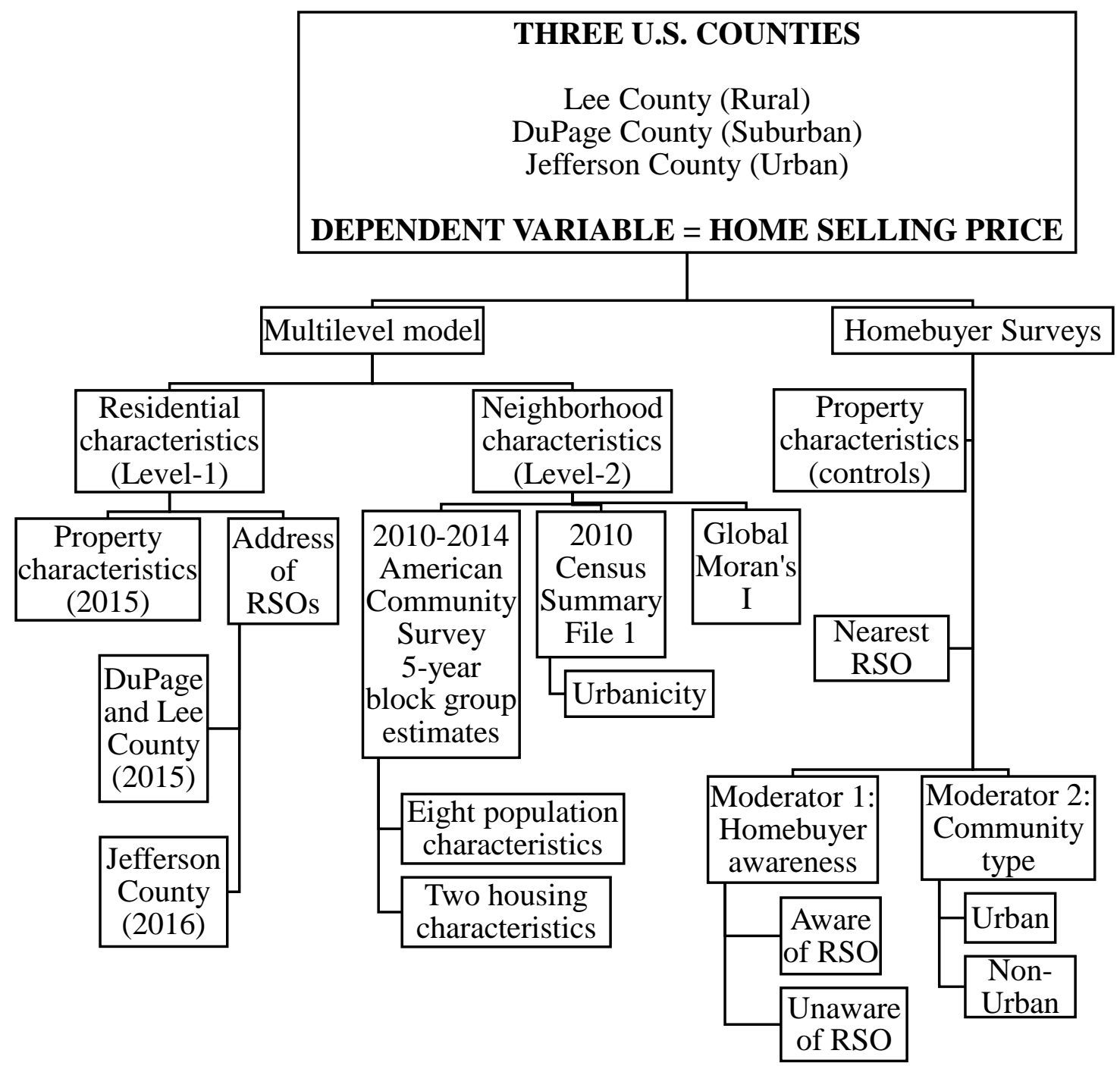

Figure 1. An illustration of the current study's data.

As described in Figure 1, data collected per U.S. county included 1) household property characteristics of sold properties, 2) addresses of RSOs, ${ }^{19}$ 3) 2010-2014

American Community Survey (ACS) 5-year block group estimates and a 2010 Census

Summary File $1,{ }^{20}$ and 4) survey responses from homebuyers. Several different analytical

\footnotetext{
${ }^{19}$ Residences of the homebuyers and RSOs are based on point data, which places a single dot in the center of these (polygonal) addresses. Parcel polygons were not used because it increases margin errors (Chajewski \& Mercado, 2009; however, see Socia, 2011; see also Zandbergen \& Hart, 2009).

${ }^{20}$ Census block groups are ideal (and significantly better than census tracts) for the assessment of neighborhood structural characteristics and when household characteristics are considered (see Cho et al.,
} 
packages were used to prepare the primary and secondary data for analysis including ArcGIS 10.2.2, GeoDa 1.10 (Anselin, Syabri, \& Kho, 2006), SPSS 24 (IBM Corporation, 2016), and multilevel modeling (HLM 7.01; Raudenbush et al., 2013). Due to the wealth of data, the methods section is bifurcated into two parts for parsimony. The first part of the methodology describes the multilevel modeling approach. The second half of the methods section describes the results of the survey process and the moderators.

Multilevel modeling. Sold homes and their residential characteristics (level-1) are nested within neighborhoods (level-2) in the multilevel model (Table 2). Level-1 characteristics included the property characteristics of sold homes. When property characteristics are accompanied with another level-1 characteristic, the distance to the nearest RSO (in feet), this grouping is referred to as residential characteristics.

Level-2 characteristics included the characteristics of the 11 census block groups that serve as proxies of the neighborhoods. Another level-2 characteristic was a spatial effect to control for spatial dependence. GeoDa created a spatial weights matrix based on a queen's criterion and computed the spatial regression models to obtain the global Moran's I coefficients. Each global Moran's I coefficient represents each neighborhood's contribution to spatial dependence (see Kubrin \& Herting, 2003).

Dependent variable. Home sale price is the dependent variable. Single-family households (including duplexes and townhome dwellings) are the unit of analysis to correspond with the housing literature (Burnell, 1988; Caudill et al., 2014; CongdonHohman, 2013; Goodman \& Thibodeau, 2007; Ihlanfeldt \& Mayock, 2010; Larsen et al.,

2006; Socia, 2011, 2012a). Assessments of perceived safety and disorder/incivilities are much more reliable at smaller geographic units, especially considering larger geographic units have the potential to obscure neighborhood variation (Coulton et al., 2004). 
2003; Linden \& Rockoff, 2008; McMillen, 2008; Navarro \& Rabe-Hemp, 2017; Pope, 2008; see Thaler, 1978; see also Yeh, 2015; Troy \& Grove, 2008; Wentland et al., 2014) ${ }^{21}$ Home sales were restricted to residential properties that sold in the year 2015, with selling prices greater than $\$ 7,500$ (Pope, 2008), and considered as an arms-length sale. ${ }^{22}$ The final samples of sold homes per county achieved the acceptable match rate threshold of $90 \%$ for accurate mapping when geocoded (Bichler \& Balchak, 2007).

With sold homes now geocoded, sale values must be assessed for any abnormalities from the real estate market per U.S. county. Figures 2, 3, and 4 illustrate the median values of owner-occupied housing units in 2015 (dark line) and how it corresponds to the present study's home sale values (light line) in Lee County (rural), DuPage County (suburban), Jefferson County (urban), respectively. As can be seen in the figures, any woes that the current study's home selling prices may have been irregular are mitigated as the fluctuations in the housing market parallel the median values of owneroccupied housing units per county as reported by the U.S. Census. Although there may be downward or upward peaks from the home selling prices per county, these peaks nevertheless overlaid with the downward or upward trends of the calculated means of the median household values of each U.S. county.

\footnotetext{
${ }^{21}$ Removal of apartment complexes and public housing projects are typical for housing and neighborhood research (Ihlanfeldt \& Mayock, 2010; Perkins \& Taylor, 1996).

${ }^{22}$ Parcels not considered arms-length home sales are distressed properties. These properties experienced underlying pressures to influence its market value, such as auctions or foreclosures.
} 


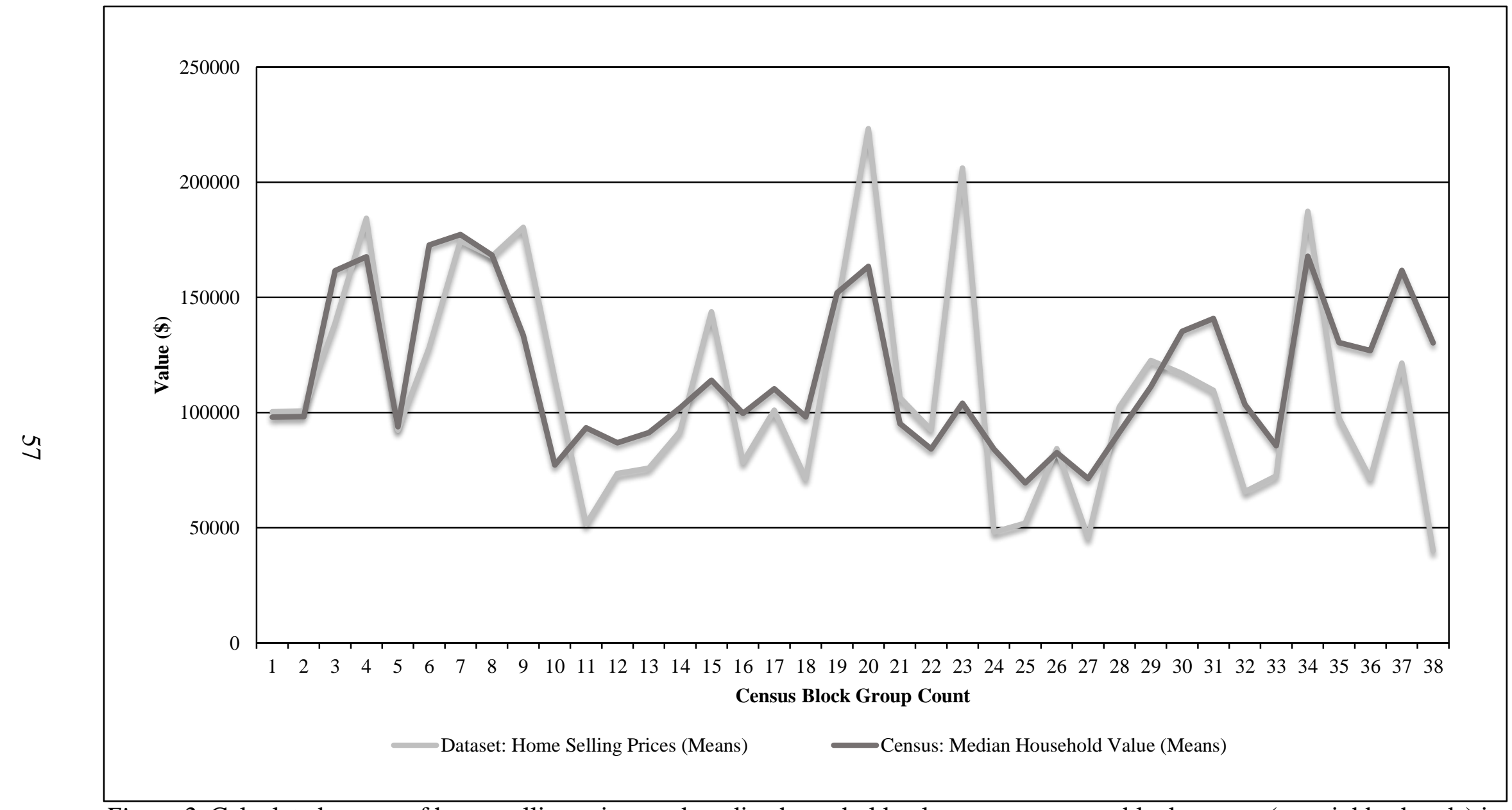

Figure 2. Calculated means of home selling prices and median household values across census block groups (or neighborhoods) in Lee County, Illinois. 


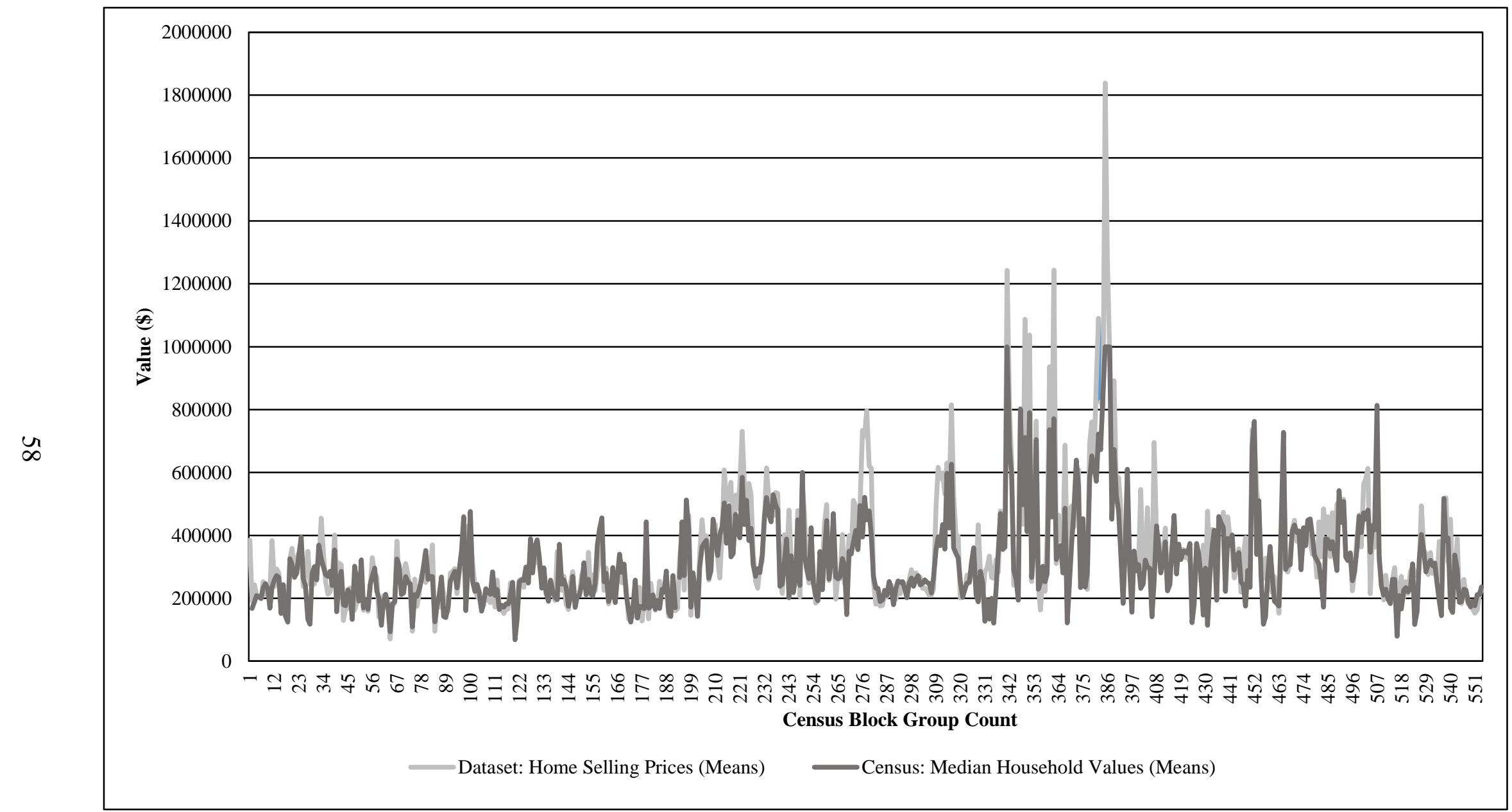

Figure 3. Calculated means of home selling prices and median household values across census block groups (or neighborhoods) in DuPage County, Illinois. 


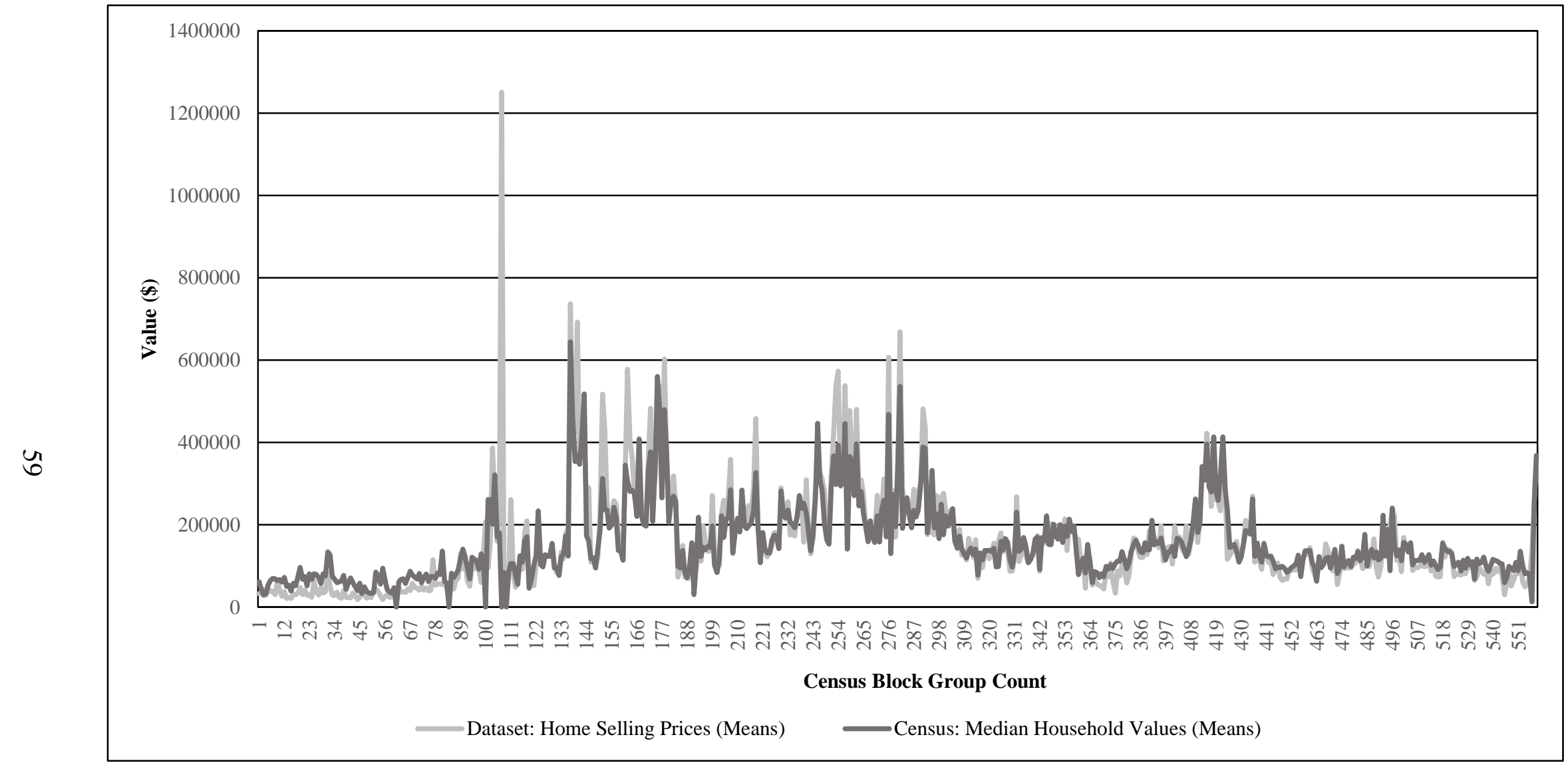

Figure 4. Calculated means of home selling prices and median household values across census block groups (or neighborhoods) in Jefferson County, Kentucky. 
Descriptive statistics indicated that home sale values were positively skewed $(M=$ $237,780.30, S D=224,881.26$ ). The natural $\log$ of the sales price was taken to normalize the dependent variable. Because the dependent variable is log transformed, the exponentiated regression coefficient is interpreted as the change in the ratio of the expected geometric means of the study's variables. Therefore, the exponentiated coefficient must be subtracted by 1.00 ; and subsequently multiplied by 100 , with the calculated outcome representing the expected percentage change in the dependent variable per one-unit change in the independent variable. On average, neighborhoods had $23.43(S D=17.59)$ sold homes with a sale value of $\$ 243,404(S D=178,574)$, with the count of sold homes ranging from 1 to 198 across 1,150 neighborhoods (Table 2). 
Table 2

Multilevel Descriptive Statistics for All Variables

\begin{tabular}{|c|c|c|c|}
\hline \multirow{2}{*}{\multicolumn{4}{|c|}{$\begin{array}{l}\text { Variables } \\
\text { Level-1 - Residential Level }^{\mathrm{a}}\end{array}$}} \\
\hline & & & \\
\hline Sale price & $237,780.30$ & $224,881.26$ & $7,580.00-4,400,000.00$ \\
\hline Sale price $(\ln )$ & 12.05 & 0.85 & $8.93-15.30$ \\
\hline Age (in years) & 48.71 & 28.45 & $0.00-185.00$ \\
\hline GLA & $1,725.59$ & 841.73 & $368.00-12,441.00$ \\
\hline Number of baths & 2.31 & 1.54 & $0.00-9.50$ \\
\hline Basement & 0.45 & 0.50 & $0.00-1.00$ \\
\hline Fireplace & 0.34 & 0.47 & $0.00-1.00$ \\
\hline Dist. RSO & $2,478.41$ & $2,449.57$ & $2.19-27,761.80$ \\
\hline \multicolumn{4}{|c|}{ Level-2 - Neighborhood Level $^{\mathrm{b}}$} \\
\hline$\%$ Black & 12.93 & 22.29 & $0.00-100.00$ \\
\hline$\%$ Hispanics & 8.40 & 12.79 & $0.00-85.18$ \\
\hline$\%$ Foreign-born & 11.37 & 11.41 & $0.00-64.98$ \\
\hline$\%$ Year+ at residence & 87.27 & 9.81 & $37.68-100.00$ \\
\hline$\% 65$ and over & 14.08 & 8.13 & $0.00-76.89$ \\
\hline$\% 17$ and younger & 22.59 & 7.73 & $0.00-48.50$ \\
\hline$\%$ 25YO+: Bach/Grad & 36.71 & 22.30 & $0.00-94.21$ \\
\hline$\%$ Poverty & 9.39 & 12.63 & $0.00-79.43$ \\
\hline$\% \mathrm{FHHs}$ & 7.67 & 8.19 & $0.00-50.59$ \\
\hline$\%$ Renter-occupied & 29.28 & 24.26 & $0.00-100.00$ \\
\hline Urbanicity & 0.97 & 0.15 & $0.00-1.00$ \\
\hline Global Moran’s I & 0.00 & 0.01 & $-0.09-0.10$ \\
\hline
\end{tabular}

Note. Age refers to the age of the property. GLA $=$ Gross living area. FHHs $=$ Femaleheaded households. ${ }^{\mathrm{a}} N=1,150 .{ }^{\mathrm{b}} N=26,945$.

Lee County (rural). Sale prices for 496 residential parcels were acquired from Lee County's assessor's office. Parcels that were not considered as an arms-length sale $(n=$ 199); reported no square footage of the parcel $(n=19)$; and reported as demolished, vacant, non-existing parcel number, or a sale price less than $\$ 7,500$ were removed $(n=$ 7). After the removal of the parcels described above, the final sample of 271 sold homes were geocoded (100\% hit rate) as displayed in Figure 5. Descriptive statistics (Table 3) indicate that the sale prices of the homes in the sample had a mean value of US\$117,080 $(S D=\mathrm{US} \$ 77,629)$ and ranged from US\$13,500 to US\$500,000. 


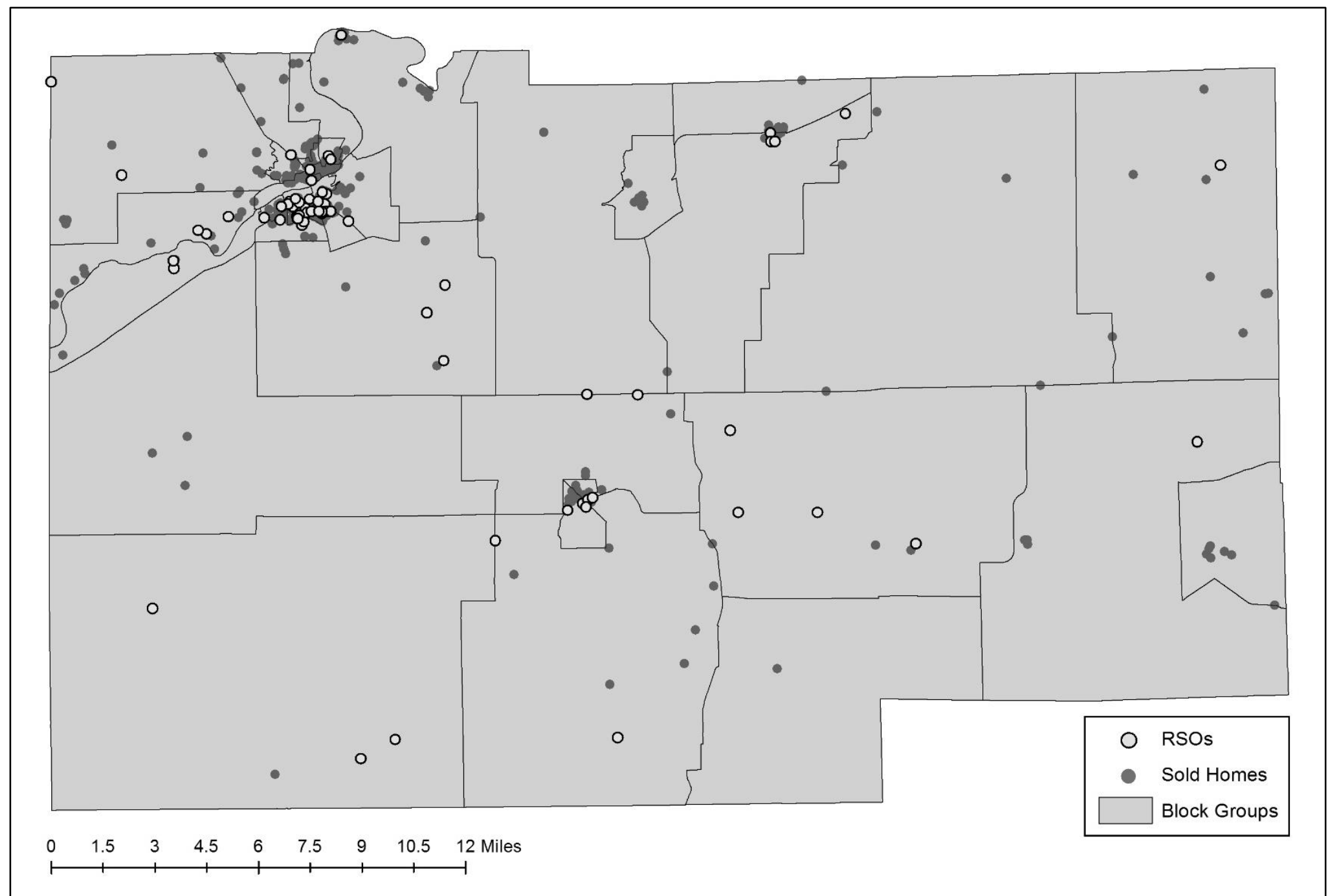

Figure 5. Locations of sold homes and RSOs across block groups in Lee County, Illinois. 
Table 3

Characteristics of Rural Sample

\begin{tabular}{|c|c|c|c|c|c|}
\hline \multirow[t]{2}{*}{ Characteristics } & & \multicolumn{4}{|c|}{ Rural $(N=271)$} \\
\hline & $n$ & $M$ & $S D$ & Minimum & Maximum \\
\hline \multicolumn{6}{|l|}{ Dependent variable } \\
\hline Sale price & & $117,079.55$ & $77,628.61$ & $13,500.00$ & $500,000.00$ \\
\hline Sale price $(\ln )$ & & 11.47 & 0.65 & 9.51 & 13.12 \\
\hline \multicolumn{6}{|l|}{ Residential } \\
\hline Age (in years) & & 72.90 & 42.39 & 4.00 & 185.00 \\
\hline GLA & & $1,565.54$ & 592.294 & 489.00 & $5,027.00$ \\
\hline Number of baths & & 1.53 & 0.63 & 0.00 & 3.50 \\
\hline Basement & & 0.89 & 0.31 & 0.00 & 1.00 \\
\hline No & 29 & & & & \\
\hline Yes & 242 & & & & \\
\hline Fireplace & & 0.30 & 0.46 & 0.00 & 1.00 \\
\hline No & 191 & & & & \\
\hline Yes & 80 & & & & \\
\hline Dist. RSO & & $5,271.39$ & $6,879.31$ & 12.56 & $27,761.80$ \\
\hline \multicolumn{6}{|l|}{ Neighborhood } \\
\hline$\%$ Black & & 4.07 & 7.36 & 0.00 & 32.21 \\
\hline$\%$ Hispanics & & 4.59 & 4.15 & 0.00 & 19.20 \\
\hline$\%$ Foreign-born & & 2.04 & 1.98 & 0.00 & 7.95 \\
\hline$\%$ Year+ at residence & & 87.39 & 8.76 & 57.47 & 98.89 \\
\hline$\% 65$ and over & & 16.56 & 6.57 & 5.40 & 44.42 \\
\hline$\% 17$ and younger & & 21.18 & 7.47 & 4.63 & 37.48 \\
\hline$\%$ 25YO+: Bach/Grad & & 18.28 & 12.41 & 4.22 & 58.07 \\
\hline$\%$ Poverty & & 7.92 & 8.95 & 0.00 & 30.91 \\
\hline$\%$ FHHs & & 7.13 & 5.74 & 0.00 & 16.67 \\
\hline$\%$ Renter-occupied & & 24.61 & 12.54 & 4.85 & 55.93 \\
\hline Urbanicity & & 0.54 & 0.47 & 0.00 & 1.00 \\
\hline Global Moran's I & & 0.00 & 0.03 & -0.09 & 0.07 \\
\hline
\end{tabular}

Note. GLA = Gross living area. FHHs = Female-headed households.

DuPage County (suburban). Sale property information for 16,239 residential

parcels was acquired from assessor's offices that manage each of the nine Townships in

DuPage County. ${ }^{23}$ Data from the townships were then cross-matched with the sales report acquired from the DuPage County assessor's office that contained details regarding

\footnotetext{
${ }^{23}$ A total of nine townships (Addison, Bloomingdale, Downers Grove, Lisle, Milton, Naperville, Wayne, Winfield, and York) exist in DuPage County.
} 
whether the parcel was considered an arms-length sale. ${ }^{24}$ After the removal of all homes not considered as arms-length sales, a sample of 10,000 sold homes were geocoded (99\% hit rate) as displayed in Figure $6 .{ }^{25}$ An additional 47 sold homes were eliminated as 38 properties maintained the same geographic point as another sold home (complicating the creation of a spatial weight), with the remaining nine being the residences of RSOs.

Altogether, DuPage County contained a final sample of 9,553 sold homes. Descriptive statistics (Table 4) indicate that the sale prices of the homes in the sample had a mean value of US\$346,439 (SD = US\$266,708) and ranged from US\$8,000 to US\$4,250,000.

${ }^{24}$ Parcels in DuPage County were excluded for the following reasons: identified as condos or townhomes ( $n=2,188)$ - complicated the creation of spatial weights, thus, eliminated-; not classified as a residence ( $n$ $=1,407)$; sold by a financial institution or government agency $(n=608)$ or a Real Estate Investment Trust $(n=4)$; sold with other parcels $(n=388)$ or with additional personal property as incentives $(n=9)$; lacked property information including address $(n=105)$ - 32 additional parcels were non-existent - building square feet $(n=236)$, and built year $(n=352)$, with 278 additional parcels eliminated because they were sold as a lot, as their built year was reported as 2016; parcel was sold multiple times in one year, which is a strong indication that the parcel was being "flipped"- thus, the most recent sale was included in the sample $(n=330)$; sold to be repurposed as apartments $(n=178)$; sold to related individuals $(n=111)$; involved significant changes (i.e., damage, additions, major remodeling, new construction, and other $[n=110]$ ); were acquired through auctions $(n=69)$, court orders $(n=86)$, or foreclosures $(n=27)$; and selling prices were lower than $\$ 7,500(n=27)$.

${ }^{25}$ A total of 94 parcels could not be geocoded. 


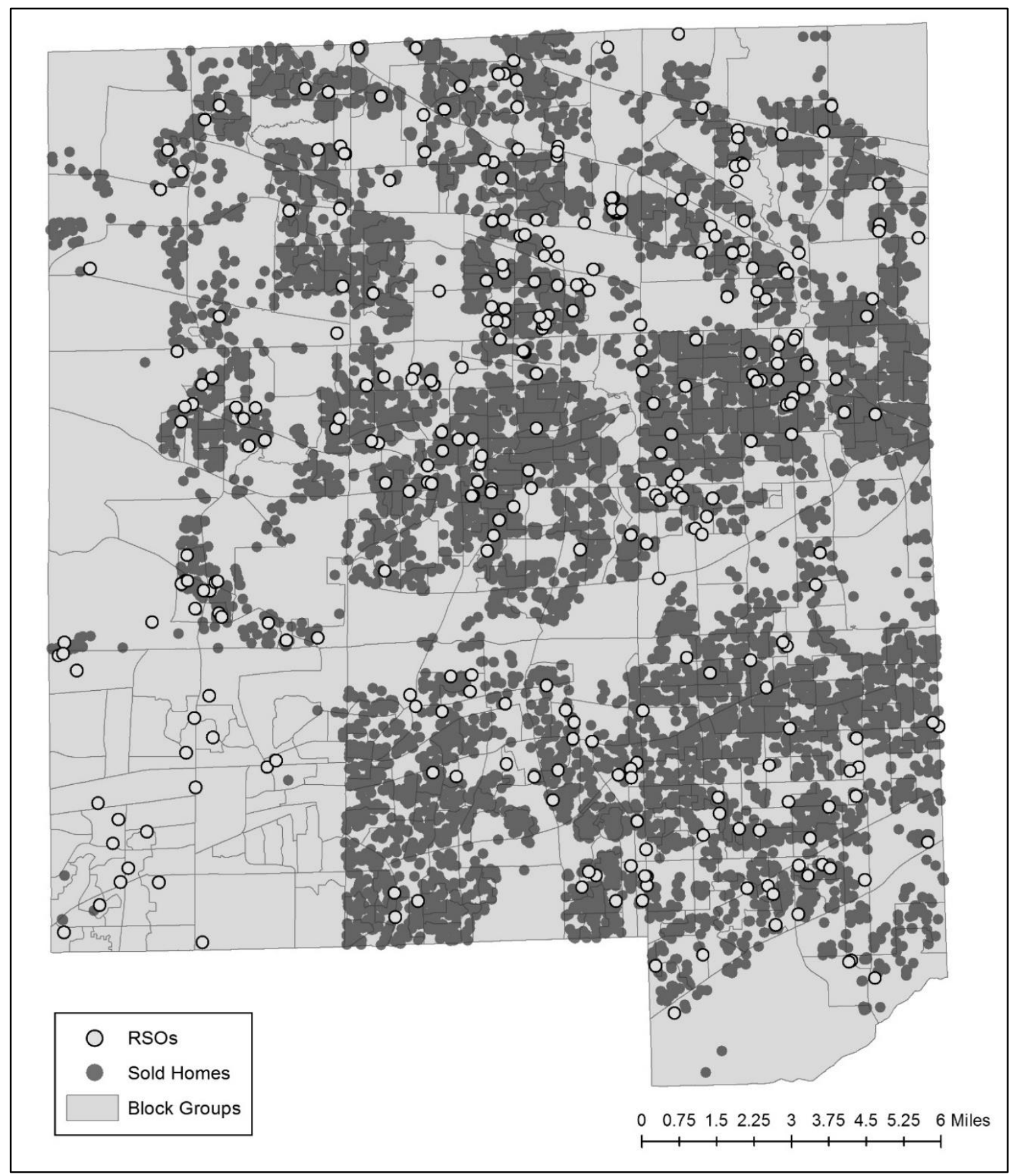

Figure 6. Locations of sold homes and RSOs across block groups in DuPage County, Illinois. 
Table 4

Characteristics of Suburban Sample

\begin{tabular}{|c|c|c|c|c|c|}
\hline \multirow[t]{2}{*}{ Characteristics } & & \multicolumn{4}{|c|}{ Suburban $(N=9,553)$} \\
\hline & $n$ & $M$ & $S D$ & Minimum & Maximum \\
\hline \multicolumn{6}{|l|}{ Dependent variable } \\
\hline Sale price & & $346,438.78$ & $266,707.61$ & $8,000.00$ & $4,250,000.00$ \\
\hline Sale price $(\ln )$ & & 12.58 & 0.57 & 8.99 & 15.26 \\
\hline \multicolumn{6}{|l|}{ Residential } \\
\hline Age (in years) & & 43.07 & 22.91 & 0.00 & 178.00 \\
\hline GLA & & $1,905.18$ & 911.05 & 505.00 & $9,342.00$ \\
\hline Number of baths & & 1.65 & 1.19 & 0.00 & 9.50 \\
\hline Basement & & 0.74 & 0.44 & 0.00 & 1.00 \\
\hline No & 2,464 & & & & \\
\hline Yes & 7,089 & & & & \\
\hline Fireplace & & 0.03 & 0.18 & 0.00 & 1.00 \\
\hline No & 9,228 & & & & \\
\hline Yes & 325 & & & & \\
\hline Dist. RSO & & $2,737.31$ & $1,823.57$ & 2.19 & $12,485.90$ \\
\hline \multicolumn{6}{|l|}{ Neighborhood } \\
\hline$\%$ Black & & 3.08 & 5.23 & 0.00 & 57.73 \\
\hline$\%$ Hispanics & & 11.45 & 13.99 & 0.00 & 85.18 \\
\hline$\%$ Foreign-born & & 15.92 & 11.01 & 0.00 & 58.02 \\
\hline$\%$ Year+ at residence & & 90.15 & 7.49 & 43.76 & 100.00 \\
\hline$\% 65$ and over & & 13.44 & 7.33 & 1.12 & 76.89 \\
\hline$\% 17$ and younger & & 23.94 & 6.77 & 0.00 & 44.05 \\
\hline$\%$ 25YO+: Bach/Grad & & 48.20 & 18.36 & 5.02 & 94.22 \\
\hline$\%$ Poverty & & 4.36 & 5.83 & 0.00 & 54.40 \\
\hline$\% \mathrm{FHHs}$ & & 4.49 & 4.56 & 0.00 & 36.47 \\
\hline$\%$ Renter-occupied & & 17.13 & 17.17 & 0.00 & 96.36 \\
\hline Urbanicity & & 0.99 & 0.00 & 0.95 & 1.00 \\
\hline Global Moran’s I & & 0.00 & 0.00 & -0.02 & 0.10 \\
\hline
\end{tabular}

Note. GLA = Gross living area. FHHs = Female-headed households.

Jefferson County (urban). Sale property information for 19,373 residential parcels

was acquired as a shapefile from the Jefferson County Property Valuation Administrator office through a data-use agreement with the Louisville and Jefferson County

Information Consortium. Parcels that were vacant, outbuildings or low-income tax credit were removed from the analysis $(n=1,139)$. Parcels with sale prices less than $\$ 7,500(n$ $=1,034)$, and contained no built year $(n=61)$ or building square footage $(n=18)$ were also excluded. After the removal of the parcels described above, a final sample of 17,121 
sold homes (16,916 residential homes and 265 residential duplexes) were geocoded (100\% hit rate) as displayed in Figure 7. Descriptive statistics (Table 5) indicate that the sale prices of the homes in the sample had a mean value of US\$179,063 ( $S D=$

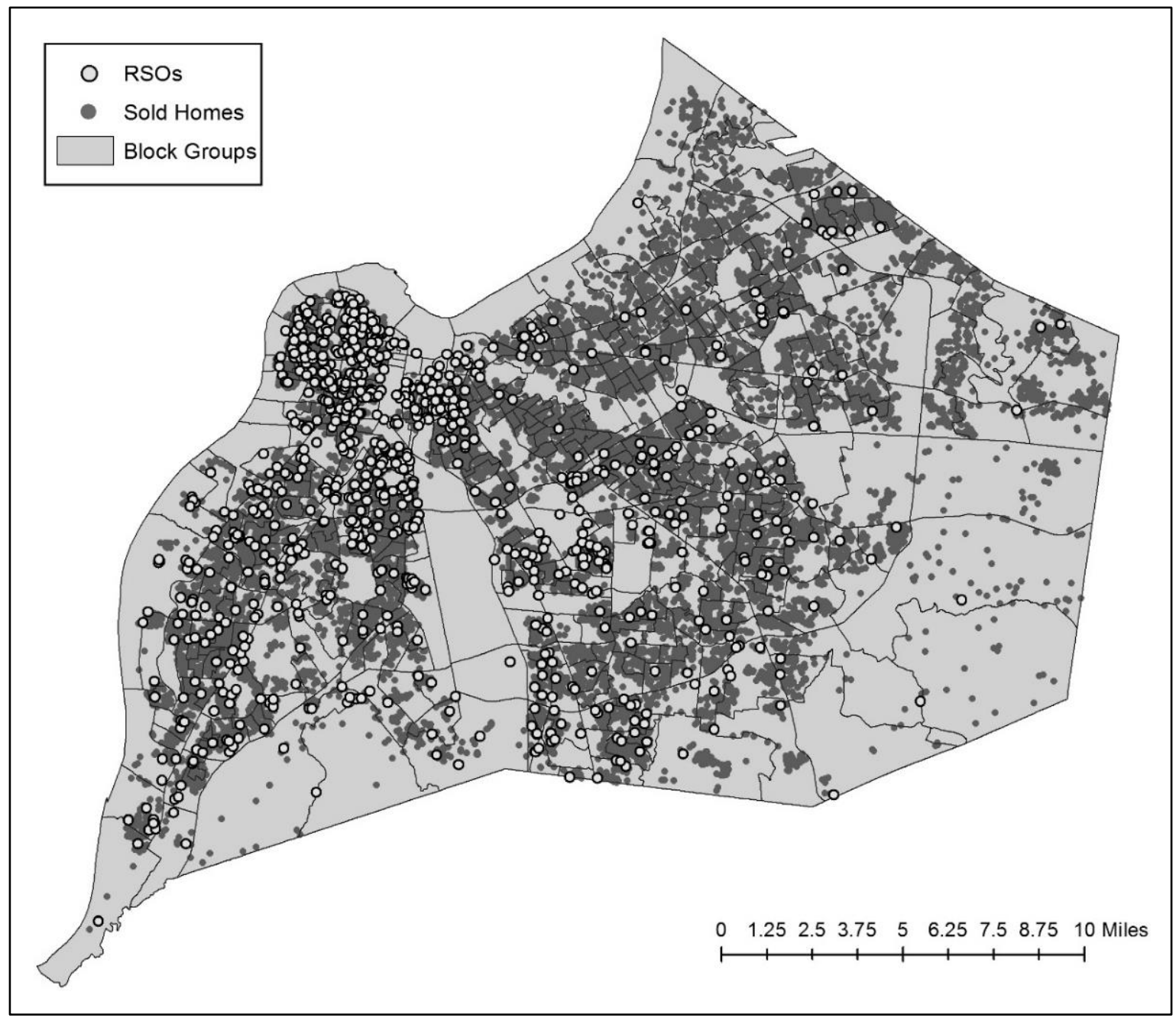

US $\$ 171,876$ ) and ranged from US\$7,580 to US $\$ 4,400,000$.

Figure 7. Locations of sold homes and RSOs across block groups in Jefferson County, Kentucky. 
Table 5

Characteristics of Urban Sample

\begin{tabular}{|c|c|c|c|c|c|}
\hline \multirow[t]{2}{*}{ Characteristics } & & \multicolumn{4}{|c|}{ Urban $(N=17,121)$} \\
\hline & $n$ & $M$ & $S D$ & Minimum & Maximum \\
\hline \multicolumn{6}{|l|}{ Dependent variable } \\
\hline Sale price & & $179,062.66$ & $171,875.54$ & $7,580.00$ & $4,400,000.00$ \\
\hline Sale price $(\ln )$ & & 11.77 & 0.84 & 8.93 & 15.30 \\
\hline \multicolumn{6}{|l|}{ Residential } \\
\hline Age (in years) & & 51.48 & 30.30 & 0.00 & 145.00 \\
\hline GLA & & $1,627.91$ & 786.44 & 368.00 & $12,441.00$ \\
\hline Number of baths & & 2.69 & 1.59 & 0.00 & 6.00 \\
\hline Basement & & 0.29 & 0.45 & 0.00 & 1.00 \\
\hline No & 12,248 & & & & \\
\hline Yes & 4,873 & & & & \\
\hline Fireplace & & 0.51 & 0.50 & 0.00 & 1.00 \\
\hline No & 8,361 & & & & \\
\hline Yes & 8,760 & & & & \\
\hline Dist. RSO & & $2,289.74$ & $2,577.87$ & 44.75 & $19,960.07$ \\
\hline \multicolumn{6}{|l|}{ Neighborhood } \\
\hline$\%$ Black & & 16.67 & 23.35 & 0.00 & 100.00 \\
\hline$\%$ Hispanics & & 3.79 & 5.90 & 0.00 & 50.58 \\
\hline$\%$ Foreign-born & & 5.43 & 6.10 & 0.00 & 64.98 \\
\hline$\%$ Year+ at residence & & 87.46 & 8.40 & 37.68 & 100.00 \\
\hline$\% 65$ and over & & 14.48 & 7.19 & 0.00 & 44.25 \\
\hline$\% 17$ and younger & & 22.63 & 7.14 & 0.00 & 48.50 \\
\hline$\% 25 \mathrm{YO}+:$ & & 32.58 & 22.10 & 0.00 & 83.85 \\
\hline \multicolumn{6}{|l|}{ Bach/Grad } \\
\hline$\%$ Poverty & & 10.72 & 13.23 & 0.00 & 79.43 \\
\hline$\% \mathrm{FHHs}$ & & 8.90 & 8.53 & 0.00 & 50.59 \\
\hline$\%$ Renter-occupied & & 28.71 & 21.53 & 0.00 & 100.00 \\
\hline Urbanicity & & 0.98 & 0.10 & 0.00 & 1.00 \\
\hline Global Moran’s I & & 0.00 & 0.00 & -0.01 & 0.01 \\
\hline
\end{tabular}

Note. GLA = Gross living area. FHHs = Female-headed households.

\section{Primary independent variable: The distance to the nearest RSO. RSO}

information was downloaded from the Illinois State Police in January 2015 with Jefferson

County, Kentucky RSO information downloaded in February $2016 .{ }^{26}$ As is standard

\footnotetext{
${ }^{26}$ RSO information were both downloaded via Microsoft Excel. Information for Illinois RSOs included: last name, first name, middle name, street address, city, state, ZIP, residence county, X and Y coordinates, height, weight, race, gender, date of birth, status (i.e., compliant, non-compliant, location unknown), classification (i.e., child murderer, sexually dangerous person, sexual predator, and sexually violent person), conviction county, conviction state, age of victim, age of offender at time of offense, and crimes.
} 
practice in the sex offender literature (Berenson \& Appelbaum, 2011; Clark \& Duwe, 2015; Hipp et al., 2010; Mustaine \& Tewksbury, 2011b; Mustaine et al., 2006a; Socia et al., 2015; Tewksbury, 2005), the removal of invalid addresses (e.g., homelessness, incarceration) and non-compliant statuses of RSOs were exercised. Because of these residential constraints, it is not irregular in the sex offender literature to remove anywhere from one-fifth $(21 \%)$ to two-thirds (62\%) of the original sample of RSOs (Clark \& Duwe, 2015; Hughes \& Kadleck, 2008; Mustaine et al., 2006a; see McCoppin, 2016; Socia et al., 2015). However, much higher rates of RSOs were retained in the present study with about nine-in-10 RSOs remaining following these removal guidelines in Lee County (90\%), DuPage County (90\%), and Jefferson County (89\%).

The final samples of RSOs were geocoded. Hit rates for RSOs who resided in DuPage County (99\%), Jefferson County (99\%), and Lee County (100\%) were all above the conventionally accepted match rate of $90 \%$ for accurate mapping suggested by Bichler and Balchak (2007). The nearest neighbor tool in ArcGIS computed the distance from each sold home to the nearest RSO.

Lee County (rural). A total of 77 individuals convicted of registerable sex offenses resided in Lee County, Illinois as of January 2015. Following the removal of individuals with invalid addresses and non-compliant status 69 RSOs remained. ${ }^{27}$ All RSOs were successfully geocoded. The mean distance between the closest RSO and each

Information for Jefferson County RSOs included: offender name, date of birth, age, street address, city, county, ZIP, status (i.e., compliant), gender, registration type (i.e., 10-year registrant, 20-year registrant, lifetime registrant), race, height, weight, hair, eye, biometric, crimes, conviction city, conviction state, conviction county, and victim(s) age(s).

${ }^{27}$ The eight RSOs who resided in Lee County, Illinois were removed because they were either homeless ( $n$ $=3$ ), non-compliant $(n=2)$, resided in a local jail $(n=2)$, or maintained an unknown address $(n=1)$. 
sold home was 5,271 feet $(S D=6,879)$, with distances that ranged from 13 to 27,762 feet (Table 3).

DuPage County (suburban). A total of 372 individuals convicted of registerable sex offenses resided in DuPage County, Illinois as of January 2015. Following the removal of individuals with invalid addresses and non-compliant status 337 RSOs remained. ${ }^{28}$ The final sample of RSOs geocoded numbered 334, with three RSOs unable to be geocoded. The mean distance between the closest RSO and each sold home was 2,737 feet $(S D=1,824)$, with distances that ranged from 2 to 12,486 feet (Table 4). Jefferson County (urban). A total of 1,289 individuals convicted of registerable sex offenses resided in Jefferson County, Kentucky as of February 2016. Following the removal of individuals with invalid addresses and non-compliant status 1,150 RSOs remained. ${ }^{29}$ The final sample of RSOs geocoded numbered 1,143, with seven RSOs unable to be geocoded. The mean distance between the closest RSO and each sold home was 2,290 feet $(S D=2,578)$, with distances that ranged from 45 to 19,960 feet (Table 5).

Control variables. Characteristics describing both the property and the neighborhood of houses in the sample are included as control variables. Property and residential characteristics are the individual-level predictors. Census block groups defined neighborhood boundaries. All control variables matched across each U.S. county.

Property characteristics. Five home property characteristics were collected to control for the possible influence on the sale price. Three of these characteristics are

\footnotetext{
28 The 35 RSOs who resided in DuPage County, Illinois were removed because they were either noncompliant $(n=14)$, resided in a local jail $(n=10)$, maintained an unknown address $(n=8)$, or homeless $(n$ $=3$ ).

${ }^{29}$ The 139 RSOs who resided in Jefferson County, Kentucky were removed because they were either noncompliant $(n=77)$, incarcerated $(n=37)$, the listed address was not their primary address $(n=10)$, a nonresident of Jefferson County $(n=7)$, resided in a local jail or detention center $(n=5)$, or homeless $(n=3)$.
} 
continuous variables, which described the age of the household ${ }^{30}$, the area of the house (or gross living area $[G L A]$ ), and the number of bathrooms. ${ }^{31}$ Two additional dummy variables are used to indicate the presence of a basement and the presence of one or more fireplaces. These five property characteristics have been consistently used as control variables in the previous RSO-home sale value literature (Bian et al., 2013; Caudill et al., 2014; Larsen et al., 2003; Linden \& Rockoff, 2008; Navarro \& Rabe-Hemp, 2017; Pope, 2008; Wentland et al., 2014; Yeh, 2015).

Neighborhood characteristics. Based on the theoretical linkages and previous sex offender literature, 12 variables were used to represent the structural conditions within each of the county's block groups (Table 6). Neighborhood-specific characteristics included 12 census block group variables (eight population and four housing characteristics). Ten of these census block group variables were provided by the 2010 2014 ACS 5-year estimates and operated as a percentage rate. Rural and urban identifiers for housing units were provided by the 2010 Census Summary File and were used to compute the proportion of housing units classified as rural or urban. Although each U.S. county is defined as rural, suburban, and urban (see Ingram \& Franco, 2014), census block groups within each of these counties are not unanimously rural or urban. There is also the additional complication including suburban community types being difficult to define (Ingram \& Franco, 2014; NCES, 2016). Therefore, the best representation of urbanicity (the degree to which a census block group is urban) is for it to operate as a

\footnotetext{
${ }^{30}$ Although it is expected for old homes to influence home sale prices, in some occasions negatively, old homes might include historical homes. Thus, historical (or old) homes will increase home sale prices (Troy \& Grove, 2008).

${ }^{31}$ Bathrooms for DuPage County were reported as full and/or half bathrooms. When these two characteristics were combined to represent total number of bathrooms, half bathrooms were labeled as "0.5".
} 
spectrum (see Sampson \& Groves, 1989). As the value increases from "0" (rural) to "1" (urban), the more urban the census block group became. Global Moran's I was used as a control for spatial dependence of sold homes. Neighborhood variables were subsequently joined to the block group shapefiles obtained from the Topologically Integrated Geographic Encoding and Referencing System (TIGER)/Line at the Census Bureau.

Table 6

Neighborhood characteristics

\begin{tabular}{lll}
\hline \multicolumn{1}{c}{ Population (percentage of) } & \multicolumn{1}{c}{ Housing (percentage of $)^{\mathrm{a}}$} \\
\hline 1 & Black & Female-headed households \\
2 & Hispanic or Latino origin & Renter-occupied housing units \\
3 & Foreign-born & Proportion of urbanicity \\
4 & Been in their current home for a year or more & Global Moran's I \\
5 & Age 65+ & \\
6 & 17 years and younger & \\
7 & $25+$ with at least a Bachelor's degree and higher & \\
8 & Families below the poverty level & \\
\hline
\end{tabular}

Note. Data for vacant housing units were downloaded but showed high collinearity to poverty in Lee County, and thus, removed as they consistently contributed less to all

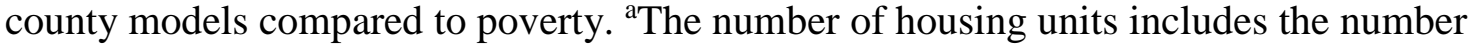
of structures in the census block groups, whereas households are in reference to the

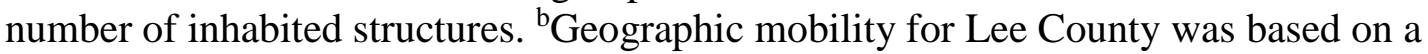
micropolitan statistical area, whereas geographic mobility for DuPage County and Jefferson County were based on a metropolitan statistical area.

It is of interest to identify how these neighborhood variables individually are related to home sale value, considering that previous RSO-home sale value research has not included observable neighborhood effects. The housing literature has demonstrated that the inclusion of neighborhood characteristics - especially in a cross-sectional examination —explained a significant portion of the variance (Archer, Ling, \& Smith, 2010). Erroneous conclusions may have resulted from spurious results from the RSOhome sale value literature because there was no assessment of the underlying effects tied with neighborhood dynamics alongside the presence of RSOs (Agan \& Prescott, 2014; 
Bitter, Mulligan, \& Dall'erba, 2007). Model misspecification problems and erroneous conclusions can occur without consideration of neighborhood characteristics as these features likely contribute to the overall real estate market, and ultimately housing prices.

\section{Model specification.}

Multilevel modeling. For the purposes here, multilevel modeling is the preferred analysis (versus an OLS) due to the organizational structure of the data. In support, prior research has indicated that multilevel modeling is the most appropriate analysis to describe how the real estate market—especially urban—is influenced by property and neighborhood characteristics (Brown \& Uyar, 2004) and can reduce issues related to housing submarkets (see Goodman \& Thibodeau, 2007). Because of the hierarchical structure of homes clustered within neighborhoods, there is the potential increase of dependence (or relatedness) among the observations due to the fact some homes may be located in the same neighborhood. Without the employment of multilevel modeling, erroneous conclusions may arise if this dependence is not accounted for (as it would not be in OLS, which assumes independence). Thus, with residential characteristics nested within neighborhoods, individual-level effects (residential characteristics) on the dependent variable (home selling price) can be simultaneously explored and are entirely independent of the level-2 predictors (neighborhood characteristics represented by 1,150 census block groups). Under these circumstances, the multilevel modeling approach can ensure unbiased estimations of the parameters and their standard errors, and ultimately control of the interdependence among the observations and reduce the likelihood of Type I error rates (McCoach, 2010; Raudenbush \& Bryk, 2002). 
Spatial weight matrix. Spatial modeling for all counties relies on a queen's criterion weighting scheme. Using the mapping software program GeoDa, the amount of spatial dependence was computed using each neighborhood's first-order neighbors that share common borders and vertices (i.e., the queen criterion [Figure 8]) and is represented by the global Moran's I statistic. Neighboring home sale values of a census block group are aggregated to assess its influence of the spatial error of a given census block group and used as a control in the multilevel model as a level-2 variable.

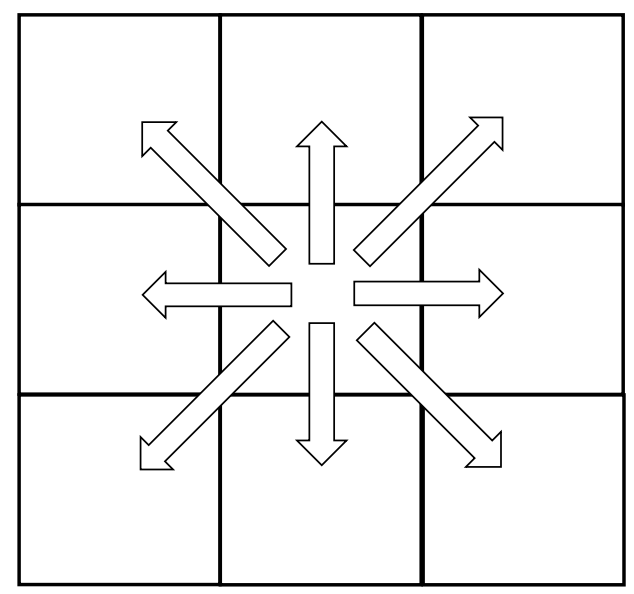

Figure 8. Queen's contiguity.

Spatial dependence. It is expected that geographic units exhibit spatial dependence because observations closest to the observation in question are more related than distant observations. When observations are correlated with one another in a spatial dimension it is referred to as spatial autocorrelation, which quantifies the degree of spatial clustering or dispersion (Anselin, Cohen, Cook, Gorr, \& Tita, 2000; see Cho et al., 2006). By not accounting for spatial autocorrelation, biased parameters, and standard error estimates, and consequently, incorrect statistical inference like false indicators of significance will result (Anselin, 2005; Kubrin \& Weitzer, 2003). It is expected that spatial autocorrelation exists among home selling prices because they are influenced by 
shared property and neighborhood characteristics (Dubin, Pace, \& Thibodeau, 1999).

Therefore, it is crucial to account for spatial autocorrelation of home sale values because the (anticipated) presence of spatial autocorrelation violates the assumption of independence, which has been a missing component in the RSO-home sale value research (except for Caudill et al., 2014).

There are two methods to measure spatial autocorrelation. The first method, global spatial clustering (or spatial autocorrelation), can be tested by Moran's I statistics. Global spatial autocorrelation is one value (of a calculated variable [i.e., lnvalue]) that indicates the degree of that variable's pattern of clustering across an entire distribution. Results in each U.S. county reveals a significant, positive global spatial autocorrelation ${ }^{32}$ ([Lee County] Moran's $I=0.31, p<0.001$; [DuPage County] Moran's $I=0.66, p<$ 0.001; [Jefferson County] Moran's $I=0.22, p<0.001$ ) of home selling prices. An indication that the home selling prices in the immediate neighborhood are dependent on the home selling prices in surrounding neighborhoods with clustering of similarly valued (either high or low) sold homes. However, global Moran's I masks the spatial patterns of relationships because it is a representation of all points/areas in the county (Anselin, 1995, 2005). An assessment of local statistics is beneficial to understand spatial patterns in greater detail (through illustrations), by ascertaining the degree of whether that observation is part of a low- or high-value cluster.

\footnotetext{
${ }^{32}$ A positive value of spatial autocorrelation is an indication that the observations are clustered in space nearby similar valued observations. A negative spatial autocorrelation indicates dispersed observations with high valued observations being near low valued observations (or neighboring neighborhoods are not alike). A global Moran's I value of "0" indicated spatial randomness (or no spatial autocorrelation) (Anselin et al., 2000).
} 
The second method, local indicator of spatial association (LISA), are indicators of local spatial clusters (or spatial autocorrelation) that display the high and low-value clusters of adjacent points/areas across space (Anselin, 1995). How neighborhoods deviated from spatial randomness can be illustrated by LISA cluster maps and are coded by the type of local spatial autocorrelation. LISA maps for Lee County (Figure 9), DuPage County (Figure 10), and Jefferson County (Figure 11) show positive local spatial autocorrelation (high-high and low-low) based on a significance cut-off value of $p<0.05$ resulting from the weighted average of the neighboring values (i.e., sold homes' logged selling prices). Both assessments of spatial autocorrelation indicate evidence of spatial dependence; additionally, the significance of how urbanicity must be accounted for as spatial dependence is most evident in urban environments. Therefore, spatial dependence must be incorporated into the multilevel modeling framework to ensure that the estimated neighborhood effects remain unbiased (Anselin, 2005; Kubrin \& Weitzer, 2003). 


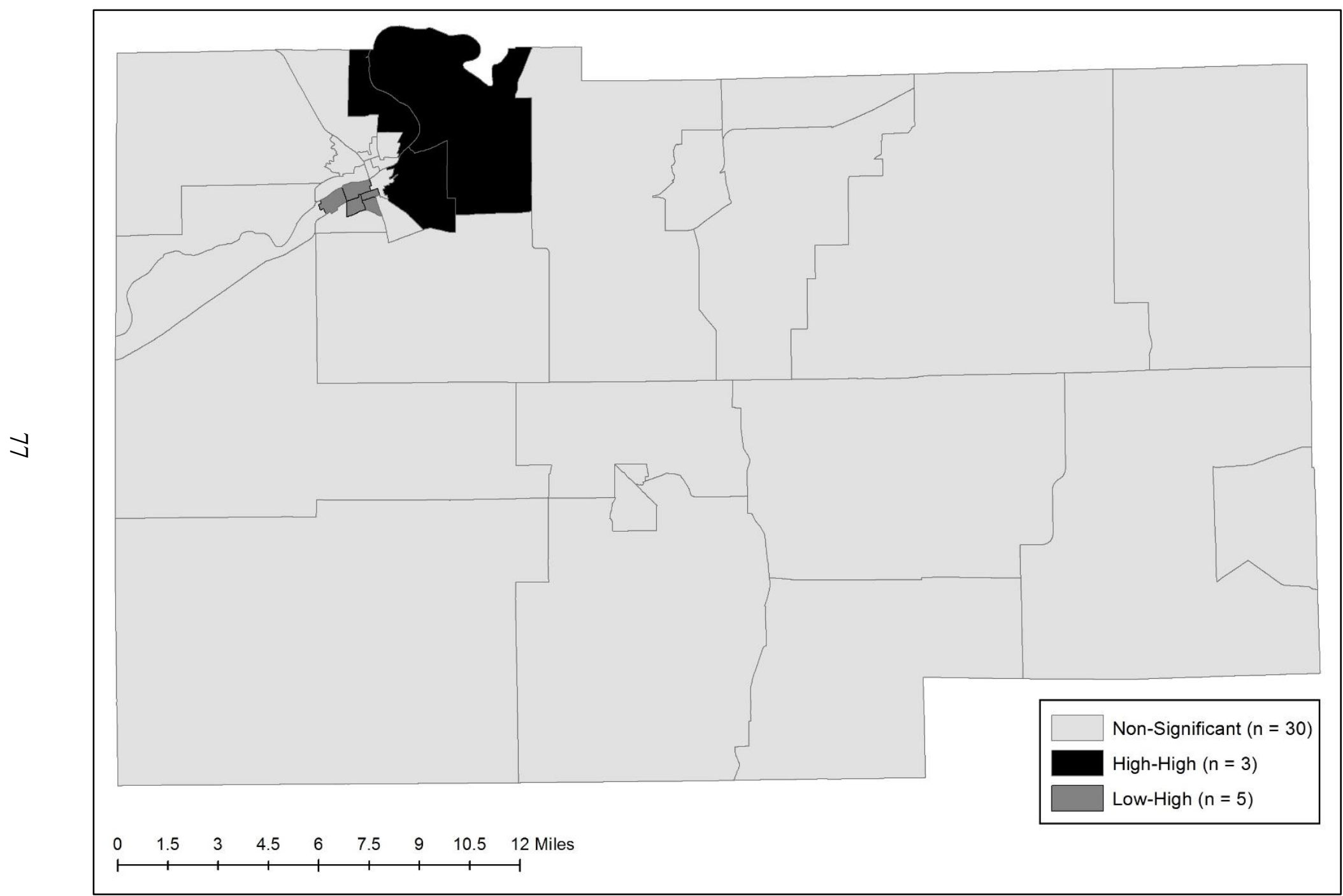

Figure 9. LISA cluster map of the weighted census block group averages of sold homes' selling prices (logged) in Lee County, Illinois. 


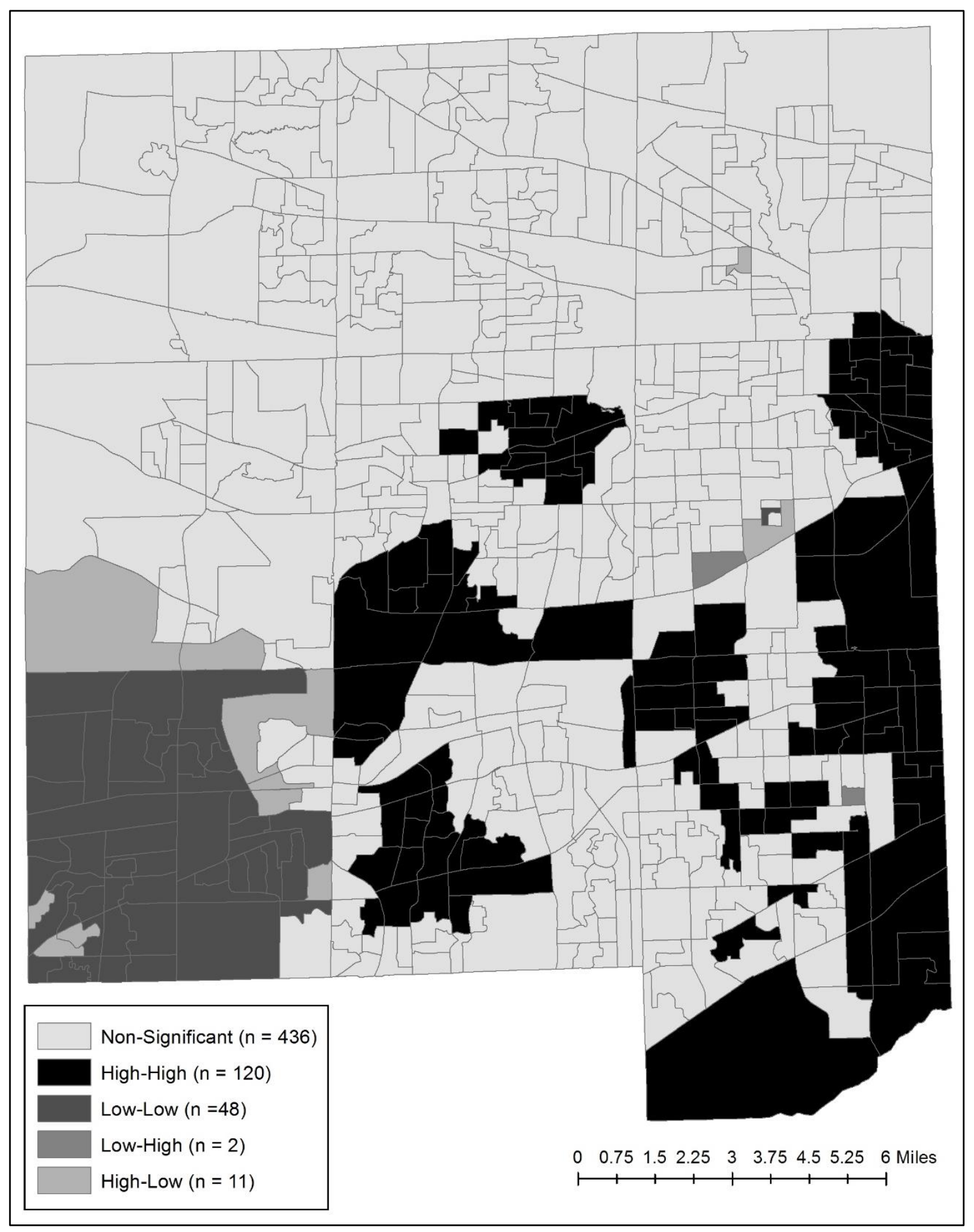

Figure 10. LISA cluster map of the weighted census block group averages of sold homes' selling prices (logged) in DuPage County, Illinois. 


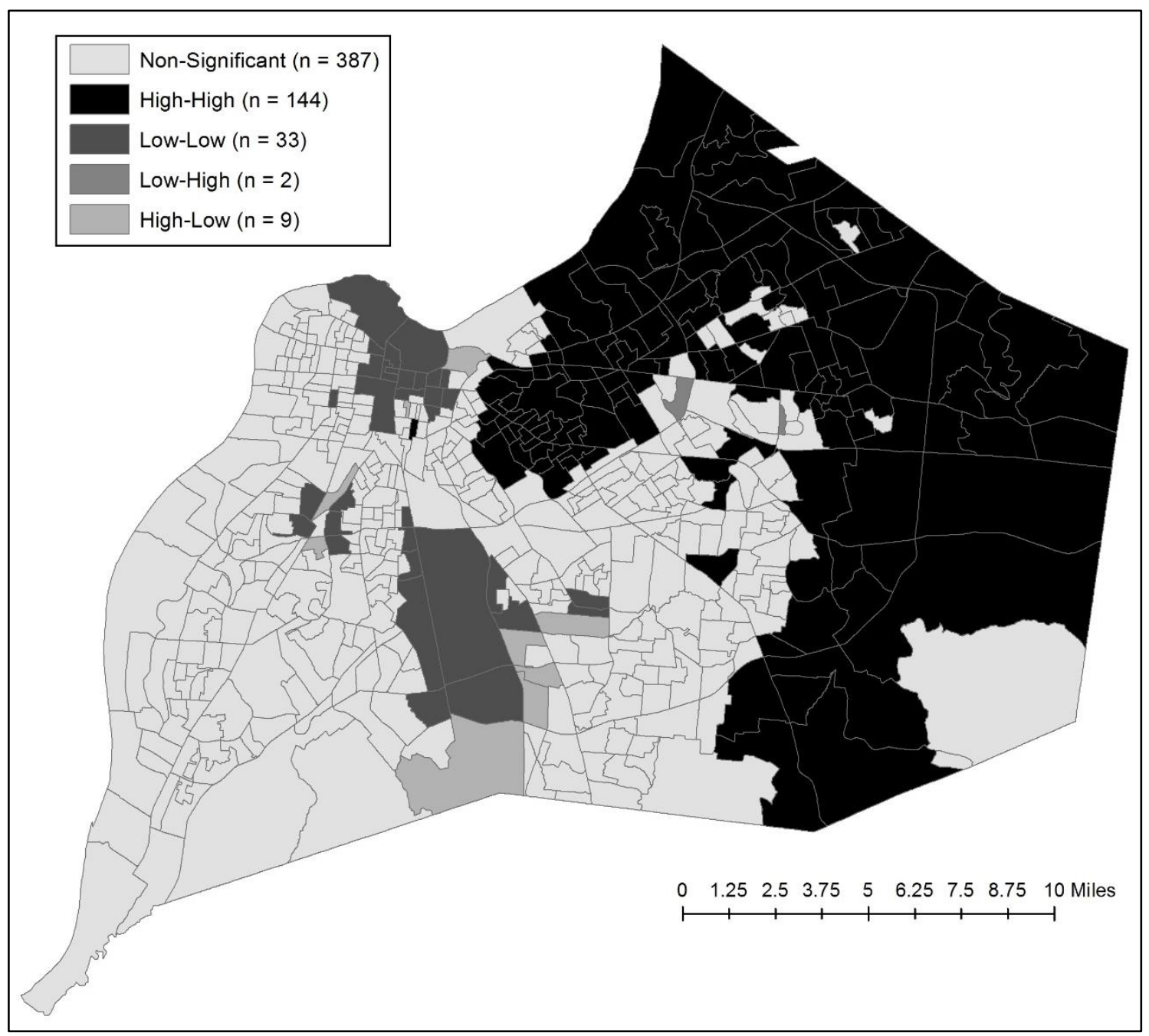

Figure 11. LISA cluster map of the weighted census block group averages of sold homes' selling prices (logged) in Jefferson County, Kentucky.

Data analyses. To address the RSO-home sale value research questions in the multilevel model, full maximum likelihood estimation (FIML) was utilized as the maximum likelihood estimation. Restricted maximum likelihood estimation (REML) was also appropriate for the present study considering the large sample size. Because of the large sample size of the current study, REML results should be fairly the same when compared to FIML results (Luke, 2004). The decision to select FIML was based on the methodological approach that additional variables may be considered because FIML is the preferred estimation method when models are compared with different fixed effects 
(McCoach, 2010; Raudenbush \& Bryk, 2002). Thus, FIML was the most cautious route for further empirical exploration in the present study.

All level-2 (neighborhood) control characteristics are grand-mean centered. Three of the five level-1 property characteristics were grand-mean centered (i.e., age, GLA, and the number of bathrooms), whereas the presence of basements and fireplaces were uncentered as they are dichotomous variables, with " 0 " indicating absence and " 1 " indicating presence. The distance to the nearest RSO was grand-mean centered. Groupmean centering the distance to the nearest RSO was not appropriate because the current study's questions are not concerned about the distances of sold homes nearby RSOs within their respective neighborhoods but rather focused on the whole sample of sold homes nearby RSOs.

A model including the level-1 and level-2 control variables was created to determine the total variability explained by the controls. First, a control model of property characteristics was created, followed by an assessment of residential characteristics - that included the distance of the nearest RSO — in a level-1 model. Second, three level-2 models assessed how the inclusions of neighborhood characteristics explained additional variance in home sale values above and beyond the property/residential characteristics. The first level-2 model contained the property characteristics and neighborhood characteristics (without spatial dependence). The second level-2 model contained residential characteristics and neighborhood characteristics (without spatial dependence). The third level-2 model contained property characteristics and all of the neighborhood characteristics. Third, a final model was 
constructed to assess whether the RSO variable continued to explain variance in home sale values above and beyond the control variables.

The data were assessed for potential multicollinearity. No multicollinearity was present in the structural characteristics. However, multicollinearity was initially present in the neighborhood variables for Lee County, but not for DuPage or Jefferson counties. Factors were not constructed as it is of greater interest for the current study to see the individual effect of each neighborhood characteristic. Originally, vacant housing units were considered as a neighborhood effect, but they were subsequently removed from Lee County (and then from DuPage and Jefferson) due to its strong correlation to poverty, coupled with its weaker contribution to across each county's models when compared to poverty. It was also theoretically beneficial to retain poverty, as it is a direct indicator of economic status (Shaw \& McKay, 1942). Although social disorganization aligns with vacant housing via residential mobility, keeping vacant housing units was superfluous given the presence of two measures for residential stability (i.e., year or more at the residence and renter-occupied housing units). Removal of vacant housing units reduced the variance inflation factor of the neighborhood characteristics to the suggested threshold of five (Bachman \& Schutt, 2016).

Moderators. The second half of the results section analyzes the surveys sent to persons who bought the sold homes in the sample. Responses by homebuyers who were of interest addressed their awareness of RSOs in their immediate vicinity. Homebuyers selected as potential survey respondents included all persons from the sample who purchased homes in Lee County (rural), and homebuyers who were within 1,000 feet of the nearest RSO in DuPage (suburban) and Jefferson County (urban). To assist in the 
visualization of 1,000 feet, it is roughly 305 meters or approximately $3 / 4$ ths of a full lap around a standard oval running track.

Auxiliary to the RSO-home sale value questions are whether the homebuyer's knowledge of RSOs and location to RSOs affected the direction and/or strength of the relation between home selling prices and the distance to the nearest RSO. Two categorical moderators were created to assess whether an interaction effect is evident between the dependent variable and the independent variable, after controlling for property characteristics. The first moderator, homebuyer awareness, is dichotomized into two groups (aware and not aware). The second moderator, homebuyers' community type, is dichotomized into two groups (non-urban and urban).

\section{Survey procedures.}

Sampling method. Homebuyers sampled strictly included respondents who are homeowners above the age of 18 and bought homes in the three counties in 2015. All rural homebuyers were sampled due to the low sample of homes sold in Lee County— 85 rural homebuyers resided within 1,000 feet of the nearest RSO. Suburban $(N=1,490)$ and urban homebuyers $(N=5,995)$ within 1,000 feet were subjected to disproportionate stratified sampling: allows every homebuyer to be selected based on some criteria (i.e., distance to the nearest RSO), in which the sampling stratum (i.e., homebuyers within 1,000 feet) is then subjected to random selection (Bachman \& Schutt, 2016). The sample is disproportionate because $75 \%$ of the proportion selected from the sampling stratum included homebuyers within 500 feet of the nearest RSO, with the remaining $25 \%$ of the proportion, being homebuyers located 501 to 1,000 feet of the nearest RSO. A disproportionate stratified sampling was conducted to ensure homebuyers within 500 feet 
are included in the sample in sufficient numbers. Further, due to an excess of suburban and urban addresses that corresponded with the sampling stratum, coupled with the presumed outcome that a number of surveys will be labeled as "return to sender," such invalid addresses were replaced with "fresh" addresses (for the third wave) to minimize low response rates.

Homebuyer survey process. Mailings to the selected homebuyers occurred in three waves over a nine-week period via first class postage on Fridays of spring 2017 (see Harbaugh, 2002). Wave one consisted of a University of Louisville envelope, a one-page cover letter stating the purpose of the $\operatorname{study}^{33}$ (see Appendix A); a double-sided, fourpage survey $^{34}$ (see Appendix B); and, a business reply return envelope. Wave two occurred three weeks after wave one and consisted of a postcard mailed to the sample, which summarized the purpose of the study, included a SurveyMonkey website link, and a survey entry code ${ }^{35}$ (see Appendix C). Wave three occurred three weeks after the postcard, and six weeks after the first wave. The third wave was conducted in the same manner as the initial mailing (see Brennan \& Charbonneau, 2009) and mailed to nonrespondents and to the "fresh" set of suburban and urban addresses who replaced the "return to sender" addresses. The survey process resulted in 4,826 surveys and 2,471 postcards delivered, thereby totaling to 7,297 mailings - first $(n=2,471)$, second $(n=$ 2,471), and third wave $(n=2,355$ [rural: $n=244$, suburban: $n=1,039$, urban: $n=$

\footnotetext{
${ }^{33}$ A "likable" cover letter design (i.e., neighborhood clipart; Gendall, 2005) together with a blue ink handsigned cover letter was exercised to increase response rates (Harbaugh, 2002).

${ }^{34}$ Surveys included a hand-stamped identifier.

35 The survey entry code is a colloquial term for the identifier attached to each homebuyer in the sample. Because wave two lacked surveys, postcards with survey entry codes (to be typed into SurveyMonkey) were necessary to ascertain who the respondent is and subsequently their distance to the nearest RSO.
} 
1,072]) — to the selected sample of 271 rural residents and 1,100 suburban and urban residents.

Homebuyers who replied in the first and second wave were removed from the third wave to minimize the potential of duplicate responses. Identifiers served as an added insurance against duplicate responses. A total of 119 mailings ( $n=8$ [rural], $n=21$ [suburban], $n=90$ [urban]) were returned labeled as "return to sender," ${ }^{, 36}$ with a blank survey returned from Lee and Jefferson County, and a suburban respondent who did not fit the criteria to be a homebuyer respondent as they were too young - a total of 122 invalid and non-respondent addresses. The nine invalid and non-respondent rural addresses could not be replaced as all rural homebuyers were sampled to be potential respondents. However, suburban and urban homebuyers were replaced with the excess suburban $(n=22)$ and urban homebuyers $(n=91)$ that conformed to the sampling stratum for wave three - these suburban and urban addresses were not subjected to the first or second wave.

Homebuyer response rates. Table 7 describes the response rates of the surveys that were distributed to homebuyers in three waves over a nine-week period. Two versions of the response rates are reported. The first response rate reflects the overall responses received. However, the one reported hereafter is the second response rate,

\footnotetext{
${ }^{36}$ A total of eight, 21, and 90 rural, suburban, urban addresses were labeled as "return to sender." The eight rural homebuyers identified as "return to sender" were due to: no such street $(n=2)$, vacant households ( $n$ $=2)$, unable to be forwarded ( $n=1)$, no mail receptacle $(n=1)$, insufficient address $(n=1)$. Twenty-one suburban homebuyers were identified as "return to sender" because the household was vacant $(n=13)$, maintained no forwarding address $(n=5)$, the recipient did not match the address $(n=2)$, and the addresses abandoned/failed to call for mail $(n=1)$. The 90 urban respondents who were identified as "return to sender' were so because the recipient did not match the address $(n=34)$, household was vacant $(n=33)$, maintained no forwarding address $(n=16)$, no such street $(n=6)$, and maintained no mail receptacle $(n=$ $1)$.
} 
which was computed after responses were adjusted following the removal of invalid addresses (i.e., return to sender) and responses (i.e., blank responses or the respondent was too young).

A total of 302 surveys were received for a response rate of $12.52 \%$, with one-ineight sampled homebuyers responding to the survey. Wave one received the highest response rate $(9.41 \%)$, followed by wave three $(3.08 \%)$, and then wave two $(0.43 \%)$. Urban homebuyers reflected over half of the respondents $(n=166,15.47 \%)$, with the subsequent highest response rate by rural homebuyers $(n=27,10.80 \%)$ trailed closely by suburban homebuyers $(n=109,10.01 \%)$. Notably, one urban homebuyer responded in both waves one and two, with their response to the second wave removed from subsequent analyses.

Table 7

Descriptives of Sampling Method per Wave and Waves Combined

\begin{tabular}{lrrrr}
\hline & Rural & Suburban & Urban & \multicolumn{1}{c}{ Total } \\
\hline Wave 1 - Surveys & 271 & 1,100 & 1,100 & 2,471 \\
\hline Responses & 19 & 83 & 119 & 221 \\
Response rate $(\%)$ & 7.01 & 7.55 & 10.82 & 8.94 \\
Response rate $(\%)^{\mathrm{a}}$ & 7.25 & 7.70 & 11.79 & 9.41 \\
Invalid address and non-responses & 9 & 22 & 91 & 122 \\
Return to sender & 8 & 21 & 90 & 119 \\
Abandoned/failed to call for mail & 0 & 1 & 0 & 1 \\
Insufficient address & 1 & 0 & 0 & 1 \\
No mail receptable & 1 & 0 & 1 & 2 \\
No such street & 3 & 0 & 6 & 9 \\
Receiptient did not match address & 0 & 2 & 34 & 36 \\
Unable to forward & 1 & 5 & 16 & 22 \\
Vacant & 2 & 13 & 33 & 48 \\
Returned blank survey & 1 & 1 & 0 & 2 \\
Too young of a respondent & 0 & 0 & 1 & 1 \\
\hline Wave 2 - SurveyMonkey & 271 & 1,100 & 1,100 & 2,471 \\
\hline Responses & 0 & 2 & $8^{\mathrm{c}}$ & 10 \\
Response rate $(\%)$ & 0.00 & 0.18 & 0.73 & 0.40 \\
Response rate $(\%)^{\text {ab }}$ & 0.00 & 0.19 & 0.79 & 0.43 \\
\hline Wave 3 - Surveys & 244 & 1,039 & 1,072 & 2,355 \\
\hline
\end{tabular}




\begin{tabular}{lrrrr}
\hline Responses & 8 & 24 & 39 & 71 \\
Response rate $(\%)$ & 3.28 & 2.31 & 3.64 & 3.01 \\
Response rate $(\%)^{\mathrm{a}}$ & 3.45 & 2.33 & 3.73 & 3.08 \\
Return to sender & 12 & 11 & 27 & 50 \\
Insufficient address & 1 & 0 & 0 & 1 \\
No such street & 1 & 1 & 1 & 3 \\
Receiptient did not match address & 0 & 3 & 8 & 11 \\
Refused & 0 & 1 & 0 & 1 \\
Unable to forward & 9 & 0 & 3 & 12 \\
Vacant & 1 & 6 & 15 & 21 \\
\hline All waves combined & 271 & 1,100 & 1,100 & 2,471 \\
\hline Responses & 27 & 109 & $166^{\mathrm{c}}$ & 302 \\
Response rate $(\%)$ & 9.96 & 9.91 & 15.09 & 12.22 \\
Response rate $(\%)^{\text {ad }}$ & 10.80 & 10.01 & 15.47 & 12.52 \\
\hline
\end{tabular}

Note. A total of 113 addresses ( $n=22$ [suburban], $n=91$ [urban]) were replaced with a population that matched the sampling stratum's standards (i.e., within a 1,000 feet of the nearest RSO via a disproportionate sampling selection) when wave three was conducted. Rural addresses dropped from 271 to 244 (wave three) due to non-responses and responses. ${ }^{a}$ Response rates after removal of invalid addresses and responses. ${ }^{b}$ Response rates accounted invalid and non-responses from wave one as the submission of addresses to the post office occurred at the same time, although mailed three weeks apart. Therefore, not enough time occurred to ascertain which addresses would be labeled as "return to sender." "Urban homebuyer responded in both wave one and two, with only wave one being accounted for in the final results. ${ }^{\mathrm{d}}$ Response rates accounted invalid and non-responses from wave three as wave one and two were replaced with a "fresh" set of valid addresses.

Rural and suburban homebuyers were collapsed into one group, and represent non-urban homebuyers. The reason for the consolidation was two-part. First, too few of rural homebuyers responded to the survey for a meaningful analysis. Second, rural homebuyer awareness of RSOs was an unfair comparison to the suburban and urban comparison because rural homebuyers were not constrained to the sampling stratum criteria of 1,000 feet. The mean distance between the closest RSO and each rural respondent in Lee County was 6,094 feet $(\mathrm{SD}=6,643)$, with distances that ranged from 12 to 20,679 feet. For the sake of constancy and equal comparisons to the suburban and urban homebuyer populations, all rural homebuyers with the nearest RSO located beyond 1,000 feet of their recently purchased home were removed. A loss of 21 rural homebuyers 
resulted when respondents who did not contain a RSO within 1,000 feet of their property were removed. Thus, non-urban respondents are represented by rural and suburban respondents $(N=115)$.

Dependent variable. Home sale price is the dependent variable. Table 8 displays the descriptive statistics for the non-urban and urban sample of homebuyers who are at least within 1,000 feet of a RSO. The sale prices of sold homes in the non-urban sample $(N=115)$ had a mean value of US\$280,258 (SD = US\$210,134) and ranged from US $\$ 26,000$ to US\$1,425,000. The sales price of the homes in the urban sample of respondents $(N=162)$ had a mean value of US\$110,216 $(S D=\mathrm{US} \$ 87,214)$ and ranged from US\$14,370 to US\$685,000. 
Table 8

Characteristics of Non-Urban Homebuyer Respondents and Urban Homebuyer Respondents within 1,000 Feet of the Nearest RSO

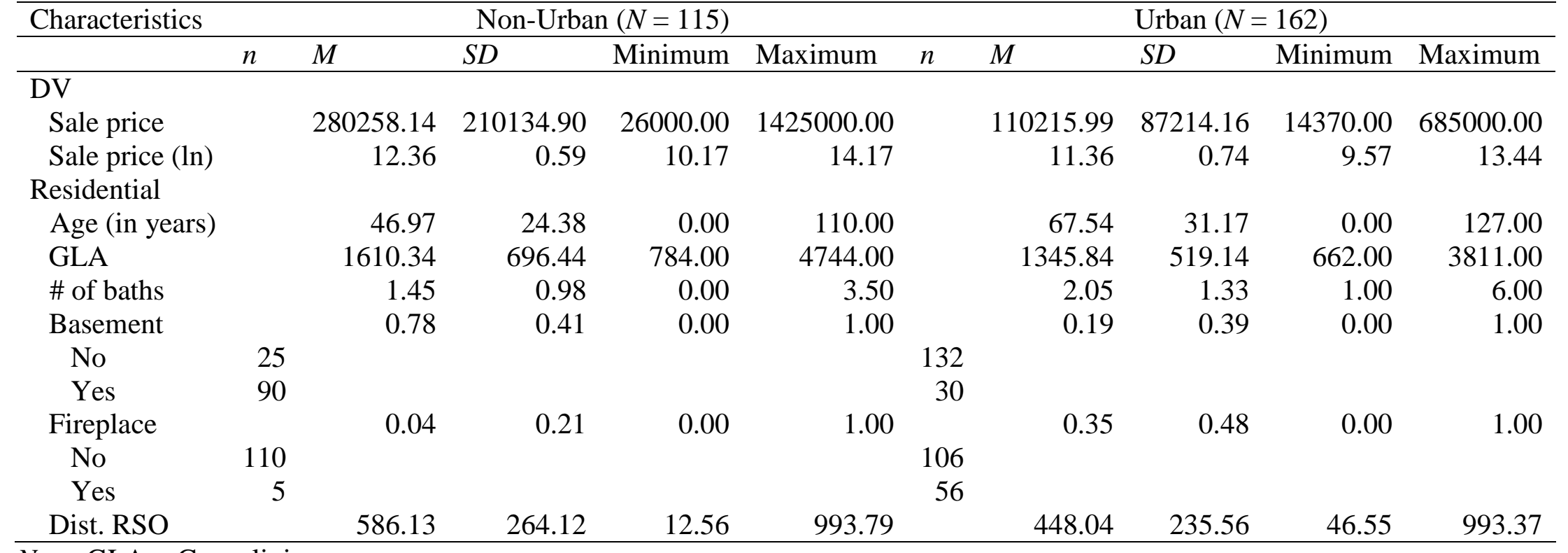

Note. GLA = Gross living area. 


\section{Independent variables.}

The distance to the nearest RSO. The mean distance between the closest RSO to each sold home in the non-urban sample was 586 feet $(S D=264)$, with distances that ranged from 12 to 993 feet. The mean value of the nearest distance to the RSO dropped from 1,680.34 feet to 586.13 feet due to the removal of 21 rural homebuyers who were distant from RSOs within their immediate vicinity. An indication of the substantial influence rural respondents would have had if respondents beyond 1,000 feet of the nearest RSO had not been removed. The urban sample's mean distance between the closest RSO and each sold home was 448 feet $(S D=235)$, with distances that ranged from 46 to 993 feet (Table 8).

Awareness. The assessment of homebuyer awareness of RSOs was based on one scaled measure, neighborhood structural characteristics (Appendix B). Awareness of items related to the social disorganization framework is assessed by ten items, which included the item of primary interest, "registered sex offender." The remaining nine included "abandoned car," "bar," "church," "litter," "liquor store," "park," "police station," "run-down property," and "school" because they had captured the various themes of social disorganization. Homebuyers' responses to "are you familiar with any of the following in your immediate neighborhood?" to the response item "registered sex offender" was dichotomized, with "yes" coded as "1" and "no/unsure" responses coded as "0." "Yes" responses are homebuyers who reported being aware of local RSOs, and "no" responses are homebuyers who reported as being unaware of local RSOs. Of the homebuyers who responded, 69 reported as being aware of the nearest RSO within 1,000 
feet of their house, with the remaining 208 ("No" $=128$, "Unsure" = 80) homebuyers being unaware of the nearest RSO within 1,000 feet of their property.

Community type. After accounting for duplicate $(n=1)$ and missing responses $(n$ =3) that originated from the urban sample, a total of 298 homebuyers responded (from the original 302 respondents) to their awareness of RSOs surrounding their recently purchased property. To be consistent with the suburban population of homebuyer respondents, 21 rural homebuyers (of the original 27 rural respondents) who did not contain a RSO within the 1,000-foot radii of their property were removed. Hereafter, results for the assessment of the moderating effects of awareness and community type are based upon a sample of 277 homebuyers. Of these homebuyers who responded, 115 remained from a non-urban community, with 162 respondents from the urban community.

Property control variables. The same five property characteristics used in the multilevel model are also used as control variables to assess for moderating effects between home sale values and the distance to the nearest RSO. Three property characteristics are continuous variables, which described the age of the household, GLA, and the number of bathrooms. ${ }^{37}$ Two additional dummy variables are used to indicate the presence of a basement and the presence of one or more fireplaces.

Data analyses. Separate from the multilevel analyses, homebuyers who responded to the survey were assessed with descriptive statistics among the variables. Cross tabulations were conducted of homebuyer respondents' who resided within 1,000

\footnotetext{
${ }^{37}$ Bathrooms for DuPage County were reported as full and/or half bathrooms. When these two characteristics were combined to represent total number of bathrooms, half bathrooms were labeled as " 0.5 ".
} 
feet of the nearest RSO between their awareness of local RSOs and community type to assess differences. Correlations among the variables were then performed. A series of regression analyses were performed to assess whether homebuyer awareness and community type moderated the relationship between home selling prices and the distance to the nearest RSO. Each predictive model was similar as it contained home sale values (logged) as the dependent variable, distances of the nearest RSO as an independent variable, and property characteristics as control variables. Distinguishing the regression models were the inclusion of the main effects and interaction terms. The main effects were dichotomous variables. The first main effect was homebuyer awareness. Homebuyers aware of the nearest RSO identified within a 1,000-foot circumference of their property were coded as " 1 ", with unaware homebuyers coded as " 0 ". The second main effect was the homebuyer's community type. Homebuyers who resided in a nonurban community were coded as " 1 " with homebuyers who resided in an urban community—Jefferson County—coded as "0". Interactions terms were computed by the multiplication of these main effects to the homebuyer's centered distance to the nearest RSO. These findings are crucial as they may strengthen the link between awareness of nearby RSOs to depressed home sale values. No multicollinearity was present in the regression models. 


\section{CHAPTER V}

\section{RESULTS}

\section{Multilevel Modeling}

To identify the effects at each level, the application of multilevel modeling partitions the variation simultaneously at both the between- (i.e., property/residential) and within-neighborhood (i.e., census block group) levels. The unconditional model included the natural log of home sale values as the outcome but did not model the residential or neighborhood characteristics (Table 9). Additional level-1 variables — with and without the distance to the nearest RSO variable - are inserted in the random coefficients models to explain the variation within- $\left(\sigma^{2}\right)$ and between-neighborhoods $\left(\tau_{00}\right)$, as shown in Table 10. Level-2 variables — with and without the RSO/spatial dependence variable - in the contextual models will try and explain the between-neighborhood differences $\left(\tau_{00}\right)$, as shown in Table 11. A final model (Table 12) included the distance to the nearest RSO and spatial dependence variable to assess for any additional variance explained in home sale values. No missing data were apparent prior to the construction of the multilevel models.

Unconditional model (one-way ANOVA with random effects model). The main purpose of the unconditional model is to assess the amount of variation in the 
dependent variable across the level-2 groups (Raudenbush \& Bryk, 2002). The estimation of the unconditional model is crucial for two reasons in the present study. First, it determines whether sale values of sold homes are similar across neighborhoods, in which spatial analyses have so far indicated home sale values are dissimilar across space. Second, the results from the unconditional model can support the decision to include neighborhood characteristics as essential explanatory variables for the sale values of sold homes. The model for the unconditional model was (Table 9):

$\operatorname{LNVALUEij}=\beta_{0 j}+r_{i j}$

Average neighborhood home sale values are statistically different from zero $\left(\gamma_{00}=\right.$ 12.06, $p<.001)$. Results of the unconditional model indicate significant variation in home sale values exists between-neighborhoods $\left(\tau_{00}=59.99 ; \chi 2[1,149]=77,800.61, p<\right.$ .001). Variation between-neighborhoods as measured by the intraclass correlation coefficient (ICC) $\left.\left[\rho=\tau_{00} / \tau_{00}+\sigma^{2}\right]\right)^{38}$ must be reported. The ICC indicates the proportion of the variance that can be explained between the clusters, and in turn, the degree of nonindependence (Luke, 2004; McCoach, 2010; Raudenbush \& Bryk, 2002). The product of the ICC ranges from " 0 " to " 1 ." As the ICC increases towards " 1 ," the greater the homogeneity between the values is present in the cluster.

The present data yielded a large ICC $(0.60 /[0.60+0.19]=.76) ; 76 \%$ of the total variation in home sale values can be attributed to the neighborhood level ( $24 \%$ is within the neighborhoods). A high ICC suggests that a multilevel model is an appropriate and useful statistical approach to assess the accompaniment of neighborhood characteristics with the property/residential characteristics of sold homes (Luke, 2004; see Brown \&

\footnotetext{
${ }^{38}$ Between cluster variance is represented by $\tau_{00}$, and within cluster variance is represented by $\sigma^{2}$.
} 
Uyar, 2004). Aside from the modeling approach, a high ICC also suggests that the data's observations are not independent (an ICC of zero means there is an independence of observations) but clustered as greater homogeneity exists within neighborhoods (or more heterogeneity between neighborhoods) (Luke, 2004; McCoach, 2010; Raudenbush \& Bryk, 2002). Such a high ICC should not come as a surprise, given the assessments of spatial dependence via the global Moran's I and LISA cluster maps. Overall, the results indicate that the context of the neighborhood does matter when examining home sale values as the variance in home sale values is due to the differences at the neighborhood level, and consequently, telling that housing sale values vary across neighborhoods.

Table 9

Unconditional Model of Home Sale Values

\begin{tabular}{lllll}
\hline Fixed effects & Coefficient $(S E)$ & $t(d f)$ & $p$ \\
\hline Model for value $(\ln )\left(\beta_{00}\right)$ & & & & \\
$\quad$ Intercept $\left(\gamma_{00}\right)$ & $12.06(0.02)$ & $521.37(1,149)$ & $<.001$ \\
\hline & & & & \\
\hline Random effects (var. components) & Variance & $d f$ & $\chi^{2}$ & $p$ \\
\hline Variance in neighborhood means $\left(\tau_{00}\right)$ & 59.99 & 1,149 & $77,800.61$ & $<.001$ \\
Variance within neighborhoods $\left(\sigma^{2}\right)$ & 18.76 & & & \\
\hline Total variability & 78.75 & & \\
\hline
\end{tabular}

Level-1 models (random coefficients models). Two level-1 models were constructed (Table 10) and acted as a baseline comparison for the subsequent contextual models. Model 1 contained only the property control characteristics of the sold homes, with the addition of the distance to the nearest RSO in Model 2 as the primary independent variable. The three property characteristics (i.e., age, GLA, and the number of bathrooms) of the sold homes and the distance to the nearest RSO are grand-mean centered. The presence of bathrooms and fireplaces are uncentered because they are 
dichotomous variables. As the primary point of interest is the neighborhood effects, property effects are fixed in the level-1 models.

Model 1. The level-1 model (Table 10) includes all property characteristics as fixed slopes:

$L N V A L U E_{i j}=\beta 0 j+\beta 1 j^{*}\left(A G E_{i j}\right)+\beta_{2 j} *(G L A i j)+\beta 3 j *\left(B A T H \_C T_{i j}\right)+\beta 4 j^{*}\left(B A S E_{-} D U M i j\right)+$ $\beta 5 j^{*}\left(F P \_D U M_{i j}\right)+r_{i j}$

$\beta 0 j=\gamma 00+u 0 j$

$\beta_{1 j}=\gamma 10$

$\beta_{2 j}=\gamma_{20}$

$\beta 3 j=\gamma 30$

$\beta 4 j=\gamma 40$

$\beta 5 j=\gamma 50$

The average home sale value across neighborhoods are statistically different from zero $\left(\gamma_{00}=11.99, p<.001\right)$, after controlling for the property characteristics of the sold homes. On average across neighborhoods, GLA $\left(\gamma_{20}=0.0003, p<.001\right)$, bath count $\left(\gamma_{30}=\right.$ $0.06, p<.001)$, and the presence of basements $\left(\gamma_{40}=0.14, p<.001\right)$ and fireplaces $\left(\gamma_{50}=\right.$ $0.08, p<.001)$ are positively and significantly related to the mean home sale values within neighborhoods. Conversely, the age of the sold home was negatively and significantly associated with the mean home sale values within neighborhoods $\left(\gamma_{10}=-\right.$ $0.003, p<.001)$. In other words, home selling prices are $0.29 \%$ lower for every standard deviation decrease in the age of sold homes. ${ }^{39}$

The computation of an $R^{2}$ value for a level-1 model was in accordance to Raudenbush and Bryk's (2002) proportional reduction in variance statistic $\left(\left[\sigma_{B}^{2}-\right.\right.$ $\left.\left.\sigma_{F}^{2}\right] / \sigma_{B}^{2}\right)$. The inclusion of the property characteristics as predictors of home sale values within neighborhood reduced the within-neighborhood variability by $35.82 \%$ ([18.76 -

\footnotetext{
${ }^{39}$ The regression coefficient must be exponentiated, with the product subtracted by 1 , and the resulted outcome multiplied by 100 .
} 
12.04] / 18.76). Property characteristics explained a small portion of the betweenneighborhood variability in home sale values $\left(\left[\hat{\tau}_{00_{b}}-\hat{\tau}_{00_{f}}\right] / \hat{\tau}_{00_{b}}\right), 0.41 \%$ ([59.99 35.14] / 59.99). Home sale values are still significantly different across the 1,150 neighborhoods $\left(\tau_{00}=35.14 ; \chi^{2}[1,149]=65,896.35, p<.001\right)$.

Model 2. As the premise of the current study argued that model misspecification resulted in a Type I error between the distance to the nearest RSO variable and home selling prices, it was of interest whether the inclusion of the distance to the nearest RSO variable would elicit a statistically significant outcome. The only distinction from Model 1 to Model 2 was the inclusion of the distance to the nearest RSO variable (Table 10) which was grand-mean centered. The purpose of Model 2 is to respond to Hypothesis \#1. Initially, the slope for the distance to the nearest RSO was randomly varying. Level-1 models with and without the random effect of the distance to the nearest RSO were performed to compare the fit of the model (Table 13). Results of the AIC, BIC, and chi-square difference tests favored the model with the distance to the nearest RSO randomly varying. However, the number of neighborhoods accounted for, declined from 1,150 to 164 . Therefore, the level-1 model (Table 10) includes all residential characteristics as fixed slopes:

$$
\begin{aligned}
& L N V A L U E_{i j}=\beta 0_{j}+\beta 1 j^{*}\left(A G E_{i j}\right)+\beta 2 j^{*}\left(G L A_{i j}\right)+\beta 3 j^{*}\left(B A T H \_C T_{i j}\right)+\beta 4 j^{*}\left(B A S E \_D U M_{i j}\right)+ \\
& \beta 5 j^{*}\left(F P \_D U M_{i j}\right)+\beta 6 j^{*}\left(R S O \_D I S T i j\right)+r_{i j} \\
& \beta 0 j=\gamma 00+u 0 j \\
& \beta 1 j=\gamma 10 \\
& \beta_{2 j}=\gamma_{20} \\
& \beta_{3 j}=\gamma 30 \\
& \beta 4 j=\gamma 40 \\
& \beta \beta_{j}=\gamma 50 \\
& \beta 6 j=\gamma 60
\end{aligned}
$$


The introduction of the distance to the nearest RSO in Model 2 resulted in unchanged effects of the property characteristics on home sale values. However, consistent with the existing research and in support of Hypothesis \#1, the distance to the nearest RSO $\left(\gamma_{60}=0.00001, p<.001\right)$ was positively and significantly related to the mean home sale values within neighborhoods, on average across neighborhoods. An indication that home sale values across neighborhoods increase the further the nearest RSOs are located from sold homes. Although the effect of nearby RSOs is statistically significant, it is not substantially significant as home selling prices are $0.001 \%$ greater for every standard deviation increase in the distance to the nearest RSO.

The inclusion of the distance to the nearest RSO as a predictor together with the property characteristics of sold homes resulted in no change in the within-neighborhood variability compared to Model 1, but explained a small additional amount of the betweenneighborhood variability in home sale values, $0.02 \%$ ([35.14 - 34.54] / 35.14). Home sale values are still significantly different across the 1,150 neighborhoods $\left(\tau_{00}=34.54\right.$;

$\left.\chi^{2}[1,149]=64,452.68, p<.001\right)$. Results from the random coefficients models suggested that there is still additional unexplained variance in home sale values that may be explained by contextual models. 
Table 10

Random Coefficients Models With Level-1 Property and Residential Characteristics

\begin{tabular}{|c|c|c|c|c|c|c|}
\hline & \multicolumn{3}{|c|}{ Model 1 - Property } & \multicolumn{3}{|c|}{ Model 2 - Residential } \\
\hline Fixed effects & Coefficient $(S E)$ & $t(d f)$ & $p$ & Coefficient $(S E)$ & $t(d f)$ & $p$ \\
\hline Model for value $(\ln )\left(\beta_{00}\right)$ & & & & & & \\
\hline Intercept $\left(\gamma_{00}\right)$ & $11.99(0.02)$ & $662.72(1,149)$ & $<.001$ & $11.99(0.02)$ & $668.12(1,149)$ & $<.001$ \\
\hline Model for Age slope $\left(\beta_{10}\right)$ & & & & & & \\
\hline Intercept $\left(\gamma_{10}\right)$ & $-0.003(0.0001)$ & $-26.13(25,790)$ & $<.001$ & $-0.003(0.0001)$ & $-26.09(25,789)$ & $<.001$ \\
\hline Model for GLA slope $\left(\beta_{20}\right)$ & & & & & & \\
\hline Intercept $\left(\gamma_{20}\right)$ & $\begin{array}{r}0.0003 \\
(0.000004)\end{array}$ & $70.43(25,790)$ & $<.001$ & $\begin{array}{r}0.0003 \\
(0.000004)\end{array}$ & $69.85(25,789)$ & $<.001$ \\
\hline $\begin{array}{l}\text { Model for Bath Count slope }\left(\beta_{30}\right) \\
\text { Intercept }\left(\gamma_{30}\right)\end{array}$ & $0.06(0.003)$ & $20.90(25,790)$ & $<.001$ & $0.06(0.003)$ & $20.88(25,789)$ & $<.001$ \\
\hline $\begin{array}{l}\text { Model for Basement slope }\left(\beta_{40}\right) \\
\text { Intercept }\left(\gamma_{40}\right)\end{array}$ & $0.14(0.006)$ & $24.76(25,790)$ & $<.001$ & $0.14(0.006)$ & $24.72(25,789)$ & $<.001$ \\
\hline $\begin{array}{l}\text { Model for Fireplace slope }\left(\beta_{50}\right) \\
\text { Intercept }\left(\gamma_{50}\right)\end{array}$ & $0.08(0.007)$ & $11.98(25,790)$ & $<.001$ & $0.08(0.007)$ & $11.89(25,789)$ & $<.001$ \\
\hline $\begin{array}{l}\text { Model for RSO slope }\left(\beta_{60}\right) \\
\text { Intercept }\left(\gamma_{60}\right)\end{array}$ & & & & $\begin{array}{r}0.00001 \\
(0.000002)\end{array}$ & $4.10(25,789)$ & $<.001$ \\
\hline
\end{tabular}

\begin{tabular}{|c|c|c|c|c|c|c|c|c|}
\hline Random effects (var. components) & Variance & $d f$ & $\chi^{2}$ & $p$ & Variance & $d f$ & $\chi^{2}$ & $p$ \\
\hline Variance in neighborhood means $\left(\tau_{00}\right)$ & 35.14 & 1,149 & $65,896.35$ & $<.001$ & 34.54 & 1,149 & $64,452.68$ & $<.001$ \\
\hline Variance within neighborhoods $\left(\sigma^{2}\right)$ & 12.04 & & & & 12.04 & & & \\
\hline Total variability & 47.18 & & & & 46.58 & & & \\
\hline
\end{tabular}

Note. GLA = Gross living area. Age, GLA, bath count, and distance to the nearest RSO are grand-mean centered. Dummy variables basement and fireplace are uncentered. 
Level-2 models (contextual models). As shown in Table 11, three contextual models were created. Property characteristics were accompanied by 11 level- 2 neighborhood control variables (that does not include spatial dependence [see Table 6]) in Model 3. Model 4 contained the property characteristics as well as the 11 neighborhood control characteristics (that does not include spatial dependence) together with the distance to the nearest RSO. The distance to the nearest RSO variable was swapped out with spatial dependence in Model 5 that contained the property and 11 neighborhood control characteristics of sold homes.

All neighborhood-level variables are grand-mean centered, and predicting only the intercept as the relationship between home sale values and the distance to the nearest RSO is of greater interest. Thus, no cross-level interactions were conducted between property/residential and neighborhood characteristics. All neighborhood effects behaved in the same manner across the contextual models with exception to the percentage of female-headed households, which was a predictor of home sale values in Model 3 but not in Models 4 and 5. Neighborhood characteristics that consistently maintained nonrelationships were both measures of residential stability. More specifically, neither the percentage of the population who stayed in the same residence for one year and longer nor the percentage of renter-occupied housing units was significant in any of the models.

Model 3. Model 3 contained property and 11 neighborhood characteristics (without spatial dependence) (Table 11):

$$
\begin{aligned}
& L N V A L U E_{i j}=\beta 0 j+\beta 1 j^{*}\left(A G E_{i j}\right)+\beta 2 j^{*}(G L A i j)+\beta 3 j^{*}\left(B A T H \_C T_{i j}\right)+\beta 4 j^{*}\left(B A S E \_D U M i j\right)+ \\
& \beta 5_{j}^{*}\left(F P \_D U M i j\right)+r i j \\
& \beta 0 j=\gamma 00+\gamma 01^{*}\left(P E R \_B j\right)+\gamma 02^{*}\left(P E R \_H I S P j\right)+\gamma 03^{*}\left(P E R \_F O R G_{j}\right)+\gamma 04^{*}\left(P E R \_R E S S_{j}\right)+ \\
& \gamma 05^{*}\left(P E R \_65 O_{j}\right)+\gamma 06^{*}\left(P E R \_P O P 1_{j}\right)+\gamma 07^{*}\left(P E R \_B A C H j\right)+\gamma 08^{*}\left(P E R \_P O V_{j}\right)+ \\
& \gamma 09^{*}\left(P E R \_F H H j\right)+\gamma 010^{*}\left(P E R \_R E N T_{j}\right)+\gamma 011^{*}\left(P R O \_H U S_{j}\right)+u 0 j
\end{aligned}
$$


$\beta_{1 j}=\gamma 10$

$\beta 2 j=\gamma 20$

$\beta 3 j=\gamma 30$

$\beta 4 j=\gamma 40$

$\beta 5 j=\gamma 50$

The overall home sale value across neighborhoods are still statistically different from zero $\left(\gamma_{00}=11.99, p<.001\right)$, after controlling for the property and neighborhood characteristics of sold homes. The effects of neighborhood characteristics that are positively and significantly related to the mean home sale values between neighborhoods included: the percentage of Hispanics $\left(\gamma_{02}=0.005, p<.001\right)$; foreign-born persons $\left(\gamma_{03}=\right.$ $0.01, p<.001)$; persons above 65 years of age $\left(\gamma_{05}=0.003, p<.001\right)$; persons 17 years and younger $\left(\gamma_{06}=0.003, p<.05\right)$; college graduates above the age of $25\left(\gamma_{07}=0.01, p<\right.$ $.001)$; and the proportion of urbanicity $\left(\gamma_{11}=0.23, p<.001\right)$. Therefore, holding the proportion of urbanicity constant at the grand mean, home selling prices were $25.86 \%$ greater for every standard deviation increase in the proportion of urbanicity. Three neighborhoods characteristics were negatively and significantly related to the home sale values between neighborhoods: the percentage of Blacks $\left(\gamma_{01}=-0.01, p<.001\right)$; families in poverty $\left(\gamma_{08}=-0.01, p<.001\right)$; and female-headed households $\left(\gamma_{09}=-0.003, p<.05\right)$. Otherwise interpreted as neighborhoods with higher concentrations of Blacks, impoverished families, and female-headed households also contained sold homes with lower selling prices. Overall, home sale values were highest in neighborhoods identified as urban, with higher concentrations of foreign-born and Bachelor or graduate degree holder populations, and lower concentrations of Black populations and impoverished families. 
The computation of an $R^{2}$ value for the two-level model was in accordance to Raudenbush and Bryk's (2002) proportional reduction in variance statistic $\left(\hat{\tau}_{00_{b}}-\right.$ $\left.\hat{\tau}_{00_{f}}\right) / \hat{\tau}_{00_{b}}$. Compared to Model 1 (Table 10 ) that contained strictly property characteristics, neighborhood characteristics accounted for $80.39 \%$ ([35.14 - 6.89] / 35.14) of variance in the between-neighborhood differences in home sale value, above and beyond what the level-1 variables explained. In justification that a multilevel modeling framework is an ideal approach to describe how the real estate market operates in the context of neighborhoods (Brown \& Uyar, 2004).

Model 3 highlighted the importance of simultaneously partitioning the variation at both the between- and within-neighborhood levels. Nearly all neighborhood characteristics contributed to the sale values of sold homes and stressed the importance of their inclusion as level-2 predictors of home selling prices. Compared to the property characteristics, a number of neighborhood characteristics had stronger effects on home selling prices. Without a doubt, the inclusion of additional, if not better predictors yielded an improved model. Although the residual between-neighborhood variance $\left(\tau_{00}=6.89\right)$ in home sale values after controlling for property and neighborhood characteristics is $p<$ .001 , indicating considerable differences still remain between neighborhoods that could be explained by other variables, $\chi^{2}(1,138)=15,583.30, p<.001$.

Model 4. Before the inclusion of an additional level-2 variable that accounts for spatial dependence, it is of interest as to whether the distance to the nearest RSO would explain additional variance in a contextual model. Model 4 contains the estimates of the fixed effects with the addition of the distance to the nearest RSO being grand-mean centered. The AIC, BIC, and chi-square difference test preferred the distance to the 
nearest RSO as a randomly-varying slope. However, like the random-coefficients model that contained residential characteristics (Table 10, Model 2), the number of neighborhoods decreased to 164 from 1,150 (Table 13, Model 2b). Therefore, the only alteration made from the previous two-level model (Table 11, Model 3) is the inclusion of a fixed slope for the distance to the nearest RSO (Model 4):

$$
\begin{aligned}
& L N V A L U E_{i j}=\beta 0 j+\beta 1 j^{*}\left(A G E_{i j}\right)+\beta_{2 j} *(G L A i j)+\beta 3 j^{*}\left(B A T H \_C T_{i j}\right)+\beta j_{j}^{*}\left(B A S E_{-} D U M_{i j}\right)+ \\
& \beta 5 j^{*}\left(F P \_D U M_{i j}\right)+\beta 6 j^{*}\left(R S O \_D I S T_{i j}\right)+r_{i j} \\
& \beta 0 j=\gamma 00+\gamma 01 *\left(P E R \_B j\right)+\gamma 02 *\left(P E R \_H I S P j\right)+\gamma 03 *\left(P E R \_F O R G_{j}\right)+\gamma 04 *\left(P E R \_R E S S_{j}\right)+ \\
& \gamma 05^{*}\left(P E R \_65 O j\right)+\gamma 06^{*}\left(P E R \_P O P 1_{j}\right)+\gamma 07^{*}\left(P E R \_B A C H j\right)+\gamma 08^{*}\left(P E R \_P O V_{j}\right)+ \\
& \gamma 09^{*}\left(P E R \_F H H_{j}\right)+\gamma 010^{*}\left(P E R \_R E N T_{j}\right)+\gamma 011^{*}\left(P R O \_H U S_{j}\right)+u 0 j \\
& \beta 1 j=\gamma 10 \\
& \beta_{2 j}=\gamma_{20} \\
& \beta 3 j=\gamma 30 \\
& \beta 4 j=\gamma 40 \\
& \beta 5 j=\gamma 50 \\
& \beta 6 j=\gamma 60
\end{aligned}
$$

In the interest of parsimony, the focus is placed on the distance to the nearest RSO as all effects in Model 4 behaved similarly to Model 3 (included property and 11 neighborhood characteristics [without spatial dependence]), with exception to femaleheaded households. The percentage of female-headed households no longer significantly affects the between-neighborhood variance in home sale values. What is more compelling is that unlike the level-1 model that contained the residential characteristics, the presence of the nearest RSO $\left(\gamma_{60}=0.000003, p=.157\right)$ to a sold home is not an influential predictor of mean home sale values between neighborhoods. Therefore, Hypothesis \#2 is supported; the inclusion of neighborhood characteristics in a model that acknowledges the hierarchical structure of sold homes nested in neighborhoods results in the presence of local RSOs being uninfluential on home selling prices. A demonstration that a multilevel modeling approach likely controlled the interdependence among the 
observations and reduced the likelihood of Type I errors (McCoach, 2010; Raudenbush \& Bryk, 2002) to a greater extent than hedonic regression modeling. Considerable differences between neighborhoods could be explained by other variables $\left(\tau_{00}=6.89\right.$; $\left.\chi^{2}[1,138]=15,639.51, p<.001\right)$. Furthermore, the variance in the between-neighborhood differences in home sale value remained unchanged in Model 4 compared to Model 3.

Model 5. Although support for Hypothesis \#2 has been indicated by Model 4, the nature of the data in the present study must account for the spatial component. Social disorganization researchers, Kubrin and Weitzer (2003) suggested spatial effects must be incorporated into a multilevel modeling framework. Thus, the purpose of Model 5 is to identify the influence of spatial dependence on the effects. The calculation for spatial dependence (via global Moran's I) was based on the weighted averages of home sale values per census block group's first-order neighbors that share common borders and vertices. As a characteristic of neighborhoods, its introduction into a contextual model is to ensure that the neighborhood effects remain unbiased. Model 5 contained the property characteristics of sold homes and all 12 of the neighborhood characteristics (Table 11):

$$
\begin{aligned}
& L N V A L U E_{i j}=\beta 0 j+\beta j_{j}^{*}(A G E i j)+\beta 2 j^{*}(G L A i j)+\beta 3^{*}\left(B A T H \_C T_{i j}\right)+\beta 4 j^{*}\left(B A S E \_D U M_{i j}\right)+ \\
& \beta 5 j^{*}\left(F P \_D U M i j\right)+r i j \\
& \beta 0 j=\gamma 00+\gamma 01^{*}\left(P E R \_B j\right)+\gamma 02^{*}\left(P E R \_H I S P j\right)+\gamma 03^{*}\left(P E R \_F O R G_{j}\right)+\gamma 04^{*}\left(P E R \_R E S S_{j}\right)+ \\
& \gamma 05^{*}\left(P E R \_65 O j\right)+\gamma 06^{*}\left(P E R \_P O P 1 j\right)+\gamma 07^{*}\left(P E R \_B A C H j\right)+\gamma 08^{*}\left(P E R \_P O V_{j}\right)+ \\
& \gamma 09^{*}\left(P E R \_F H H_{j}\right)+\gamma 010^{*}\left(P E R \_R E N T_{j}\right)+\gamma 011^{*}\left(P R O \_H U S_{j}\right)+\gamma 012^{*}\left(M O R I \_Q 1 j\right)+u 0 j \\
& \beta 1 j=\gamma 10 \\
& \beta 2 j=\gamma 20 \\
& \beta 3 j=\gamma 30 \\
& \beta 4 j=\gamma 40 \\
& \beta 5 j=\gamma 50
\end{aligned}
$$

All effects in Model 5, including the relationship between the distance to the nearest RSO and the outcome, behaved similarly to Model 4 (contained property 
characteristics 11 neighborhood characteristics without spatial dependence). The primary difference between Model 3 and 5 was the non-relationship between female-headed households and home sale values. The percentage of female-headed households no longer significantly affects the between-neighborhood variance in home sale values when spatial dependence is introduced into the contextual model. The inclusion of spatial dependence $\left(\gamma_{012}=-0.78, p=.581\right)$ resulted in virtually unchanged property and neighborhood effects and between-neighborhood differences $\left(\tau_{00}=6.89 ; \chi^{2}[1,137]=15,587.64, p<.001\right)$ when compared to the two previous contextual models. Suggesting that the spatial structure was explained in Model 5 (Pierewan \& Tampubolon, 2014). 
Table 11

Contextual Models With Level-1 (Property/Residential-Level) and Level-2 (Neighborhood-Level) Control Characteristics

\begin{tabular}{|c|c|c|c|c|c|c|c|c|c|}
\hline & \multicolumn{3}{|c|}{ Model $3-\mathrm{P}$ and $\mathrm{N}$} & \multicolumn{3}{|c|}{ Model $4-\mathrm{P}, \mathrm{N}$, and RSO } & \multicolumn{3}{|c|}{ Model $5-\mathrm{P}, \mathrm{N}$, and $\mathrm{M}$} \\
\hline Fixed effects & $\begin{array}{l}\text { Coefficient } \\
(S E)\end{array}$ & $t(d f)$ & $p$ & $\begin{array}{l}\text { Coefficient } \\
(S E)\end{array}$ & $t(d f)$ & $p$ & $\begin{array}{l}\text { Coefficient } \\
(S E)\end{array}$ & $t(d f)$ & $p$ \\
\hline $\begin{array}{l}\text { Model for value } \\
(\ln )\left(\beta_{00}\right)\end{array}$ & & & & & & & & & \\
\hline Intercept $\left(\gamma_{00}\right)$ & $11.99(0.009)$ & $\begin{array}{r}1336.66 \\
(1,138)\end{array}$ & $<.001$ & $11.99(0.009)$ & $\begin{array}{r}1336.12 \\
(1,138)\end{array}$ & $<.001$ & $11.99(0.009)$ & $\begin{array}{r}1336.90 \\
(1,137)\end{array}$ & $<.001$ \\
\hline $\begin{array}{l}\text { Residential (Leve } \\
\text { Model for Age } \\
\text { slope }\left(\beta_{10}\right)\end{array}$ & $1-1)$ & & & & & & & & \\
\hline Intercept $\left(\gamma_{10}\right)$ & $\begin{array}{r}-0.003 \\
(0.0001)\end{array}$ & $\begin{array}{r}-26.22 \\
(25,790)\end{array}$ & $<.001$ & $\begin{array}{r}-0.003 \\
(0.0001)\end{array}$ & $\begin{array}{r}-26.19 \\
(25,789)\end{array}$ & $<.001$ & $\begin{array}{r}-0.003 \\
(0.0001)\end{array}$ & $\begin{array}{r}-26.21 \\
(25,790)\end{array}$ & $<.001$ \\
\hline $\begin{array}{l}\text { Model for } \\
\text { GLA slope } \\
\left(\beta_{20}\right)\end{array}$ & & & & & & & & & \\
\hline Intercept $\left(\gamma_{20}\right)$ & $\begin{array}{r}0.0003 \\
(0.000004)\end{array}$ & $\begin{array}{r}71.25 \\
(25,790)\end{array}$ & $<.001$ & $\begin{array}{r}0.0003 \\
(0.000004)\end{array}$ & $\begin{array}{r}70.88 \\
(25,789)\end{array}$ & $<.001$ & $\begin{array}{r}0.0003 \\
(0.000004)\end{array}$ & $\begin{array}{r}71.25 \\
(25,790)\end{array}$ & $<.001$ \\
\hline $\begin{array}{l}\text { Model for } \\
\text { Bath Count } \\
\text { slope }\left(\beta_{30}\right)\end{array}$ & & & & & & & & & \\
\hline Intercept $\left(\gamma_{30}\right)$ & $0.05(0.003)$ & $\begin{array}{r}19.86 \\
(25,790)\end{array}$ & $<.001$ & $0.05(0.003)$ & $\begin{array}{r}19.85 \\
(25,789)\end{array}$ & $<.001$ & $0.05(0.003)$ & $\begin{array}{r}19.85 \\
(25,790)\end{array}$ & $<.001$ \\
\hline $\begin{array}{l}\text { Model for } \\
\text { Base slope } \\
\left(\beta_{40}\right)\end{array}$ & & & & & & & & & \\
\hline Intercept $\left(\gamma_{40}\right)$ & $0.15(0.006)$ & $\begin{array}{r}25.69 \\
(25,790)\end{array}$ & $<.001$ & $0.15(0.006)$ & $\begin{array}{r}25.67 \\
(25,789)\end{array}$ & $<.001$ & $0.15(0.006)$ & $\begin{array}{r}25.70 \\
(25,790)\end{array}$ & $<.001$ \\
\hline
\end{tabular}




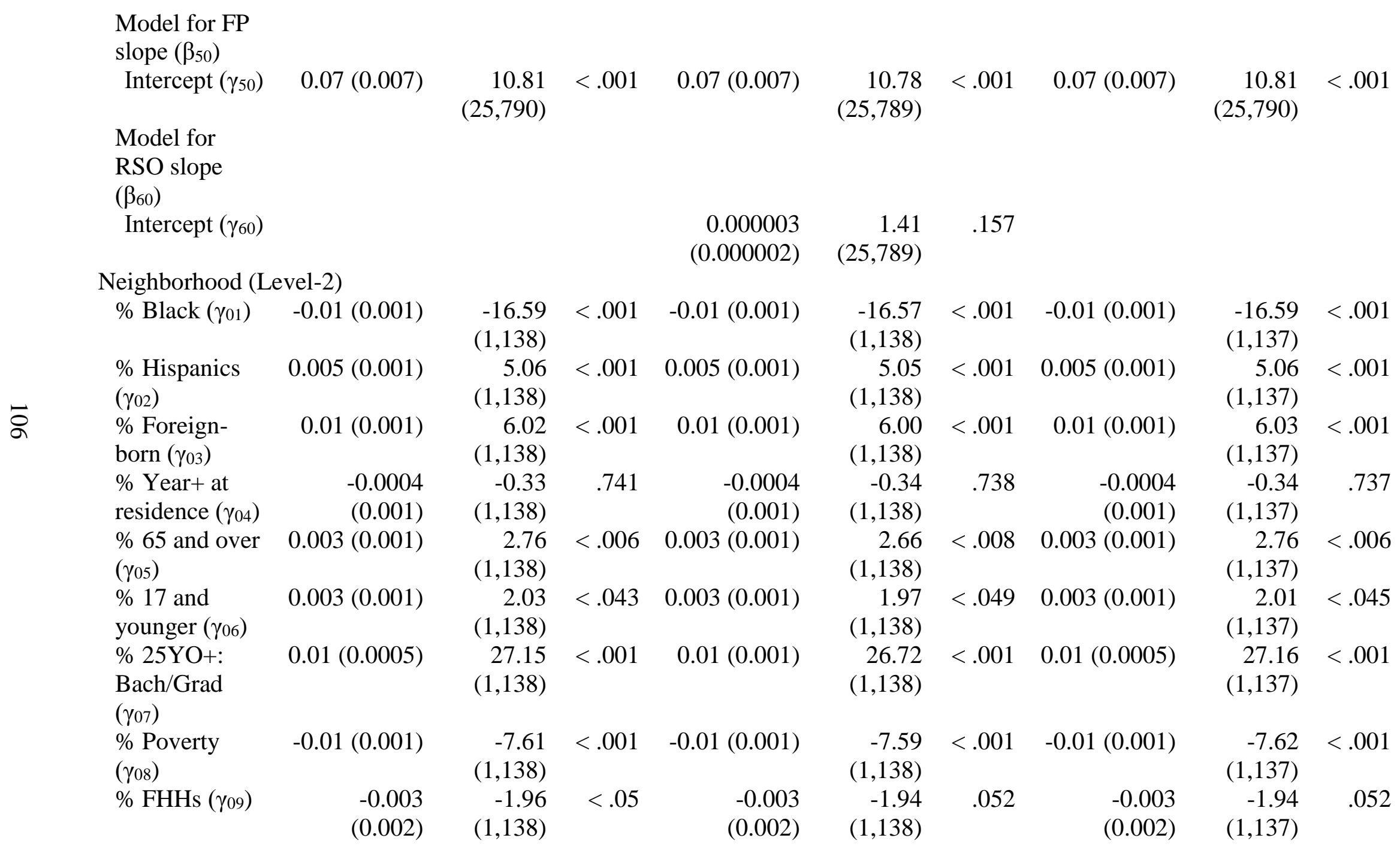




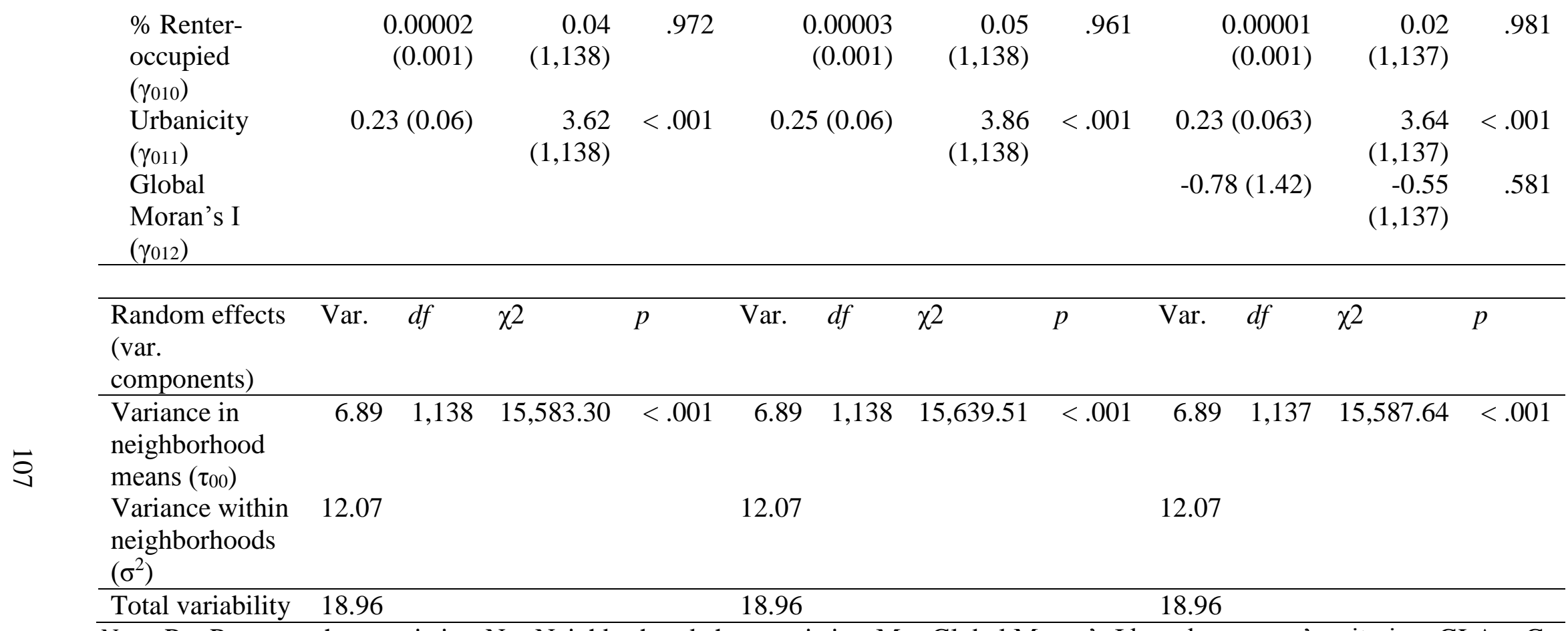

Note. $\mathrm{P}=$ Property characteristics. $\mathrm{N}=$ Neighborhood characteristics. M = Global Moran's I based on queen's criterion. GLA = Gross living area. FP = Fireplace. FHHs = Female-headed households. All neighborhood characteristics are randomly varying. All residential characteristics are fixed. Uncentered variables include the presence of a basement and fireplace(s), with remaining variables grand-mean centered. 
Final model. The final model is a spatial multilevel model to address Hypothesis $\# 2$, which stated that the inclusion of neighborhood characteristics would yield in a nonsignificant relationship between home sale values and the distance to the nearest RSO. Property characteristics are fixed, with age, GLA, and the number of bathrooms grandmean centered, and the presence of a basement and fireplace(s) as uncentered. Estimates in the final model included the distance to the nearest RSO and neighborhood characteristics as fixed, grand-mean centered effects. Presented here is the final model (Table 12):

$L N V A L U E_{i j}=\beta 0 j+\beta 1 j^{*}\left(A G E_{i j}\right)+\beta_{2 j} *(G L A i j)+\beta_{3 j} *\left(B A T H \_C T_{i j}\right)+\beta 4 j^{*}\left(B A S E_{-} D U M_{i j}\right)+$ $\beta 5 j^{*}\left(F P \_D U M_{i j}\right)+\beta 6 j^{*}\left(R S O \_D I S T i j\right)+r_{i j}$

$\beta 0 j=\gamma 00+\gamma 01^{*}\left(P E R \_B j\right)+\gamma 02^{*}\left(P E R \_H I S P_{j}\right)+\gamma 03^{*}\left(P E R \_F O R G_{j}\right)+\gamma 04^{*}\left(P E R \_R E S S_{j}\right)+$ $\gamma 05^{*}\left(P E R \_65 O_{j}\right)+\gamma 06^{*}\left(P E R \_P O P 1_{j}\right)+\gamma 07^{*}\left(P E R \_B A C H j\right)+\gamma 00^{*}\left(P E R \_P O V_{j}\right)+$ $\gamma 09^{*}\left(P E R \_F H H_{j}\right)+\gamma 010^{*}\left(P E R \_R E N T_{j}\right)+\gamma 011^{*}\left(P R O \_H U S_{j}\right)+\gamma 012^{*}\left(M O R I \_Q 1_{j}\right)+u 0 j$ $\beta 1 j=\gamma 10$ $\beta 2 j=\gamma 20$ $\beta_{3 j}=\gamma 30$ $\beta 4 j=\gamma 40$ $\beta 5_{j}=\gamma 50$ $\beta 6 j=\gamma 60$

In the final model, the intercept $\left(\gamma_{00}=11.99, p<.001\right)$ represents the average home sale value for the 1,150 neighborhoods after controlling for property and neighborhood characteristics. Although there are virtually no changes in the effects of each of the property and neighborhood characteristics compared to the previous contextual models, some of the changes in the $p$-value of the neighborhood characteristics are notable. Comparable to Model 4 and 5 that contained either the addition of the RSO/spatial dependence variable (Table 11), the percentage of the population that has been in their current home for a year or more $\left(\gamma_{06}=-0.0004, p<\right.$ $.734)$, female-headed households ( $\left.\gamma_{09}=0.003, p<.052\right)$, renter-occupied housing units 
$\left(\gamma_{10}=0.00002, p<.969\right)$, and spatial dependence $\left(\gamma_{12}=-0.75, p<.596\right)$ continued to be non-predictors of neighborhood mean home sale values. The inclusion of spatial dependence and the distance to the nearest RSO have weakened the predictive relationship of the percentage of the population 17 years and younger $\left(\gamma_{06}=-0.003, p<\right.$ .052) in neighborhoods onto the neighborhood mean home sale values (Table 12).

Table 12

Final Model With Level-1 (Residential-Level) and Level-2 (Neighborhood-Level) Control Characteristics

\begin{tabular}{|c|c|c|c|}
\hline \multirow{2}{*}{\multicolumn{4}{|c|}{$\begin{array}{l}\text { Fixed effects } \\
\text { Model for value }(\ln )\left(\beta_{00}\right)\end{array}$}} \\
\hline & & & \\
\hline Intercept $\left(\gamma_{00}\right)$ & $11.99(0.01)$ & $1336.35(1,137)$ & $<.001$ \\
\hline \multicolumn{4}{|l|}{ Residential (Level-1) } \\
\hline \multicolumn{4}{|l|}{ Model for Age slope $\left(\beta_{10}\right)$} \\
\hline Intercept $\left(\gamma_{10}\right)$ & $-0.003(0.0002)$ & $0.0001(25,789)$ & $<.001$ \\
\hline \multicolumn{4}{|l|}{ Model for GLA slope $\left(\beta_{20}\right)$} \\
\hline Intercept $\left(\gamma_{20}\right)$ & $0.0003(0.00007)$ & $0.000004(25,789)$ & $<.001$ \\
\hline \multicolumn{4}{|l|}{ Model for Bath Count slope $\left(\beta_{30}\right)$} \\
\hline Intercept $\left(\gamma_{30}\right)$ & $0.05(0.003)$ & $0.003(25,789)$ & $<.001$ \\
\hline \multicolumn{4}{|l|}{ Model for Basement slope $\left(\beta_{40}\right)$} \\
\hline Intercept $\left(\gamma_{40}\right)$ & $0.15(0.007)$ & $0.006(25,789)$ & $<.001$ \\
\hline \multicolumn{4}{|l|}{ Model for Fireplace slope $\left(\beta_{50}\right)$} \\
\hline Intercept $\left(\gamma_{50}\right)$ & $0.07(0.008)$ & $0.007(25,789)$ & $<.001$ \\
\hline \multicolumn{4}{|l|}{ Model for RSO slope $\left(\beta_{60}\right)$} \\
\hline Intercept $\left(\gamma_{60}\right)$ & $0.000003(0.000003)$ & $0.000002(25,789)$ & .16 \\
\hline \multicolumn{4}{|l|}{ Neighborhood (Level-2) } \\
\hline$\%$ Black $\left(\gamma_{01}\right)$ & $-0.01(0.001)$ & $-16.58(1,137)$ & $<.001$ \\
\hline$\%$ Hispanics $\left(\gamma_{02}\right)$ & $0.005(0.001)$ & $5.04(1,137)$ & $<.001$ \\
\hline$\%$ Foreign-born $\left(\gamma_{03}\right)$ & $0.01(0.001)$ & $6.01(1,137)$ & $<.001$ \\
\hline$\%$ Year+ at residence $\left(\gamma_{04}\right)$ & $-0.0004(0.001)$ & $-0.34(1,137)$ & .734 \\
\hline$\% 65$ and over $\left(\gamma_{05}\right)$ & $0.003(0.001)$ & $2.66(1,137)$ & $<.008$ \\
\hline$\% 17$ and younger $\left(\gamma_{06}\right)$ & $0.003(0.001)$ & $1.95(1,137)$ & .052 \\
\hline$\% 25 \mathrm{YO}+:$ Bach/Grad $\left(\gamma_{07}\right)$ & $0.01(0.001)$ & $26.72(1,137)$ & $<.001$ \\
\hline$\%$ Poverty $\left(\gamma_{08}\right)$ & $-0.01(0.001)$ & $-7.60(1,137)$ & $<.001$ \\
\hline$\%$ FHHs $\left(\gamma_{09}\right)$ & $-0.003(0.002)$ & $-1.92(1,137)$ & .055 \\
\hline$\%$ Renter-occupied $\left(\gamma_{010}\right)$ & $0.00002(0.001)$ & $0.04(1,137)$ & .969 \\
\hline Urbanicity $\left(\gamma_{011}\right)$ & $0.25(0.06)$ & $3.88(1,137)$ & $<.001$ \\
\hline Global Moran's I $\left(\gamma_{012}\right)$ & $-0.75(1.42)$ & $-0.53(1,137)$ & .596 \\
\hline Random effects (var. components) & Variance & $d f$ & $\mathrm{p}$ \\
\hline
\end{tabular}




\begin{tabular}{lrrrr}
\hline Variance in neighborhood means & 6.89 & 1,137 & $15,643.35$ & $<.001$ \\
$\left(\tau_{00}\right)$ & & & & \\
Variance within neighborhoods $\left(\sigma^{2}\right)$ & 12.07 & & \\
\hline Total variability & 18.96 & & \\
\hline
\end{tabular}

Notes. GLA = Gross living area. FHHs = Female-headed households. All neighborhood characteristics are randomly varying. All residential characteristics are fixed. Uncentered variables include the presence of a basement and/or fireplace(s), with remaining variables grand-mean centered.

In support of Hypothesis \#2, the final model indicated that mean home sale values between neighborhoods are not related to the residence of the nearest RSO $\left(\gamma_{60}=\right.$ $0.000003, p<.16$ ), after controlling for property and neighborhood characteristics (Table 12). Despite the scholarship that has found that the presence of RSOs are related to home sale values (Bian et al., 2013; Caudill et al., 2014; Larsen et al., 2003; Linden \& Rockoff, 2008; Navarro \& Rabe-Hemp, 2017; Pope, 2008; Wentland et al., 2014; Yeh, 2015), RSOs are not related to the selling prices of sold homes in this study's spatial multilevel framework. Therefore, the present study's conclusions concerning model misspecification issues present in the RSO-home sale research are supported by the results of the spatial multilevel modeling framework.

Variance components in the final model are essentially unchanged from the contextual models, possibly due to a lack of contribution by the additional characteristics. Significant variability across the 1,150 neighborhoods continued to be unexplained $\left(\tau_{00}=\right.$ $\left.6.89 ; \chi^{2}[1,137]=15,639.51, p<.001\right)$, after controlling for property and neighborhood characteristics. Using Model 3 from Table 11 as a baseline as it contained property and neighborhood characteristics (without spatial dependence), no additional variance in the between- and within- neighborhood differences was explained by the inclusion of spatial dependence or the presence of nearby RSOs on home sale values. Additional variables can still be added to the final model to explain the differences between- and within- 
neighborhoods since the residual between-neighborhood variance $\left(\tau_{00}=6.89\right)$ of home sale values continues to be $p<.001$.

From a methodological standpoint, the relationship between home selling prices and the distance to the nearest RSO becomes non-existent when neighborhood characteristics (including spatial dependence) are considered. It still could be argued regardless of misspecification issues, the non-relationship between home sale values and the presence of RSOs may be contributed to the public's lack of awareness of RSOs in their respective communities. Addressed next are whether the relationship between home sale values and the distance to the nearest RSO is dependent on homebuyer awareness and/or homebuyer community type, after controlling for property characteristics. 
Table 13

Model Fit Comparisons

\begin{tabular}{|c|c|c|c|c|c|c|c|c|}
\hline Model & Description & $\begin{array}{l}\text { Number of } \\
\text { parameters }\end{array}$ & Deviance & $\chi^{2}(d f)$ & AIC & $\mathrm{BIC}$ & $\begin{array}{l}\text { Preferred } \\
\text { model }\end{array}$ & Units \\
\hline $1 \mathrm{a}$ & Comparison: Table 10, Model 1 & 8 & $24,018.93$ & & $24,034.93$ & $24, .075 .31$ & & All \\
\hline $1 b$ & RSO random & 11 & $23,846.78$ & $172.15(3) * * *$ & $23,868.78$ & $23,924.30$ & $1 b$ & 164 \\
\hline $1 \mathrm{c}$ & RSO fixed & 9 & $24,002.27$ & $16.67(1) * * *$ & $24,065.70$ & $24,020.27$ & & All \\
\hline $2 \mathrm{a}$ & Comparison: Table 11, Model 3 & 19 & $22,310.52$ & & $22,348.52$ & $22,444.42$ & & All \\
\hline $2 b$ & RSO random & 22 & $22,195.74$ & $114.78(3) * * *$ & $22,239.74$ & $22,350.79$ & $2 b$ & 164 \\
\hline $2 \mathrm{c}$ & RSO fixed & 20 & $22,308.52$ & $1.99(1)$ & $22,348.52$ & $22,449.47$ & & All \\
\hline $3 a$ & Comparison: Table 11, Model 5 & 20 & $22,310.21$ & & $22,348.21$ & $22,444.11$ & & All \\
\hline $3 b$ & RSO random & 23 & $22,195.18$ & $115.03 * * *$ & $22,241.18$ & $22,357.27$ & $3 b$ & 164 \\
\hline $3 c$ & RSO fixed & 21 & $22,308.24$ & $1.97(1)$ & $22,350.24$ & $22,456.24$ & & All \\
\hline
\end{tabular}

$\Xi \quad \frac{3 \mathrm{c}}{\text { Note. } * * *} p<.001 . \mathrm{RSO}=$ distance to the nearest RSO. 


\section{Moderators}

Although the first half of the study used multilevel analyses with neighborhood effects, it was not possible to extend similar analyses to describe how homebuyer awareness and community setting influenced home sale values and the distance to the nearest RSO due to insufficient clusters. A sufficient number of clusters, at a minimum, must be 30 to produced unbiased variance component estimates (McCoach, 2010). The present study's sample was still too small to be satisfactory even with larger geographically bounded clusters (i.e., census tracts). Furthermore, the inclusion of neighborhood effects was also not possible, as it would have violated the independence of observations (Luke, 2004; McCoach, 2010; Raudenbush \& Bryk, 2002). Therefore, an assessment of moderating effects yielded by homebuyer awareness and their community type was most appropriate with regression analyses.

Description of homebuyer respondents. Roughly one-in-four (24.9\%) homebuyers were aware of RSOs within 1,000 feet of their property (Table 14). The rates of awareness of nearby RSOs are comparable between rural (16.7\%) and suburban homebuyers (17.4\%) —although based on one rural homebuyer. Cross tabulations showed no statistical differences are evident between rural and suburban homebuyers regarding awareness of RSOs within 1,000 feet of their newly purchased house, $X^{2}(1, n=115)=$ $0.01, p>.05)$.

Urban homebuyers are nearly twice as likely to be aware of RSOs (30.2\%) within 1,000 -foot radii of their new property than their non-urban counterparts (17.4\%). Worthy of mentioning is that the disparities of awareness of local RSOs are greater among nonurban respondents (17.4\% vs. $82.6 \%)$ than urban respondents (30.2\% vs. $69.8 \%)$ within 
1,000 feet of the nearest RSO. Cross tabulations found statistically significant differences between homebuyer community type and awareness of RSOs within 1,000 feet of the respondents' recently purchased home, $\left.X^{2}(1, N=277)=5.94, \mathrm{p}<.05\right)$. Approximately one-in-six non-urban respondents were aware of RSOs within 1,000 feet of their newly purchased house compared to the one-in-three urban respondents. Although it was hypothesized that non-urban homebuyers would be more aware of RSOs within 1,000 feet of their house than urban homebuyers, it is rejected because urban respondents were more aware of local RSOs than non-urban respondents (Hypothesis \#3).

Table 14

Descriptives and Cross Tabulations of Non-Urban and Urban Respondents Awareness of RSOs Within 1,000 Feet of Their Property

\begin{tabular}{lrrrrr}
\hline & $N$ & \multicolumn{1}{c}{ Aware } & \multicolumn{1}{c}{ Unaware } & \multicolumn{1}{c}{$\chi^{2}$} & \multicolumn{1}{c}{$p$} \\
\hline Sample & 277 & $69(24.9 \%)$ & $208(75.1 \%)$ & 5.94 & $<.017$ \\
\hline Non-urban respondents & 115 & $20(17.4 \%)$ & $95(82.6 \%)$ & 0.01 & 1.000 \\
Rural respondents & 6 & $1(16.7 \%)$ & $5(83.3 \%)$ & & \\
Suburban respondents & 109 & $19(17.4 \%)$ & $90(82.6 \%)$ & & \\
Urban respondents & 162 & $49(30.2 \%)$ & $113(69.8 \%)$ & & \\
Note. ${ }^{*} p<.05 . * * p<.01 . * * p<.001$. & & & &
\end{tabular}

Bivariate analyses. Table 15 shows the bivariate analysis of the respondents' residential characteristics, awareness, and community type. Excluding the presence of a fireplace(s), four property characteristics showed statistically significant relationships. Of these four property characteristics, only the age of the sold home was negatively correlated with home selling prices. The GLA, the number of bathrooms, and the presence of a basement were positively correlated with home selling prices, as well as and residential locations in a non-urban community. Comparable to the multilevel results, sold homes that were younger, bigger, contained a basement and more bathrooms were significantly correlated with higher home selling prices. Another similarity to the 
multilevel model (that contained only property characteristics and the RSO variable [Model 2]) was that as the distance to the nearest RSO increases, so too does sale values of sold homes, $r(277)=.29, p<.001$.

The primary intent of the bivariate analysis is to assess the strength and direction of the relationship between the distance to the nearest RSO and the main effects (awareness and community type) to ascertain the potential predictive effects of the interaction terms. Although unanticipated, homebuyer awareness was not correlated with the distance to the nearest RSO. Suggestive that residential proximity to RSOs did not inform homebuyers of the presence of RSOs. In contrast, the community type of the respondents exhibited a moderately strong relationship to the nearest distances of RSOs $(r[277]=.27, p<.001)$. The latter finding should come to no surprise, as urban respondents $(M=448.4)$ in the sample resided roughly 138 feet closer to RSOs than nonurban respondents $(M=586.13)$. 
Table 15

Correlations $(N=277)$

\begin{tabular}{|c|c|c|c|c|c|c|c|c|}
\hline & Sale price $(\ln )$ & Age & GLA & Baths & Basement & Fireplace & Dist. RSO & Aware \\
\hline \multicolumn{9}{|c|}{ Sale price $(\ln )$} \\
\hline Age & $-0.51 * * *$ & & & & & & & \\
\hline GLA & $0.56 * * *$ & $-0.24 * * *$ & & & & & & \\
\hline Baths & $0.20 * * *$ & $-0.26 * * *$ & $0.46 * * *$ & & & & & \\
\hline Basement & $0.52 * * *$ & $-0.25 * * *$ & $0.22 * * *$ & -0.06 & & & & \\
\hline Fireplace & 0.00 & 0.05 & $0.24 * * *$ & $0.45 * * *$ & -0.03 & & & \\
\hline Dist. RSO & $0.29 * * *$ & $-0.16^{* *}$ & 0.10 & 0.06 & $0.22 * * *$ & 0.02 & & \\
\hline Aware & -0.06 & 0.05 & 0.07 & 0.09 & $-0.17 * *$ & 0.10 & -0.08 & \\
\hline Non-Urban & $0.59 * * *$ & $-0.34 * * *$ & $0.21 * * *$ & $-0.24 * * *$ & $0.59 * * *$ & $-0.36 * * *$ & $0.27 * * *$ & $-0.15 *$ \\
\hline
\end{tabular}

= $\quad$ Note. GLA = Gross living area. Reference groups: No basement, no fireplace, unaware of nearest RSO, and urban community type. $* p<.05 . * * p<.01$. *** $p<.001$. 
Regression analyses. Displayed in Table 16 are a series of multivariate analyses with home selling prices as the dependent variable. All OLS regression models included the property characteristics of sold homes as controls and the distance to the nearest RSO. Differences across the multivariate models occurred when the main effects (homebuyer awareness and homebuyer community type) and the interaction terms were included.

The continuous variable, the distance to the nearest RSO, was centered to avoid issues of multicollinearity in the OLS analyses when examining whether the dichotomous variables, awareness and community type, moderated the relationship between home sale values and local RSOs. Here, the mean distance to the nearest RSO for the sample ( $N=$ 277) was subtracted from each respondent. The resulting product represents the difference of each respondent to the sample's mean distance to the nearest RSO (otherwise referred to as the centered distance to the nearest RSO). Interaction terms were computed by multiplying the homebuyers' centered distance to the nearest RSO to their awareness and community type.

Consistent throughout all of the regression model results are the effects of the five property control characteristics of the respondents' sold homes and the distance to the nearest RSO onto the dependent variable. A discussion of the effects of the property characteristics deserves mention, although it is not of primary concern in the analyses for the assessment of potential moderation effects. Unlike the multilevel models, the number of bathrooms and the presence of a fireplace(s) is no longer a significant predictor of home sale values for respondents. The remaining significant predictors for property characteristics operate comparative to the multilevel models, with younger, bigger, and sold homes containing a basement associated with higher priced sale values. Though the 
effects of the distance to the nearest RSO are small, it is still a significant predictor for all multivariate models $(b=0.0004, p<.001$ [Model 1]; $b=0.0004, p<.01$ [Model 2]; $b=$ 0.0003, $p<.05$ [Model 3]; $(b=0.01, p<.001$ [Model 4] $)$. Similar to Model 2 of the multilevel analysis and the bivariate analyses, increased selling prices of sold homes were predicted by increased distance to the nearest RSOs.

Homebuyer awareness. Models 1 and 2 assessed whether the relationship between home selling price and the distance to the nearest RSO is moderated by homebuyer awareness of local RSOs. The main effect in Models 1 and 2 was a dummy variable representing homebuyers who are aware and unaware of the nearest RSO within 1,000 feet of their property. The interaction term in Model 2 was homebuyer awareness multiplied by the sample's $(N=277)$ centered distance to the nearest RSO. Awareness models significantly predicted home selling prices, with both Model $1(F[7,277]=56.31$, $p<.001)$ and $2(F[8,277]=49.09, p<.001)$ explaining $59 \%$ of the variance in home selling prices.

After controlling for the property characteristics of the sold homes, homebuyer awareness of local RSOs (main effect) is not a predictor of home sale values in either Model 1 or 2 . The inclusion of the interaction term in Model 2 shows that the relationship between the home selling prices and the distance to the nearest RSO is not different when the homebuyer is aware or unaware after controlling for the property characteristics of the sold homes. Both findings of the main effect and the interaction term endorse the correlation results. Homebuyer awareness of RSOs within a 1,000-foot radius of the homebuyer is not dependent on whether the homebuyer is very close or distant from a 
RSO. Hypothesis \#4 is rejected, as homebuyer awareness had not moderated the relationship between home sale values and the distance to the nearest RSO.

Community type. Models 3 and 4 assessed whether the relationship between home selling price and the distance to the nearest RSO is moderated by the homebuyer's community type. The main effect in Models 3 and 4 was a dummy variable representing non-urban and urban homebuyers who are within a 1,000 feet of their property. The interaction term in Model 4 was the homebuyer's community type multiplied by the sample's $(N=277)$ centered distance to the nearest RSO.

Community type models significantly predicted home selling prices, with both Model $3(F[7,277]=68.52, p<.001)$ and $4(F[8,277]=63.00, p<.001)$ explaining $64 \%$ and $65 \%$ of the variance in home selling prices, respectively. Unlike the main effect of homebuyer awareness, the homebuyer's community type (main effect) was a predictor $(b=0.57, p<.01$ [Model 3]; $(b=0.58, p<.01$ [Model 4]) of home sale values after controlling for property characteristics of sold homes. Compared to an urban homebuyer who resided within 1,000 feet of a RSO of their newly purchased property (Model 3), a non-urban residence predicted a $76.83 \%$ increase in the standard deviation of the selling prices of sold homes. Whereas homebuyer awareness had not exhibited a moderating effect, community type of the homebuyer $(b=-0.00, p<.01)$ does moderate the relationship between home selling prices and the distance to the nearest RSO after controlling for the property characteristics of the sold homes. Hypothesis \#5 is supported, with the effect of the distance to the nearest RSO on home sale prices weaker in nonurban community types and stronger in an urban county. 
Table 16

OLS Regressions of Home Selling Prices with Property Characteristics as Controls, Distance to the Nearest RSO, and Moderators (N = 277)

\begin{tabular}{|c|c|c|c|c|c|c|c|c|c|c|c|c|}
\hline \multirow{3}{*}{ Variables } & \multicolumn{6}{|c|}{ Awareness } & \multicolumn{6}{|c|}{ Community Type } \\
\hline & \multicolumn{3}{|c|}{ Model 1 - No moderator } & \multicolumn{3}{|c|}{ Model 2 - Moderator } & \multicolumn{3}{|c|}{ Model 3 - No moderator } & \multicolumn{3}{|c|}{ Model 4-Moderator } \\
\hline & $b$ & S.E. & $\beta$ & $b$ & S.E. & $\beta$ & $b$ & S.E. & $\beta$ & $b$ & S.E. & $\beta$ \\
\hline Age & -0.01 & 0.00 & $-0.31 * * *$ & -0.01 & 0.00 & $-0.31 * * *$ & -0.01 & 0.00 & $-0.25 * * *$ & -0.01 & 0.00 & $-0.25 * * *$ \\
\hline GLA & 0.00 & 0.00 & $0.44 * * *$ & 0.00 & 0.00 & $0.44 * * *$ & 0.00 & 0.00 & $0.36 * * *$ & 0.00 & 0.00 & $0.36 * * *$ \\
\hline Number of baths & -0.02 & 0.03 & -0.03 & -0.02 & 0.03 & -0.03 & 0.04 & 0.03 & 0.05 & 0.04 & 0.03 & 0.06 \\
\hline Basement & 0.52 & 0.07 & $0.30 * * *$ & 0.52 & 0.07 & $0.30 * * *$ & 0.27 & 0.08 & $0.16^{* * *}$ & 0.25 & 0.08 & $0.15^{* *}$ \\
\hline Fireplace & -0.15 & 0.09 & -0.07 & -0.15 & 0.09 & -0.07 & 0.04 & 0.09 & 0.02 & 0.01 & 0.09 & 0.01 \\
\hline Dist. RSO & 0.00 & 0.00 & $0.14 * * *$ & 0.00 & 0.00 & $0.14 * *$ & 0.00 & 0.00 & $0.09 *$ & 0.00 & 0.00 & $0.20 * * *$ \\
\hline Aware & -0.01 & 0.08 & 0.00 & -0.10 & 0.08 & 0.00 & & & & & & \\
\hline Dist. RSO x Aware & & & & 0.00 & 0.00 & 0.00 & & & & & & \\
\hline Non-Urban & & & & & & & 0.57 & 0.10 & $0.33 * * *$ & 0.58 & 0.10 & $0.34 * * *$ \\
\hline Dist. RSO x Non-Urban & & & & & & & & & & -0.00 & 0.00 & $-0.16 * *$ \\
\hline Constant & 11.03 & 0.15 & $* * *$ & 11.04 & 0.15 & $* * *$ & 10.88 & 0.14 & $* * *$ & 10.73 & 0.15 & $* * *$ \\
\hline$R^{2}$ & .59 & & & .59 & & & .64 & & & .65 & & \\
\hline Adj. $R^{2}$ & .58 & & & .58 & & & .63 & & & .64 & & \\
\hline S.E. & 0.54 & & & 0.54 & & & 0.51 & & & 0.50 & & \\
\hline$F$ & 56.31 & & $* * *$ & 49.09 & & $* * *$ & 68.52 & & $* * *$ & 63.00 & & $* * *$ \\
\hline$d f$ & 7 & & & 8 & & & 7 & & & 8 & & \\
\hline
\end{tabular}

Note. GLA = Gross living area. Reference groups: No basement, no fireplace, unaware of nearest RSO, and urban community type. $* p<.05 . * * p<.01 . * * * p<.001$. 
Figures. Three figures were created to depict how homebuyer awareness and community type operate in the realm of home selling prices and local distances of RSOs after controlling for five property characteristics. In each of the figures, " 0 " represents the average distance to the nearest RSO across the sample of respondents within 1,000 feet of the nearest RSO $(N=277)$. Respondents above " 0 " are residing in recently purchased homes located further than the sample's average distance to the nearest RSO. In contrast, respondents below " 0 " are homebuyers who are below the sample's average distance to the nearest RSO.

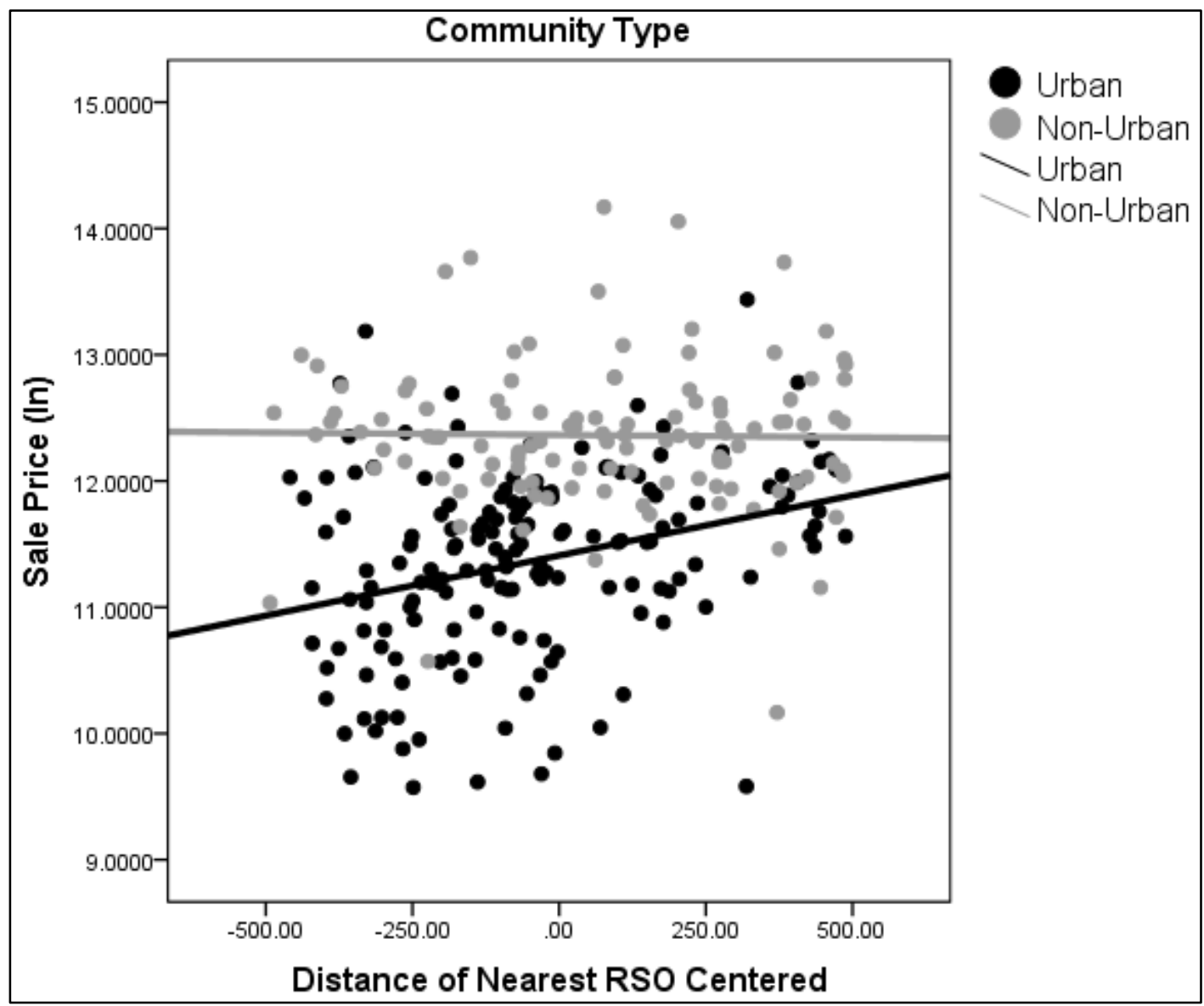

Figure 12. Scatter plot of community type moderating the relationship between home selling prices and the centered distance to the nearest RSO.

Figure 12. Figure 12 illustrates the moderating effect of community type found in the regression analyses (Model 4). The strength of the community type effect is 
dramatically stronger for urban homebuyers (black line), which aligns with the predictive effect of the interaction term in the regression model. Selling prices of homes bought by urban respondents increased as they became more distant from RSOs. In contrast to their urban counterparts, the scatter plot elucidates the weaker effect of community type for non-urban respondents, as the relationship among the charted variables was quite flat. Although counterintuitive, the sale values of homes bought by non-urban respondents (gray line) casually decreased the further they are from the sample's mean distance to the nearest RSO.

Figures 13 and 14. The purposes of Figures 13 (non-urban respondents) and 14 (urban respondents) are exploratory, and to clarify the findings of Figure 12. Figures 13 and 14 depict community types classified by awareness placed onto axes that contain selling prices and the centered distance to the nearest RSO, after controlling for property characteristics. Interests with these figures are to illustrate how unaware non-urban and urban homebuyers, and aware non-urban and urban homebuyers function within the universe of home selling prices and local RSOs.

Figure 13 suggests unaware non-urban homebuyers likely bought homes at random given the inverse relationship of aware non-urban homebuyers. Non-urban homebuyers unaware of RSOs in their immediate area purchased high valued homes nearby RSOs. Unaware non-urban homebuyers may not have factored nearby RSOs in their home buying decision-making process, as they were not informed of the presence of nearby RSOs. It could be possible that had unaware non-urban homebuyers been aware of RSOs around their residence they may have been compelled to negotiate for a lower sale value or purchase homes further away from local RSOs. 


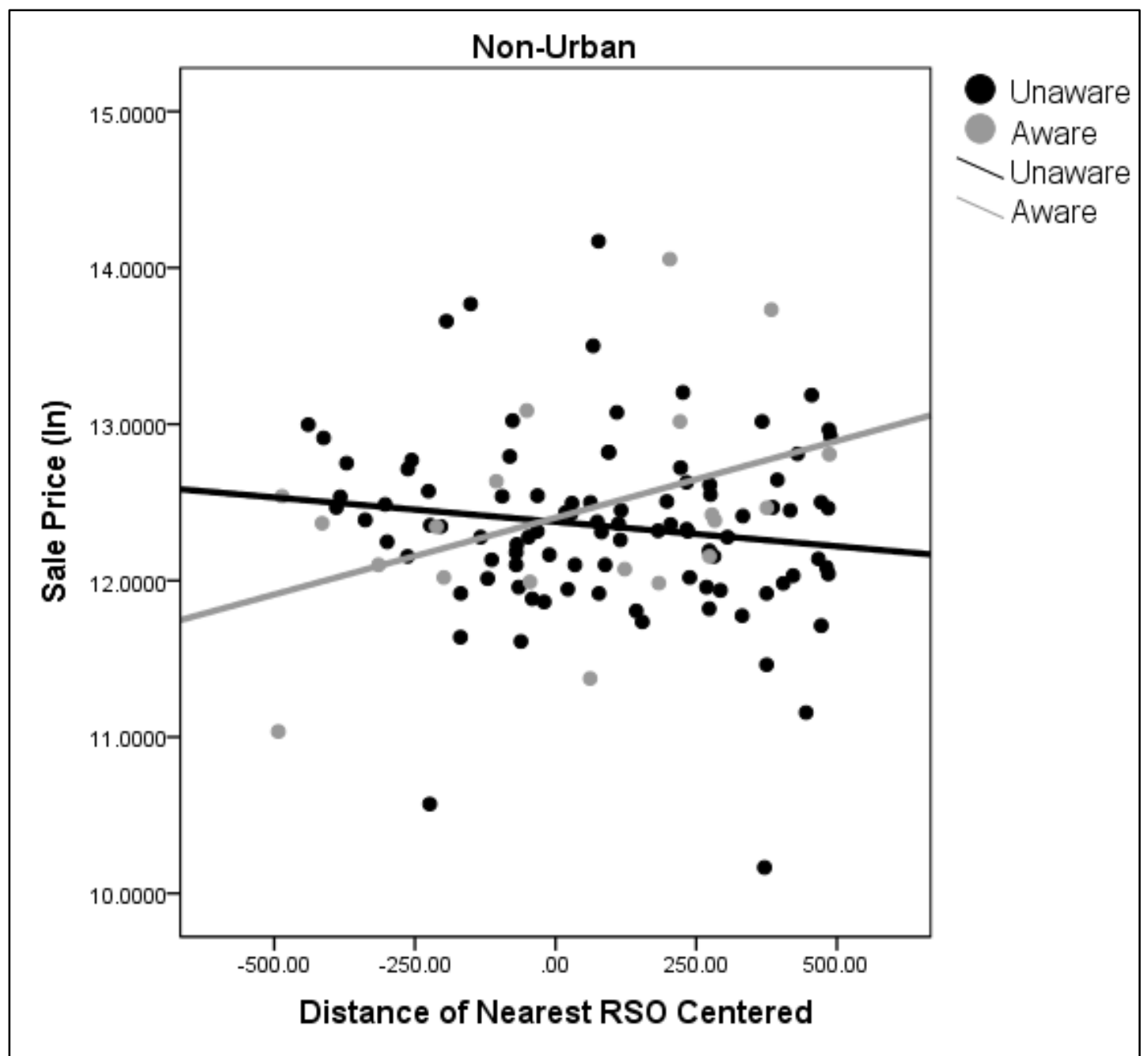

Figure 13. Scatter plot of non-urban homebuyers (classified by awareness) and its relationship between home selling prices and the centered distance to the nearest RSO.

The home buying behaviors of aware (non-urban and urban) homebuyers apply to unaware urban respondents. These three groups of homebuyers bought higher priced homes, which were located further away from RSOs. It could still be that unaware urban homebuyers randomly chose homes like their unaware non-urban homebuyers, but the former group selected homes with high selling prices that happened to be located further away from RSOs.

The suggestions stated about these figures are not definitive conclusions as it is not possible to discern whether homebuyer awareness influenced home-buying decision 
making. It is difficult to disentangle if the decision-making process in home buying was at random or an unwillingness to reside nearby a known RSO. Nonetheless, these moderating relationships possibly captured broader social-ecological factors that were cooccurring within the realm of the real estate market, homebuyer awareness of local RSOs, and the property and neighborhood characteristics of homebuyers and RSOs. The conclusions concerning the role of homebuyer awareness and community type have between home selling prices and the distance to the nearest RSO warrants further research.

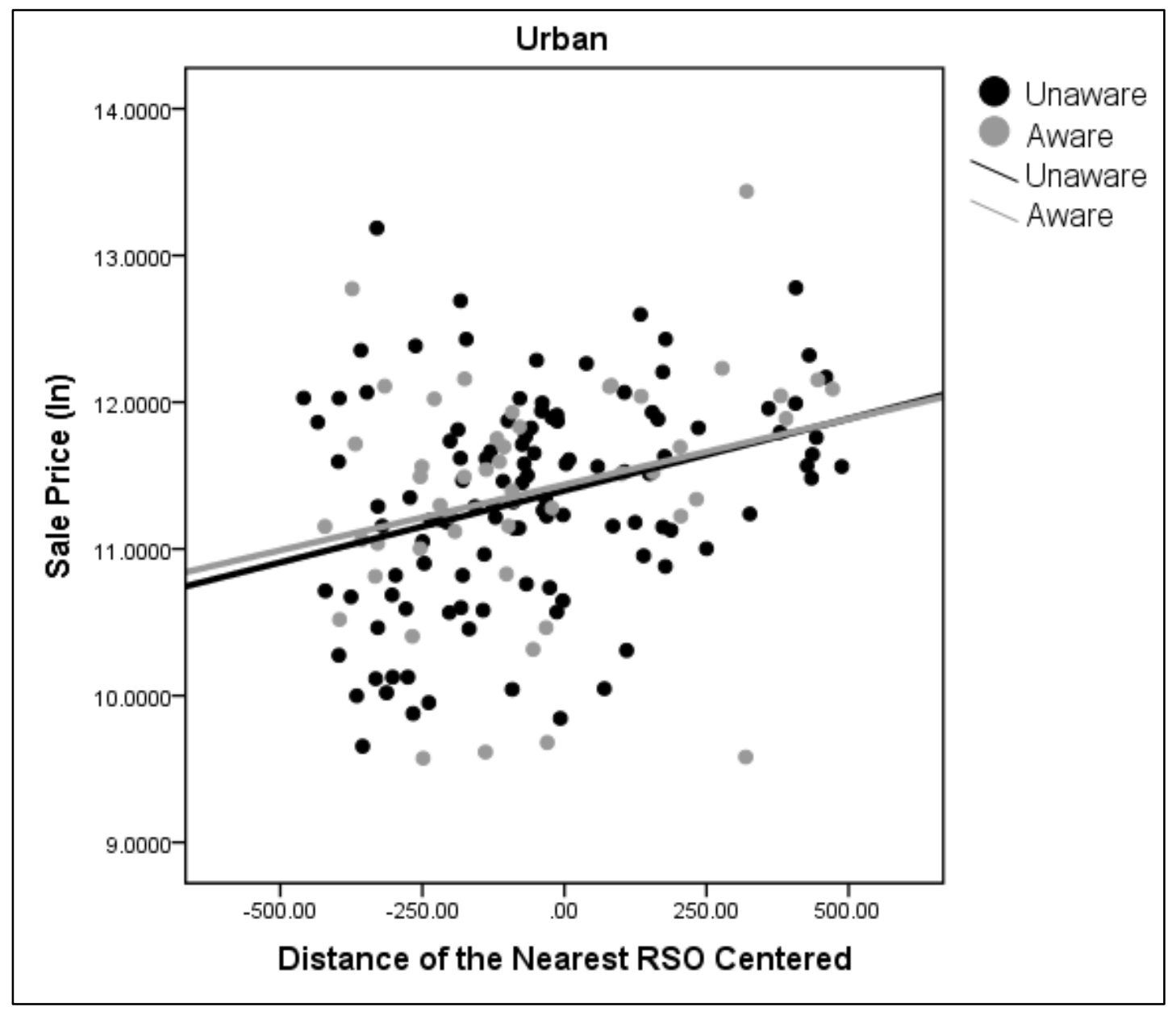

Figure 14. Scatter plot of urban homebuyers (classified by awareness) and its relationship between home selling prices and the centered distance to the nearest RSO. 


\section{Summary of Results}

The spatial multilevel results essentially paralleled with the theoretical framework of social disorganization. A model that strictly included property characteristics showed a relationship to RSOs, but when neighborhood features (accompanied with property characteristics) were incorporated the relationship between RSOs and home sale values dissolved. Environmental aspects considerably augmented the multilevel model and showed the substantial roles like the concentrations of Blacks, impoverished families, persons with higher educations, and community type (i.e., urbanicity) have on the real estate market. Also indicated by the spatial multilevel results were the uninfluential effects of the distance of the nearest RSOs and measures of population turnover onto selling prices of sold homes. Overall, these efforts in a spatial multilevel framework were to address the anticipated model misspecification that results in a model that includes only RSOs and property characteristics, with a wholly different outcome when neighborhood characteristics are amalgamated into the model.

The non-relationship between the distance of the nearest RSO and home sale values in the final spatial multilevel model is likely contributed by homebuyers not being aware of RSOs within 1,000 feet of their newly purchased property. Although residential proximity does not predict homebuyer awareness of local RSOs, the significance of the environment is again highlighted by the homebuyer's community. Like the spatial multilevel results, an urban landscape was linked to higher home selling prices, with urban homebuyers nearly twice as likely to be aware of RSOs within their property's vicinity as non-urban homebuyers. Homebuyers who are aware of local RSOs bought higher priced homes that were also located further away from said RSOs, with unaware 
homebuyers not revealing a definitive pattern among the universe of the distance of the nearest RSO and home sale values, suggesting home buying decisions were made without consideration of local RSOs.

More broadly, these results have captured how communities function within the context of sex offender policies. The contents within communities revealed themselves as strong influences on home sale values with property characteristics being lesser contributors to home sale values. Often linked with unfavorable neighborhood conditions are RSOs. However, RSOs likely do not carry the same weight when compared to the examined neighborhood characteristics. Therefore, it is logical to suggest that RSOs are not considered as an ingredient in the decision-making process of home buying. Most poignant, these results question the goals of policies that mandate tracking RSOs and need to be revisited.

Table 17

Summary of Hypotheses and Findings

\begin{tabular}{|l|l|}
\hline Hypothesis & Finding \\
\hline $\begin{array}{l}\text { Distance to the nearest RSO is associated with home sale values after } \\
\text { controlling for property-level characteristics. }\end{array}$ & Supported. \\
\hline $\begin{array}{l}\text { Distance to the nearest RSO is not associated with home sale values after } \\
\text { controlling for property-level and neighborhood-level characteristics } \\
\text { (including spatial dependence). }\end{array}$ & Supported. \\
\hline $\begin{array}{l}\text { Non-urban homebuyers are more aware of RSOs within 1,000 feet of their } \\
\text { property than urban homebuyers. }\end{array}$ & Rejected. \\
\hline $\begin{array}{l}\text { Homebuyer awareness of RSOs within 1,000 feet of their recently } \\
\text { purchased properties will moderate the relationship between home selling } \\
\text { prices and the distance to the nearest RSO, after controlling for the sold } \\
\text { homes' property characteristics. }\end{array}$ & Rejected. \\
\hline $\begin{array}{l}\text { The homebuyer's community type will moderate the relationship between } \\
\text { home selling prices and the distance to the nearest RSO within 1,000 feet } \\
\text { of their recently purchased property, after controlling for the sold homes' } \\
\text { property characteristics. }\end{array}$ & Supported. \\
\hline
\end{tabular}




\section{CHAPTER VI}

\section{DISCUSSION}

In the context of the social disorganization theory, the central premise of the current study was to clarify the contradiction of how RSOs are related to depressed home selling prices (Bian et al., 2013; Caudill et al., 2014; Larsen et al., 2003; Linden \& Rockoff, 2008; Navarro \& Rabe-Hemp, 2017; Pope, 2008; Wentland et al., 2014). When, at the same time, the public is grossly unaware of local RSOs (Anderson \& Sample, 2008; Beck \& Travis, 2006; Burchfield, 2012; Craun, 2010; Kernsmith, Comartin, et al., 2009; Lieb \& Nunlist, 2008; Phillips, 1998). A paradoxical outcome because lowered home sale values should reflect feelings of contempt toward RSOs by the public.

In extending the current sex offender and housing literature, the first half of the study focused on the methodological flaws that may have misattributed the presence of RSOs to home sale values. Briefly, RSOs are not associated with home selling prices in a spatial multilevel framework. The inclusion of observable neighborhood characteristics, including spatial dependence and urbanicity, yielded an outcome that indicated RSOs are no longer an influential variable onto home sale values. The caveat is that RSOs are related to home sale values when only property characteristics are incorporated into the equation. 
Ideal in describing the real estate market within localities (Brown \& Uyar, 2004), multilevel models were not used as analytical approaches in prior RSO-home sale value research. Although neighborhood fixed effects or characteristics were used on occasion (Pope, 2008; Yeh, 2015), it disallowed for the estimation of observable neighborhood characteristics. Without the inclusion of observable neighborhood characteristics, erroneous conclusions may have resulted in the RSO-home sale value literature. There simply was no assessment of the underlying effects tied with neighborhood dynamics alongside the presence of RSOs (Agan \& Prescott, 2014; Bitter et al., 2007). Incorporation of neighborhood characteristics is especially crucial in a cross-sectional examination as they can explain a significant portion of the variance (Archer et al., 2010) as it did in the present study. Overall, spatial multilevel findings are in alignment with the premise of Shaw and McKay's (1942) theoretical foundation of social disorganization theory, which is that social-ecological interactions in a neighborhood are substantially influential in predicting home sale values.

Multilevel findings are mixed within the framework of Shaw and McKay's social disorganization theory. Neighborhoods with greater Black populations and impoverished families yielded one of the strongest neighborhood influences to decreased home sale values. These findings agreed with the foundation of Shaw and McKay's (1942) argument that neighborhoods with higher rates of minorities and poverty were also related to greater indicators of undesirable conditions. The argument of minorities being a negative neighborhood feature was not all encompassing. Equally as strong of a neighborhood effect, greater neighborhood populations of foreign-born persons increased 
sale values. Additionally, and albeit a weaker effect, greater populations of Hispanics were associated with higher selling prices of sold homes.

In contrast to Shaw and McKay's (1942) theoretical outline concerning population turnover, indicators of residential stability were not influential on home selling prices. Sale values of sold homes were consistently not related to the percentage of the neighborhood populations that resided at their residence for a year or more and the percentage of housing units. Emerging housing literature has commented on that renteroccupied housing are indicative of an urban community (Troy \& Grove, 2008), with such housing units stimulants of higher property values in the surrounding areas (Archer et al., 2010). Given the unforeseen effects of an inverse relationship between indicators of residential stability, it serves as a warning of the construction of structural characteristics of neighborhoods as it may convolute the contribution per characteristics as evident of female-headed households.

The banishment of RSOs into socially disadvantaged communities (see Table 1) is one reaction that is related to the public's contempt toward stigmatized persons. RSOs in Illinois and Kentucky are likely to reside in disadvantaged areas (Burchfield \& Mingus, 2008; Hughes \& Burchfield, 2008; Mustaine \& Tewksbury, 2008; Mustaine et al., 2006a, 2006b; Navarro \& Rabe-Hemp, 2017; Socia \& Stamatel, 2012; Suresh et al., 2010; Tewksbury \& Mustaine, 2008; Tewksbury et al., 2016; Tewksbury et al., 2007). Further, it is the fact that RSOs are more likely to live in disadvantaged areas, and when neighborhood characteristics are not accounted for in models, it appears that the presence of RSOs depresses home sale values. This study reveals that the relationship is essentially spurious — once neighborhood characteristics are considered-RSOs no longer influence 
home sale prices. The dangers of not including neighborhood characteristics are evident for variables such as education. The greater the neighborhood populations of persons with a Bachelor's degree or higher resulted in a consistently strong, positive effect on home sale values.

Another form of banishment is legally endorsing relocations of RSOs out of main urban locations (Berenson \& Appelbaum, 2011; Chajewski \& Mercado, 2009; see Huebner et al., 2013; see also Socia, 2011, 2012a; Zandbergen \& Hart, 2006). In accordance with Ingram and Franco's (2014) rural-urban classification scheme, not one RSO-home sale value researcher explored a non-urban area. The present study used this classification scheme as a guide to select a rural, suburban, and urban county. Regardless of these labels, the degree of urbanicity varies within each of these settings. The introduction of urbanicity as a neighborhood characteristic allowed for home sale values to operate across a spectrum of neighborhoods that ranged from rural to urban. Of all of the neighborhood characteristics, urbanicity yielded the strongest predictor of home sale values, with urban-based homes associated with higher selling prices.

The spatial distribution of sold homes indicated sale values are affected by the larger geographic environment, and that space matters in explaining the real estate market. Home sale values are inherently affected by spatial dependence (things close to one another are more related), which gives rise to the likelihood that spatial autocorrelation (observations correlated with one another in a spatial dimension) exists among sale values because of shared property and neighborhood characteristics (Dubin et al., 1999). By not accounting for the spatial autocorrelation that was present in each of the examined U.S. counties, the effects of the characteristics within a model are likely to 
be influenced in an imprecise manner (Anselin, 2005; Kubrin \& Weitzer, 2003), as demonstrated in Caudill et al. (2014) attenuated effects of RSOs onto sale values. The multilevel estimates of spatial dependence showed non-relationships to home sale values. Here, the spatial structure was explained by the introduction of neighborhood effects and contributed to an understanding of the spatial structures of each county.

With an emphasis on policy implications, the second half of the study examined homebuyer awareness of RSOs near their recently purchased house. One-in-four homebuyers were aware of RSOs within a 1,000-foot radius of their recently purchased home. The lowest rate of homeowner awareness of local RSOs so far reported in the relatable literature (Anderson \& Sample, 2008; Burchfield, 2012; Craun, 2010; Kernsmith, Comartin, et al., 2009; Lieb \& Nunlist, 2008; Phillips, 1998).

These low rates of awareness are causes for concern. First, these homebuyers recently purchased sold homes. The presumption is that these sampled homeowners informed themselves about the surroundings of their new residence. Second, only homebuyers constrained within 1,000 feet (or 305 meters) of the nearest RSO were surveyed. For a barometer, Craun (2010) reported nearly one-in-three homeowners (31\%) within one-tenth of a mile ( 528 feet) of the nearest RSO were aware of his/her presence in a county that exercises passive notification. The ratio of homebuyers who are aware of RSOs within 1,000 feet does not change when the distance boundary is altered to onetenth of a mile (24.9\% and $26.7 \%)$. Third, contributing to a low rate of homebuyer awareness of RSOs may not be on the resident, but the actual precedent of passive notification strategies practiced in Illinois and Kentucky (Beck \& Travis, 2006). 
When the sample of homebuyers disaggregates by community type, urban homebuyers were twice more likely to be aware of RSOs nearby their houses than nonurban homebuyers. Substantiating RSOs' beliefs that urban environments had led to a greater exposure of their offender status (Tewksbury \& Mustaine, 2010). It could be that the population density of Jefferson County influenced an increase in the awareness of local RSOs. Lending credence to Anderson et al. (2009), who argued urban residents are more likely to encounter persons at a greater rate than rural residents (in their respective environments), and in turn, a greater curiosity of the sexual histories of persons near them.

As one of the many contributions of the present study, urban homebuyer awareness of nearby RSOs was in direct contradiction of Phillips' (1998) findings of Washington residents nearly twenty years ago, who found rural community members are more likely to be aware of local RSOs than urban community members. Rural homebuyers in the sample were the least aware of local RSOs, followed by suburban homebuyers, with the most aware homebuyers deriving from an urban county. Quite a paradox, given that rural residents, held a greater fear of being sexually victimized than urban residents (Brown et al., 2008). Logically, a greater held fear of victimization should lead to a greater awareness of (registered sex) offenders nearby one's residence. In support of Tewksbury et al. (2007) untested opinion, rural-based RSOs must not be mistaken in their belief as rural environments do offer greater anonymity. Like rural homebuyers, non-urban homebuyers continued to be lower than anticipated. The present study's ratio of one-in-six homebuyers (17.4\%) was far less than Burchfield's (2012) one-in-three non-urban homeowners who were aware of local RSOs (29\%). 
Survey respondents shed additional light on the processes of how homebuyer awareness and homebuyer community type function within the sphere of home sale values and distance to the nearest RSO. Craun's (2010) data demonstrated that homeowner awareness of local RSOs is dependent on the distance to RSOs, with homeowners within one-tenth of a mile more aware of nearby RSOs than their distant counterparts. Although counterintuitive, homebuyer knowledge of nearby RSOs is not related to their residential proximity, which suggests that homebuyers are discovering the presence of local RSOs via alternative methods other than residing near a RSO. It is also indicative that homebuyers may not be capitalizing on the privileges afforded to them by accessing publically available (online) sex offender registries established by Megan's Law. Nor did the relationship between sale values and RSOs depend on whether the homebuyer was aware or unaware of nearby RSOs.

Although no moderation effect was evident between awareness and the distance to the nearest RSO, the moderating effect of community types, on the other hand, perhaps captured several other ecological dynamics that are co-occurring - real estate market, RSO, community type, and homebuyer's neighborhood characteristics. For instance, RSOs are pushed away from affluent and urban communities (Chajewski \& Mercado, 2009; Clark \& Duwe, 2015; Hipp et al., 2010; Hughes \& Burchfield, 2008; Hughes \& Kadleck, 2008; Mustaine \& Tewksbury, 2011b; Mustaine et al., 2006a, 2006b; see Burchfield \& Mingus, 2008; Sloas et al., 2012; Socia, 2012a; Tewksbury et al., 2016). Disadvantaged communities do not contain the same meaningful social resources like affluent communities in order to push out RSOs who are linked as disruptors of the social-ecological homeostasis of communities (Clark \& Duwe, 2015; Hughes \& 
Burchfield, 2008; Hughes \& Kadleck, 2008). Urban-based RSOs have been relegated to neighborhoods markedly characterized by disadvantaged features unlike their non-urban based RSOs. In support, urban respondents were located in neighborhoods with nearly sevenfold the percentage of Black populations (25.05\% vs. 3.64\%) and roughly 2.5 times the percentage of impoverished family populations ( $16.74 \%$ vs. $6.66 \%)$. These are the same two neighborhood characteristics that exhibited strong, negative effects on home sale values in the multilevel models. The significance of

The highest valued sold homes were located the furthest away from RSOs, with exception to the unaware non-urban group. Although the latter comment might be trivial, consider that RSOs seek refuge in "cheaper" areas as they are pushed away from urban areas (multilevel analyses determined urban-based sold homes are the most expensive) because living expenses are more affordable in non-urban areas (Berenson \& Appelbaum, 2011; Chajewski \& Mercado, 2009; Huebner et al., 2013; see Socia, 2011, 2012a; see also Socia et al., ,2015; Zandbergen \& Hart, 2006). It could also be that aware non-urban and urban homebuyers possibly conceded to higher valued sold homes to reside further from RSOs, likely linked to the mere action that they could afford this decision-making process. Unaware non-urban and urban homebuyers selected sold homes at random or were financially forced to reside nearby RSOs. The latter group of residents who are unaware of local RSOs may consequently be residing in neighborhoods that are not prepared to inform others adequately about the presence of RSOs (Zevitz, 2004).

\section{Policy Implications and Recommendations}

The findings paint a picture that sex offender policies may not be beneficial to any population. Complicating the lives of all entities and persons involved, including the 
criminal justice system, the RSOs who are now stigmatized persons, and vulnerable populations. The stringent legal requirements imposed on RSOs that have stimulated (or at a minimum, associated with) a socioeconomic decline across neighborhoods, with the results suggesting revisiting the legal implementation and its (potential) ramifications.

Does increased awareness of local RSOs (who by the way rarely tend to recidivate [Elbogen et al., 2003; Levenson et al., 2007b]) result in any meaningful product? The central premise of Megan's Law is to notify the public the identities and residences of RSOs in communities (Zevitz, 2004); although the study's findings indicate that, its implementation is counterproductive. Because an endorsement of misconceptions like RSOs are recidivistic criminals (Evans \& Cubellis, 2015; Elbogen et al., 2003; Levenson et al., 2007b; Prescott \& Rockoff, 2011; Sperber et al., 2010), should lead to a greater likelihood that residents are aware of the presence of RSOs in their vicinity. However, that is far from the truth as the general public is unaware of RSOs in their communities (Anderson \& Sample, 2008; Beck \& Travis, 2006; Burchfield, 2012; Craun, 2010; Kernsmith, Comartin et al., 2009; Lieb \& Nunlist, 2008; Phillips, 1998).

Sex offender registries are designed to encourage public awareness of RSOs (Levenson et al., 2007a; Mustaine \& Tewksbury, 2013), even though it appears to be an ineffective manner to publicize RSO information given the low rates of homebuyer awareness. Community members are unable to engage effectively in protective behaviors because they have not adequately informed themselves about nearby RSOs (Levenson et al., 2007a; Levenson \& Cotter, 2005). Though, members of the community should be more concerned about the potential sexual victimization conducted by family members as opposed to strangers (Colombino et al., 2011; Maguire \& Singer, 2011). 
By increasing the punitiveness of sex offender policies it has worsened the situations of RSOs by relocating offenders into disadvantaged, vulnerable, and/or rural communities (Chajewski \& Mercado, 2009; Clark \& Duwe, 2015; Hipp et al., 2010; Mustaine et al., 2006a, 2006b; Sloas et al., 2012; Socia, 2012a; Tewksbury et al., 2016). In turn, the conditions imposed onto RSOs may encourage recidivism often cited by scholars (Burchfield \& Mingus, 2014; Evans \& Cubellis, 2015; Elbogen et al., 2003; Levenson et al., 2007b; Prescott \& Rockoff, 2011; Sperber et al., 2010). Forced social isolation of stigmatized persons - in this case, RSOs—are unhealthy tactics to take into action for offenders who have begun their reentry into a society already socially handicapped (Goffman, 1963; Huebner et al., 2013; Hughes \& Burchfield, 2008; Zevitz $\&$ Farkas, 2000b).

\section{Limitations}

Limitations in the present study encompass four elements: housing data, sex offenders, surveys, and geography. Encapsulated among these three limitations is that the data presented a cross-sectional look at the influence of RSOs on home sale values of three U.S. counties. Thus, causality cannot be inferred from the results due to the nature of cross-sectional studies.

Housing. Heterogeneity of variances among the home sale values within each cluster may have been present. In other words, although Figures 2, 3, and 4 illustrated the data's home sale values paralleled with the census block groups' median household values, it could be that that the data contained extreme scores that coincidentally amounted to the census block groups median household value. The property characteristics of homes used in the model may not have wholly captured the conditions 
of sold homes. As suggested by Larsen et al. (2003), perhaps the external color of the sold home presented a strong enough negative connotation to influence negatively onto the home sale value. It must be understood though that these markers of housing condition would have been subjective perceptions of sold homes, used as a comparison across multiple counties, and an uncommon feature observed in previous RSO-home sale value research (Bian et al., 2013; Caudill et al., 2014; Larsen et al., 2003; Navarro \& Rabe-Hemp, 2017; Pope, 2008; Wentland et al., 2014).

Sex offenders. Results may suffer from temporal incongruity. Residential data of Kentucky RSOs were based on 2016 data, but sale data for residential properties for all counties under examination were based on the year 2015. Regardless of this temporal gap, it is still uncertain whether RSOs were remotely present as neighbors during the time of the selling period of the data's residential properties. It must also be considered that the effect of RSOs on home sale values is temporary (Pope, 2008; see Congdon-Hohman, 2013), with transient RSOs not associated with depressed home sale values (Yeh, 2015).

RSOs were not disaggregated by distinguishing features. For instance, all registrants were collapsed into one group and not separated by classification. ${ }^{40}$ RSOs were not explored for their associations based on classification because registration implementation policies are dubious (CSG, 2010; Ragusa-Salerno \& Zgoba, 2012; Sperber et al., 2010). It might explain why previous RSO-home sale value research reported mixed results whether a more "dangerous" RSO are associated with greater depressions in home selling prices (Larsen et al., 2003; Navarro \& Rabe-Hemp, 2017;

\footnotetext{
${ }^{40}$ The state of Illinois implements a four-tier RSO classification system (sex offender, sexual predator, sexually dangerous person, sexually violent person). The state of Kentucky had exercised a three-tier RSO classification system (10-year [low-risk], 20-year [moderate-risk], \& lifetime registration) but is currently a dichotomy (20-year \& lifetime registration).
} 
Pope, 2008; Wentland et al., 2014). The public's concerns may also contribute mixed results are greater regarding the stigma associated with the label of being a sex offender rather than their classification category (Mustaine \& Tewksbury, 2011a). In support, high-risk RSOs (as determined by a risk-assessment instrument) did not encourage a greater adoption of self-protective behaviors by community members, which lent credence that the public does not differentiate RSOs by their status (Bandy, 2011). Further, sold homes were not classified by their distance to the nearest RSO as previous RSO-home sale value research, which found that the effect of RSOs varies by certain distances (Caudill et al., 2014; Larsen et al., 2003; Linden \& Rockoff, 2008; Pope, 2008; Wentland et al., 2014).

The presence of additional RSOs was not considered. Clusters of RSOs have been regarded as a form of social disorder because its presence resulted in the same pattern of neighborhood decline as other forms of physical and social disorder (Gordon, 2013). The present study was a stepping-stone to explore whether the nearest RSO to a sold home was associated with home selling prices in a spatial multilevel framework. However, the presence of clusters of RSOs could have influenced the direction of and effect onto the sale values of sold homes and homebuyer awareness of local RSOs.

A concentrative effect may have been exhibited by RSOs who resided in apartments, who themselves create a geographic dilemma. The distance from the street to RSOs' apartment may vary, as offenders must navigate themselves (e.g., elevator) to the street (Leipnik et al., 2016). Researchers may consider it geographically sound to remove RSOs who reside in apartments from their sample. Further, a substantial loss may not occur if intending on removing RSOs who reside in apartments as more than three- 
quarters of RSOs (78\%) do reside in single-family households, at least in Seminole County, Florida (Tewksbury \& Mustaine, 2006).

Surveys. An overall response rate of 12.5 percent is low. Comparable in research design, Craun's (2010) response rate of 45 percent of surveys gauging homeowner awareness of RSOs is substantially higher than the present study's overall response rate. What may have compromised the overall response rate was the mailing of postcards in the second wave that served as reminders to homebuyers to respond to the surveys. The third wave following the mailing of postcards resulted in higher response rates, which endorsed the notion that postcards with a web link to an online-based survey may not be an ideal alternative. At the same time, postcards may have also elevated the response rates of the initial wave.

A response bias may have occurred that affected homebuyer awareness of local RSOs. It is unlikely then that persons from marginalized groups (e.g., elderly, poor, uneducated) responded, as they may have felt undervalued (Green, 1996). Persons who tend to respond to surveys are likely to be of middle-class rather than those from the lower- or upper-classes as the latter groups have their reservations regarding their values.

Rural homebuyers were collapsed to reflect non-urban homebuyers. In doing so, the rural landscape's awareness of local RSOs was not truly captured. However, the amalgamation with suburban homebuyers was not detrimental to the overall non-urban rates of awareness due to similar awareness rates.

The receipt and questions of the survey may have inspired homebuyers to check the online sex offender registry. Alternatively, homebuyers may not have been familiar with the presence of the nearby RSOs until after they moved into their new residence. In 
which case, local RSOs had not dictated their relocation. Temporal incongruity is present with the receipt of the survey in 2017, which is roughly within a two-year period of the homebuyer moving into their house sometime in 2015.

Geography. There may be measurement error in the spatial procedures implemented. Street geocoding (versus parcel geocoding) may have yielded a larger geographic placement error resulting in less accuracy and reliability (Zandbergen \& Hart, 2009). The incorrectly geocoded location of a RSO typically resulted in the incorrect placement along the correct street, in which cannot be ameliorated by improved address cleaning. For instance, positional error increases when street segments were longer. Comparatively, address geocoding is more accurate in urban areas than in the countryside (Cayo \& Talbot, 2003). Regardless of these results, it can be argued that geocoding processes have improved since these publications.

Rather than point data, parcel polygons may have been a better alternative to computing the distance analyses between the residences' of homebuyers and RSOs (see Zandbergen \& Hart, 2009; Socia, 2011). Distance violations are determined by the length of the boundary lines of a proscribed venue and the residence of RSOs. Using the same logic, it may have been preferred to compute the distance analyses as such, but this was not possible as it the data were not in a polygon format.

Although several spatial weights were considered, Anselin (2002) concluded that there is no one ideal spatial weight matrix. Each spatial weight matrix has their strengths and weakness. A queen's contiguity may not be methodologically reasonable (especially in the rural landscapes of all counties) as larger census block groups may be adjacent to another census block group, but the homes' are located miles away from each other-and 
also not possible with points. Future research should align with Caudill et al. (2014), who also explored the relationship between home sale values and the distance to RSOs, but with a spatial weight matrix that considered the two nearest neighbors.

\section{Future Research}

There are still additional notes for assessments of the relationship between neighborhoods and the presence of RSOs. Explorations of the present study's research agenda should be applied to other U.S. states to identify if the same ecological dynamics occurred in other jurisdictions and increased generalizability.

Sex offender registries do not disaggregate RSOs by ethnicity, specifically, whether the offender was of Hispanic or Latino descent - at least in the registries of Florida (Ackerman \& Furman, 2013), Illinois (Socia \& Stamatel, 2012), and Kentucky. It would be of interest whether Hispanic or Latino RSOs were associated with selling prices, in light of the increase in sale values associated with neighborhoods associated with greater populations of foreign-born person and Hispanics. Hispanics/Latinos are severely undercounted in the criminal justice system as they are often collapsed as being

White (Urban Institute, 2016). Such a practice not only short changes the largest minority population in the U.S., but also masks the disparity between Blacks and Whites as well as promotes ineffective policy reformation toward this ethnic group.

Additional efforts in a multilevel approach can address a multitude of analyses. Cross-level interactions can explore how neighborhoods with dense Black or White populations moderate the relationship between home sale values and RSOs. The clustering effects of RSOs can ascertain whether RSOs do have an influential effect on home selling prices, but it is only evident when a certain number of RSOs are present 
(see Bian et al., 2013). Future researchers compelled to compute a concentration rate should take the count of RSOs within a particular distance (e.g., one-tenth of a mile) that is then divided by the number of households per neighborhood (e.g., the number of RSOs/number of households per block group *100).

Aside from these neighborhood characteristics, additional neighborhood characteristics should be considered to explore potential interactions between neighborhoods with and without RSOs. Although it was outside the purposes of the present study, future scholars should explore the effect of certain indices (e.g., concentrated disadvantage index) that are theoretically aligned with the social disorganization theory. The primary reason as to the exploration of the effects of nonaggregated neighborhood characteristics is due to the potential divergent outcomes of each neighborhood characteristic on home sale values, as evident in the present study. As neighborhood characteristics have not yet been considered in RSO-home sale value research, the aggregation of neighborhood characteristics into indices may have diminished the importance and muddled the effects of neighborhood characteristics onto home sale values when considering the effect RSOs.

The research of moderators can then be addressed in multilevel models, with neighborhoods represented by larger geographic units like census tracts. Additional assessments for the moderating effects of homeowner awareness of nearby RSOs can also include the effect of the ethnicity and/or race of the RSO. As proximity to RSOs does not influence homebuyer awareness of RSOs, it could be that the level of informal social control or access to the sex offender registry affected homebuyer awareness. Support for 
the former cements the significance of neighborhood dynamics, whereas the latter touches upon the effectiveness of sex offender policy.

How the survey procedures operated across community type deserves additional research. The present study's urban sample of homebuyers made has been influenced to respond in greater rates because one it was within the sampled urban setting. To minimize such a response bias, survey research should be conducted in settings that would not elicit such a bias to clarify Green's (1996) mixed findings concerning response rates of each setting. Additional research should also assess whether postcards marked with web links to surveys are a worthy method to increase response rates in contemporary society given the omnipresence of the Internet. Regardless of the omnipresence of the Internet in contemporary society, it may be that potential respondents prefer the traditional hard copy for survey research.

The sex offender literature should refrain from census tracts as a geographic unit. Tracts are far too large of a geographic area to encapsulate the social fabric of an environment and can obscure the structural aspects within that geographic unit. Rather, sex offender scholars adhere to smaller geographic units like census block groups as it can provide a much more refined picture of the subtle socio-ecological nuances inherent in neighborhoods (Coulton et al., 2004; Hipp, 2007; see Cho et al., 2006; Socia, 2011, 2012a).

Mentioned as a limitation in the present study, future scholars should address heterogeneity in the home sale values within groups. The range of the home sale values may have reported diverse differences that coincidentally achieved a comparable value to 
the census' median household value. Non-uniform home sale values lead to issues in summarizing the meaning of the results.

\section{Conclusion}

The methodological approaches in the multilevel modeling framework captured the environmental essence of social disorganization theory. Once neighborhood characteristics were taken into account, the presence of RSOs did not affect home sale values. The social-ecological effects of RSOs in communities were also demonstrated by how residents of various community types varied in their awareness of nearby RSOs. It is possible that contributions to this non-relationship were that homebuyers are largely unaware of local RSOs. At the same time, homebuyers who were aware of RSOs purchased higher valued homes that were also located further away from RSOs. These findings ultimately question the legitimacy and ramifications of sex offender policies inspired by an American cultural zeitgeist to tackle the concerns of sex offenders. The idiom, out of sight, out of mind, wholly captures the crux of the study's findings, as legal constraints placed onto RSOs assisted in the public's endeavors to push RSOs to the fringes of societal belongingness due to their stigmatized status. 


\section{REFERENCES}

Abdullah, A., Marzbali, M. H., Woolley, H., Bahauddin, A., \& Maliki, N. Z. (2014). Testing for individual factors for the fear of crime using a multiple indicatormultiple cause model. European Journal on Criminal Policy and Research, 20(1), 1-22. doi: 10.1007/s10610-013-9208-4

Ackerman, A. R., \& Furman, R. (2013). An analysis of Latino male immigrant sex offenders in Florida: The impact of national solutions on a transnational problem. Estudios Fronterizos, 14, 35-50.

Agan, A. Y., \& Prescott, J. J. (2014). Sex offender law and the geography of victimization. Journal of Empirical Legal Studies, 11, 784-828.

Anderson, A. L., Evans, M. K., \& Sample, L. L. (2009). Who accesses the sex offender registries? A look at legislative intent and citizen action in Nebraska. Criminal Justice Studies, 22, 313-329. doi: 10.1080/14786010903167096

Anderson, A. L., \& Sample, L. L. (2008). Public awareness and action resulting from sex offender community notification laws. Criminal Justice Policy Review, 19, 371396. doi: 10.1177/0887403408316705

Anselin, L. (1995). Local indicators of spatial association-LISA. Geographical Analysis, 27, 93-115.

Anselin, L. (2002). Under the hood: Issues in the specification and interpretation of spatial regression models. Agricultural economics, 27, 247-267. 
Anselin, L. (2005). Exploring spatial data with GeoDa: A workbook. Urbana, IL: Luc Anselin.

Anselin, L., Syabri, I., \& Kho, Y. (2006). GeoDa: An introduction to spatial data analysis. Geographical Analysis, 38, 5-22.

Anselin, L., Cohen, J., Cook, D., Gorr, W., \& Tita, G. (2000). Spatial analysis of crime. In D. Duffee, D. McDowall, L. Mazerolle, \& S. Mastrofski (Eds.) Measurement and analysis of crime and justice (Vol. 4, pp. 213-262). Washington, DC: National Institute of Justice.

Archer, W. R., Ling, D. C., \& Smith, B. C. (2010). Ownership duration in the residential housing market: The influence of structure, tenure, and household and neighborhood factors. The Journal of Real Estate Finance and Economics, 40, 4161. doi: 10.1007/s11146-008-9126-2

Austin, D. M., Furr, L. A., \& Spine, M. (2002). The effects of neighborhood conditions on perceptions of safety. Journal of Criminal Justice, 30, 417-427.

Bachman, R. D., \& Schutt, R. K. (2016). The practice of research in criminology and criminal justice ( $6^{\text {th }}$ ed.). Los Angeles, CA: Sage Publications.

Bandy, R. (2011). Measuring the impact of sex offender notification on community adoption of protective behaviors. Criminology \& Public Policy, 10, 237-263. doi: $10.1111 / \mathrm{j} .1745-9133.2011 .00705 . \mathrm{x}$

Barnes, J. C., Dukes, T., Tewksbury, R., \& De Troye, T. M. (2009). Analyzing the impact of a statewide residence restriction law on South Carolina sex offenders. Criminal Justice Policy Review, 20, 21-43. doi: 10.1177/0887403408320842 
Beck, V. S., \& Travis, L. F., III. (2004). Sex offender notification and fear of victimization. Journal of Criminal Justice, 32, 455-463. doi: 10.1016/j.jcrimjus.2004.06.007

Beck, V. S., \& Travis, L. F., III. (2006). Sex offender notification: An exploratory assessment of state variation in notification processes. Journal of Criminal Justice, 34, 51-55. doi: 10.1016/j.jcrimjus.2005.11.005

Berenson, J. A., \& Appelbaum, P. S. (2011). A geospatial analysis of the impact of sex offender residency restrictions in two New York counties. Law and Human Behavior, 35, 235-246. doi: 10.1007/s10979-010-9235-3

Bian, X., Brastow, R., Waller, B., Stoll, M., \& Wentland, S. (2013). Neighborhood tipping and sorting dynamics in real estate: Evidence from the Virginia sex offender registry. Social Science Research Network. Retrieved from http://papers.ssrn.com/sol3/papers.cfm?abstract_id=2338223

Bichler, G., \& Balchak, S. (2007). Address matching bias: Ignorance is not bliss. Policing: An International Journal of Police Strategies and Management, 30, 3260. doi: 10.1108/13639510710725613

Bitter, C., Mulligan, G. F., \& Dall'erba, S. (2007). Incorporating spatial variation in housing attribute prices: A comparison of geographically weighted regression and the spatial expansion method. Journal of Geographical Systems, 9, 7-27. doi: 10.1007/s10109-006-0028-7

Brennan, M., \& Charbonneau, J. (2009). Improving mail survey response rates using chocolate and replacement questionnaires. The Public Opinion Quarterly, 73, 368-378. doi: 10.1093/poq/nfp030 
Brown, S., Deakin, J., \& Spencer, J. (2008). What people think about management of sex offenders in the community. The Howard Journal, 47, 259-274. doi: 10.1111/j.1468-2311.2008.00519.x

Brown, K. H., \& Uyar, B. (2004). A hierarchical linear model approach for assessing the effects of house and neighborhood characteristics on housing prices. Journal of Real Estate Practice and Education, 7, 15-23.

Brunton-Smith, I., \& Sturgis, P. (2011). Do neighborhoods generate fear of crime? An empirical test using the British Crime Survey. Criminology, 49, 331-369. doi: 10.1111/j.1745-9125.2011.00228.x

Burchfield, K. B. (2012). Assessing community residents' perceptions of local registered sex offenders. Deviant Behavior, 33, 241-259. doi:

10.1080/01639625.2011.573396

Burchfield, K. B., \& Mingus, W. (2008). Not in my neighborhood: Assessing registered sex offenders' experiences with local social capital and social control. Criminal Justice and Behavior, 35, 356-374. doi: 10.1177/0093854807311375

Burchfield, K. B., \& Mingus, W. (2014). Sex offender reintegration: Consequences of the local neighborhood context. American Journal of Criminal Justice, 39, 109-124. doi: 10.1007/s12103-012-9195-X

Burnell, J. D. (1988). Crime and racial composition of contiguous communities as negative externalities: Prejudiced households' evaluation of crime rate and segregation nearby reduces housing values and tax revenues. The American Journal of Economics and Sociology, 47, 177-193. 
Caputo, A. A., Brodsky, S. L. (2004). Citizen coping with community notification of released sex offenders. Behavior Sciences and the Law, 22. doi: 10.1002/bsl.566

Cayo, M. R., \& Talbot, T. O. (2003). Positional error in automated geocoding of residential addresses. International Journal of Health Geographics, 2, 10-22. Retrieved from https://www.ncbi.nlm.nih.gov/pmc/articles/PMC324564/pdf/1476-072X-2-10.pdf

Caudill, S. B., Affuso, E., \& Yang, M. (2014). Registered sex offenders and house prices: An hedonic analysis. Urban Studies, 52(13), 1-16. doi:

$10.1177 / 0042098014547368$

Chajewski, M., \& Mercado, C. C. (2009). An evaluation of sex offender residency restriction functioning in town, county, and city-wide jurisdictions. Criminal Justice Policy Review, 20, 44-61. doi: 10.1177/0887403408320845

Cho, S., Clark, C. D., \& Park, W. M. (2006). Two dimensions of the spatial distribution of housing: Dependency and heterogeneity across Tennessee's six metropolitan statistical areas. Journal of Agricultural and Applied Economics, 38, 299-316.

Clark, V. A., \& Duwe, G. (2015). Factors associated with sex offender concentrations in Minnesota neighborhoods. Retrieved from Minnesota Department of Corrections website:

http://www.doc.state.mn.us/pages/files/2814/3767/0983/Sex_Offender_Concentra tion_-_July_2015.pdf

Colombino, N., Mercado, C. C., Levenson, J., \& Jeglic, E. (2011). Preventing sexual violence: Can examination of offense location inform sex crime policy? 
International Journal of Law and Psychiatry, 34, 160-167. doi:

10.1016/j.ijlp.2011.04.002

Congdon-Hohman, J. M. (2013). The lasting effects of crime: The relationship of discovered methamphetamine laboratories and home values. Regional Science and Urban Economics, 43, 31-41. doi: 10.1016/j.regsciurbeco.2012.11.005

Coulton, C. J., Cook, T., \& Irwin, M. (2004). Aggregation issues in neighborhood research: A comparison of several levels of census geography and resident defined neighborhoods. Retrieved from Center on Urban Poverty and Social Change website:

http://mcstudy.norc.org/publications/files/Coulton_APPAM_2004_Aggregate_reli abilit.pdf

Craun, S. W. (2010). Evaluating awareness of registered sex offenders in the neighborhood. Crime \& Delinquency, 56, 414-435. doi:

$10.1177 / 0011128708317457$

Craun, S. W., \& Theriot, M. T. (2009). Misperceptions of sex offender perpetration: Considering the impact of sex offender registration. Journal of Interpersonal Violence, 24, 2057-2072. doi: 10.1177/0886260508327706

Dubin, R., Pace, R. K., \& Thibodeau, T. G. (1999). Spatial autoregression techniques for real estate data. Journal of Real Estate Literature, 7, 79-95.

Duwe, G., \& Donnay, W. (2008). The impact of Megan's Law on sex offender recidivism: The Minnesota experience. Criminology, 46, 411-446. doi: $10.1177 / 0093854807313690$ 
Duwe, G., Donnay, W., \& Tewksbury, R. (2008). Does residential proximity matter? A geographic analysis of sex offense recidivism. Criminal Justice and Behavior, 35, 484-504.

Elbogen, E. B., Patry, M., \& Scalora, M. J. (2003). The impact of community notification laws on sex offender treatment attitudes. International Journal of Law and Psychiatry, 26, 207-219.

Evans, D. N., \& Cubellis, M. A. (2015). Coping with stigma: How registered sex offenders manage their public identities. American Journal of Criminal Justice, 40, 593-619. doi: 10.1007/x12103-014-9277-z

Gau, J. M., \& Pratt, T. C. (2008). Broken windows or window dressing? Citizens' (in)ability to tell the difference between disorder and crime. Criminology \& Public Policy, 7. 163-194. doi: 10.1111/j.1745-9133.2008.00500.x

Gendall, P. (2005). Can you judge a questionnaire by its cover? The effect of questionnaire cover design on mail survey response. International Journal of Public Opinion Research, 17, 346-361. doi: 10.1037/1082-989X.12.2.121

Goffman, E. (1963). Stigma: Notes on the management of spoiled identity. Englewood Cliffs, NJ: Prentice-Hall.

Goodman, A. C., \& Thibodeau, T. G. (2007). The spatial proximity of metropolitan area housing submarkets. Real Estate Economics, 35, 209-232.

Gordon, K. E. (2013). The registered sex offender population as a marker of social disorganization. The Howard Journal of Criminal Justice, 52, 527-542. doi: 10.1111/hojo.12024 
Green, K. E. (1996). Sociodemographic factors and mail survey response. Psychology \& Marketing, 13, 171-184.

Harbaugh, R. (2002, October). Good mail survey response rates. $M M \& M$, 71-76.

Hipp, J. R. (2007). Block, tract, and levels of aggregation: Neighborhood structure and crime and disorder as a case in point. American Sociological Review, 72, 659-680.

Hipp, J. R., Turner, S., \& Jannetta, J. (2010). Are sex offenders moving into social disorganization? Analyzing the residential mobility of California parolees. Journal of Research in Crime \& Delinquency, 47, 558-590. doi:

$10.1177 / 0022427810381093$

Huebner, B. M., Bynum, T. S., Rydberg, J., Kras, K., Grommon, E., Pieggenkuhle, B. (2013). An evaluation of sex offender residency restrictions in Michigan and Missouri (NIJ 2008-DD-BX-0002). Retrieved from National Criminal Justice Reference Service website: https:/www.ncjrs.gov/pdffiles1/nij/grants/242952.pdf

Hughes, L. A., \& Burchfield, K. B. (2008). Sex offender residence restrictions in Chicago: An environmental injustice? Justice Quarterly, 25, 647-673. doi: $10.1080 / 07418820802119976$

Hughes, L. A., \& Kadleck, C. (2008). Sex offender community notification and community stratification. Justice Quarterly, 25, 469-495. doi: $10.1080 / 07418820701710941$

IBM Corporation. Released 2016. IBM SPSS Statistics for Windows, Version 24.0. Armonk, NY: IBM Corp. 
Ihlanfeldt, K., \& Mayock, T. (2010). Panel data estimates of the effects of different types of crime on housing prices. Regional Science and Urban Economics, 40, 161-172. doi: 10.1016/j.regsciurbeco.2010.02.005

Ingram, D. D., \& Franco, S. J. (2014). 2013 NCHS urban-rural classification scheme for counties (DHHS Publication NO. 2014-1366). Retrieved from Center for Disease Control and Prevention website: https://www.cdc.gov/nchs/data/series/sr_02/sr02_166.pdf

Kaylen, M. T., \& Pridemore, W. A. (2013). Social disorganization and crime in rural communities. British Journal of Criminology, 53, 905-923. doi: 10.1093/bjc/azt031

Kelling, G. L., \& Wilson, J. Q. (1982, March). Broken windows: The police and neighborhood safety. The Atlantic, 29-39.

Kernsmith, P. D., Comartin, E., Craun, S. W., \& Kernsmith, R. M. (2009). The relationship between sex offender registry utilization and awareness. Sexual Abuse: A Journal of Research and Treatment, 21, 181-193. doi:

$10.1177 / 1079063209332235$

Kernsmith, P. D., Craun, S. W., \& Foster, J. (2009). Public attitudes toward sexual offenders and sex offender registration. Journal of Child Sexual Abuse, 18, 290301. doi: 10.1080/10538710902901663

Kruttschnitt, C., Uggen, C., \& Shelton, K. (2000). Predictors of desistance among sex offenders: The interaction of formal and informal social controls. Justice Quarterly, 17, 61-87. 
Kubrin, C. E., \& Herting, J. R. (2003). Neighborhood correlates of homicide trends: An analysis using growth-curve modeling. The Sociological Quarterly, 44, 329-350.

Kubrin, C. E., \& Weitzer, R. (2003). New directions in social disorganization theory. Journal of Research in Crime and Delinquency, 40, 374-402. doi: $10.1177 / 0022427803256238$

Larsen, J. E., Lowrey, K. J., \& Coleman, J. W. (2003). The effect of proximity to a registered sex offender's residence on a single-family house selling price. The Appraisal Journal, 71, 253-265.

Leipnik, M., Ye, X., Serna, J., Strong, J., Wilkins, C., \& Wu, L. (2016). Spatial aspects of restrictions on registered sex offenders. Geographical Review, 106, 312-330.

Letourneau, E. J., Levenson, J. S., Bandyopadhyay, D., Sinha, D., \& Armstrong, K. S. (2010). Effects of South Carolina's sex offender registration and notification policy on adult recidivism. Criminal Justice Policy Review, 21, 435-458. doi: $10.1177 / 0887403409353148$

Levenson, J. S., Brannon, Y. N., Fortney, T., \& Baker, J. (2007a). Public perceptions about sex offenders and community protection policies. Analyses of Social Issue and Public Policy, 7, 137-161.

Levenson, J. S., \& Cotter, L. P. (2005). The effect of Megan's Law on sex offender reintegration. Journal of Contemporary Criminal Justice, 21, 49-66. doi: $10.1177 / 1043986204271676$

Levenson, J. S., D’Amora, D. A., Hern, A. L. (2007b). Megan's Law and its impact on community re-entry for sex offenders. Behavioral Sciences and the Law, 25, 587607. doi: $10.1002 / \mathrm{bsl} .770$ 
Lieb, R., \& Nunlist, C. (2008). Community notification as viewed by Washington's citizens: A 10-year follow-up (Rep. No. 08-03-1101). Olympia, WA: Washington State Institute for Public Policy. Retrieved from http://www.wsipp.wa.gov/ReportFile/1010/Wsipp_Community-Notification-asViewed-by-Washingtons-Citizens-A-10-Year-Follow-Up_Full-Report.pdf

Linden, L., \& Rockoff, J. E. (2008). Estimates of the impact of crime risk on property values from Megan's Laws. American Economic Review, 98, 1103-1127. doi: 10.1257/aer.98.3.1103

Luke, D. A. (2004). Multilevel modeling (Sage University Paper series on Quantitative Applications in the Social Sciences, 07-143). Thousand Oaks, CA: Sage Publications.

Maguire, M., \& Singer, J. K. (2011). A false sense of security: Moral panic driven sex offender legislation. Critical Criminology, 19, 301-312. doi: 10.1007/s10612-0109127-3

McCoach, B. D. (2010). Hierarchical linear modeling. In G. R. Hancock \& R. O. Mueller (Eds.), Quantitative methods in the social and behavioral sciences: A guide for researchers and reviewers (pp. 123-140). New York, NY: Routledge.

McCoppin, R. (2016, July 24). Sex offenders sue, saying registry laws keep them from church, living with family. Chicago Tribune. Retrieved from http://www.chicagotribune.com/news/ct-sex-offender-registry-suit-met20160724-story.html 
McMillen, D. P. (2008). Changes in the distribution of house prices over time: Structural characteristics, neighborhood, or coefficients? Journal of Urban Economics, 64, 573-589. doi: 10.1016/j.jue.2008.06.002

Meloy, M. L., Miller, S. L., \& Curtis, K. M. (2008). Making sense out of nonsense: The deconstruction of state-level sex offender residence restrictions. American Journal of Criminal Justice, 33, 209-222. doi: 10.1007/s12103-008-9042-2

Mills, S. (2015, January 25). State keeps 1,250 parolees behind bars due to housing shortage. Chicago Tribune. Retrieved from http://www.chicagotribune.com/news/local/ct-violating-at-the-door-met20150125-story.html

Mustaine, E. E., \& Tewksbury, R. (2008). Registered sex offenders, residence, and the influence of race. Journal of Ethnicity in Criminal Justice, 6, 65-82. doi: 10.1300/J222v06n01_05

Mustaine, E. E., \& Tewksbury, R. (2011a). Assessing informal social control against the highly stigmatized. Deviant Behavior, 32, 944-960. doi:

$10.1080 / 01639625.2010 .538361$

Mustaine, E. E., \& Tewksbury, R. (2011b). Residential relegation of registered sex offenders. American Journal of Criminal Justice, 36, 44-57. doi: 10.1007/s12103010-9102-2

Mustaine, E. E., \& Tewksbury, R. (2013). What can be learned from an online sex offender registry site? An eight-year follow-up. Journal of Community Corrections, 23, 5-10. 
Mustaine, E. E., Tewksbury, R., \& Stengel, K. M. (2006a). Residential location and mobility of registered sex offenders. American Journal of Criminal Justice, 30, 177-192. doi: 10.1007/BF02885890

Mustaine, E. E., Tewksbury, R., \& Stengel, K. M. (2006b). Social disorganization and residential locations of registered sex offenders: Is this a collateral consequence? Deviant Behavior, 27, 329-350. doi: 10.1080/01639620600605606

National Center for Education Statistics. (2016). Common core of data: Identification of rural locales. Retrieved from https://nces.ed.gov/ccd/rural_locales.asp

Navarro, J. C., \& Rabe-Hemp, C. (2017). The financial impact of registered sex offenders on home sale prices: A case study of McLean County, Illinois. International Journal of Rural Criminology, $x$, xx-xx. doi:

Nobles, M. R., Levenson, J. S., \& Youstin, T. J. (2012). Effectiveness of residence restrictions in preventing sex offense recidivism. Crime \& Delinquency, 58, 491513. doi: $10.1177 / 0011128712449230$

Office of Justice Programs (OJP). (2016). SORNA implementation status. Retrieved from National Sex Offender Public Website: http://www.smart.gov/sorna-map.htm Park, R. E., \& Burgess, E. W. (1925). The city. Chicago, IL: The University of Chicago Press.

Perkins, D. D., \& Taylor, R. B. (1996). Ecological assessments of community disorder: Their relationship to fear of crime and theoretical implications. American Journal of Community Psychology, 24, 63-107. 
Phillips, D. M. (1998). Community notification as viewed by Washington's citizens (Rep. No. 98-03-1101). Olympia, WA: Washington State Institute for Public Policy. Retrieved from http://wsipp.wa.gov/ReportFile/1281

Pierewan, A. D., \& Tampubolon, G. (2014). Spatial dependence multilevel model of well-being across regions in Europe. Applied Geography, 47, 168-176.

Pope, J. C. (2008). Fear of crime and housing prices: Household reactions to sex offender registries. Journal of Urban Economics, 64, 601-614. doi:

10.1016/j.jue.2008.07.001

Prescott, J. J., \& Rockoff, J. E. (2011). Do sex offender registration and notification laws affect criminal behavior, Journal of Law \& Economics, 54, 161-206. Retrieved from

https://www0.gsb.columbia.edu/faculty/jrockoff/papers/Prescott\%20and\%20Rock off\%20jle.pdf

Rade, C. B., Desmarais, S. L., \& Mitchell, R. E. (2016). A meta-analysis of public attitudes toward ex-offenders. Criminal Justice and Behavior, 43, 1260-1280. doi: $10.1177 / 0093854816655837$

Ragusa-Salerno, L. M., Zgoba, K. M. (2012). Taking stock of 20 years of sex offender laws and research: An examination of whether sex offender legislation has helped or hindered our efforts. Journal of Crime and Justice, 35, 335-355. doi: 10.1080/0735648X.2012.662069

Raudenbush, S., \& Bryk, A. (2002). Hierarchical linear models: Applications and data analysis methods (2nd Ed.). Thousand Oaks: Sage. 
Raudenbush, S. W., Bryk, A. S., \& Congdon, R. (2013). HLM 7.01 for Windows [Computer software]. Skokie, IL: Scientific Software International, Inc

Ross, C. E., \& Mirowsky, J. (1999). Disorder and decay. The concept of measurement of perceived neighborhood disorder. Urban Affairs Review, 34, 412-432. doi: $0.1177 / 10780874990340030$

Sample, L. L., \& Kadleck, C. (2008). Sex offender laws: Legislators' accounts of the need for policy. Criminal Justice Policy Review, 19, 40-62. doi: $10.1177 / 0887403407308292$

Sampson, R. J., \& Groves, W. B. (1989). Community structure and crime: Testing social disorganization. American Journal of Sociology, 94, 774-802.

Sampson, R. J., Raudenbush, S. W., \& Earls, F. (1997). Neighborhoods and violent crime: A multilevel study of collective efficacy. Science, 277, 918-924.

Shaw, C. R., \& McKay, H. D. (1942). Juvenile delinquency and urban areas. Chicago, IL: University of Chicago Press.

Skogan, W. G. (1990). Disorder and decline: Crime and the spiral of decay in American neighborhoods. New York, NY: The Free Press.

Skogan, W. G., \& Maxfield, M. G. (1981). Coping with crime: Individual and neighborhood reactions. Beverly Hills, CA: Sage.

Sloas, L. B., Steele, P. D., \& Hare, T. S. (2012). Geographical access to treatment for sex offenders under community supervision in Kentucky. Journal of Sexual Aggression, 18, 294-310. doi: 10.1080/13552600.2011.580064 
Socia, K. M. (2011). The policy implications of residency restrictions on sex offender housing in Upstate NY. Criminology \& Public Policy, 10, 351-389. doi: 10.1111/j.1745-9133.2011.00713.x

Socia, K. M. (2012a). Residence restrictions and the association with registered sex offender clustering. Criminal Justice Policy Review, 24, 441-472. doi: $10.1177 / 0887403412445613$

Socia, K. M. (2012b). The efficacy of county-level sex offender residence restrictions in New York. Crime \& Delinquency, 58, 612-642. doi: 10.1177/0011128712441694

Socia, K. M. (2016). Examining the concentration of registered sex offenders in upstate New York census tracts. Crime \& Delinquency, 62, 748-776. doi: $10.1177 / 0011128714526563$

Socia, K. M., Levenson, J. S., Ackerman, A. R., \& Harris, A. J. (2015). "Brothers under the bridge": Factors influencing the transience of registered sex offenders in Florida. Sexual Abuse: A Journal of Research and Treatment, 27, 550-586. doi: $10.1177 / 1079063214521472$

Socia, K. M., \& Stamatel, J. P. (2012). Neighborhood characteristics and the social control of registered sex offenders. Crime \& Delinquency, 58, 565-587. doi: $10.1177 / 0011128711420111$

Sperber, K. G., Lowenkamp, C. T., Carter, D. E., \& Allman, R. (2010). A sheep in wolf's clothing or a wolf in sheep's clothing? Ohio sex offender registration and the role of science. Criminal Justice Policy Review, 21, 500-519. doi:

$10.1177 / 0887403409350909$ 
Sullum, J. (2016, December 5). Two federal courts call BS on banning sex offenders from 'child safety zones'. Reason.com. Retrieved from http://reason.com/blog/2016/12/05/two-federal-courts-call-bs-on-banning-se

Suresh, G., Mustaine, E. E., Tewksbury, R., \& Higgins, G. E. (2010). Social disorganization and registered sex offenders: An exploratory spatial analysis. Southwest Journal of Criminal Justice, 7, 180-213.

Sutherland, E. H. (1939). Principles of criminology. Chicago, IL: J. B. Lippincott Company.

Tewksbury, R. (2005). Collateral consequences of sex offender registration. Journal of Contemporary Criminal Justice, 21, 67-81. doi: 10.1177/1043986204271704

Tewksbury, R. (2012). Stigmatization of sex offenders. Deviant Behavior, 33, 606-623. doi: $10.1080 / 01639625.2011 .636690$

Tewksbury, R., \& Jennings, W. G. (2010). Assessing the impact of sex offender registration and community notification on sex-offending trajectories. Criminal Justice and Behavior, 37, 570-582. doi: 10.1177/0093854810363570

Tewksbury, R., \& Lees, M. (2006). Perceptions of sex offender registration: Collateral consequences and community experiences. Sociological Spectrum, 26, 309-334. doi: $10.1080 / 02732170500524246$

Tewksbury, R., \& Mustaine, E. E. (2006). Where to find sex offenders: An examination of residential locations and neighborhood conditions. Criminal Justice Studies, 19, 61-75. doi: 10.1080/14786010600615991 
Tewksbury, R., \& Mustaine, E. E. (2008). Where registered sex offenders live:

Community characteristics and proximity to possible victims. Victims \& Offenders, 3, 86-98. doi: 10.1080/15564880701752371

Tewksbury, R., \& Mustaine, E. E. (2010). Stress and collateral consequences for registered sex offenders. Journal of Public Management \& Social Policy, 54, 537551. doi: 10.1177/0306624X09339180

Tewksbury, R., Mustaine, E. E., \& Rolfe, S. (2016). Sex offender residential mobility and relegation: The collateral consequences continue. American Journal of Criminal Justice, 41, 852-866. doi: 10.1007/s12103-016-9341-y

Tewksbury, R., Mustaine, E. E., \& Stengel, K. M. (2007). Residential concentrations of rural registered sex offenders. American Journal of Criminal Justice, 31, 49-63. doi: $10.1007 / \mathrm{s} 12103-007-9004-0$

Tewksbury, R., Mustaine, E. E., \& Stengel, K. M. (2008). Examining rates of sexual offenses from a routine activities perspective. Victims \& Offenders, 3, 75-85.

Thaler, R. (1978). A note on the value of crime control: Evidence from the property market. Journal of Urban Economics, 5, 137-145.

The Council of State Governments (CSG). (2010). Final report: Sex offender management policy in the states: Strengthening policy and practice. Retrieved from The Council of State Governments website: http://www.csg.org/policy/documents/SOMFinalReport-FINAL.pdf The Minnesota Governor's Council on Developmental Disabilities. (2016). Professor John McKnight: Capacity building beyond community services. Retrieved from http://mn.gov/mnddc/mcKnight/johnMcKnight04.html 
Troy, A., \& Grove, J. M. (2008). Property values, parks, and crime: A hedonic analysis in Baltimore, MD. Landscape and Urban Planning, 87, 233-245. doi: 10.1016/j.landurbplan.2008.06.005

Unze, D., \& Marohn, K. (2016, November 21). Jacob Wetterling's killer gets 20 years for porn, apologizes for murder. USA Today. Retrieved from http://www.usatoday.com/story/news/nation-now/2016/11/21/confessed-killerjacob-wetterling-gets-20-years-porn-case/94223558/

Urban Institute. (2016). The alarming lack of data on Latinos in the criminal justice system. Retrieved from http://apps.urban.org/features/latino-criminal-justice-data/ U.S. Census Bureau. (2016a). State and county quick facts: DuPage County, Illinois. Retrieved from the Urban Institute website: http://www.census.gov/quickfacts/table/PST045215/17043

U.S. Census Bureau. (2016b). State and county quick facts: Jefferson County, Kentucky. Retrieved from http://www.census.gov/quickfacts/table/PST045214/21111

U.S. Census Bureau. (2016c). State and county quick facts: Lee County, Illinois. Retrieved from http://www.census.gov/quickfacts/table/HCN010212/17103

Weisheit, R. A., \& Wells, L. E. (2005). Deadly violence in the Heartland: Comparing homicide patterns in nonmetropolitan and metropolitan counties. Homicide Studies, 9, 55-80. doi: 10.1177/1088767904271434

Wentland, S., Waller, B., \& Brastow, R. (2014). Estimating the effect of crime risk on property values and time on market: Evidence from Megan's Law in Virginia. Real Estate Economics, 42, 223-251. 
Wolfson, A. (2015, August 9). No place to live, sex offenders kept in prison. The Courier Journal. Retrieved from http://www.courierjournal.com/story/news/local/2015/08/06/place-live-sex-offenders-keptprison/31250707/

Yeh, S. (2015). Revealing the rapist next door: Property impacts of a sex offender registry. International Review of Law and Economics, 44, 42-60. doi: 10.1016/j.irle.2015.08.001

Zandbergen, P. A., \& Hart, T. C. (2006). Reducing housing options for convicted sex offenders: Investigating the impact of residence restriction laws using GIS. Justice Research and Policy, 8(2), 1-24. doi: 10.3818/JRP.8.2.2006.1

Zandbergen, P. A., \& Hart, T. C. (2009). Geocoding accuracy considerations in determining residences restrictions for sex offenders. Criminal Justice Policy Review, 20, 67-90. doi: 10.1177/0887403408323690

Zevitz, R. G. (2004). Sex offender placement and neighborhood social integration: The making of a scarlet letter community. Criminal Justice Studies, 17, 203-222. doi: $10.1080 / 0888431042000235039$

Zevitz, R. G. (2006). Sex offender community notification: Its role in recidivism and offender reintegration. Criminal Justice Studies, 19, 193-208. doi: $10.1080 / 14786010600764567$

Zevitz, R. G., \& Farkas, M. A. (2000a). Sex offender community notification: Assessing the impact in Wisconsin (NCJ Research Brief No. 179992). Washington, DC: United States Department of Justice, National Institute of Justice. Retrieved from https://www.ncjrs.gov/pdffiles1/nij/179992.pdf 
Zevitz, R. G., \& Farkas, M. A. (2000b). Sex offender community notification: Managing high risk criminals or exacting further vengeance? Behavior Science Law, 18, $375-391$.

\section{LEGISLATION AND CASES}

720 ILCS $\S 5 / 11-9.3$.

720 ILCS $\S 5 / 11-9.4-1$.

725 ILCS $\S 205 / 1.01$.

725 ILCS $\S 207 / 5$.

730 ILCS $\S 150 / 2$.

730 ILCS $\S 150 / 5-10$.

730 ILCS $§ 150 / 6$.

730 ILCS $\S 150 / 7$.

730 ILCS $\S 150 / 8$.

730 ILCS $\S 152 /$.

Adam Walsh Child Protection Act, 2006, Pub. L. No. 109-248, 120 Stat. 587.

Commonwealth v. Baker, 295 S.W.3d 437 (Ky. 2009)

Jacob Wetterling Crimes Against Children and Sexually Violent Offender Registration

Program of 1994, 42 U.S. CBLA. $§ 14071$.

KRS $\S 17.500$.

KRS $§ 17.510$.

KRS $\S 17.520$.

KRS $§ 17.545$. 
KRS $§ 17.580$.

Megan's Law of 1996, Pub. L. No. 104-145, 110 Stat. 1345. 


\section{APPENDIX A}

Uor. Insthutional Revlew Boards IRB NUMBER: 17.0058

IFB APPROVAL DATE: 02/10/2017

IFB EXPIRATION DATE: 02/09/2018

Dear Community Resident,

You are being invited to participate in a research study by answering the attached survey about your neighborhood. Your responses are important as they will help assess the quality of life of residents across communities. There are no known risks for your participation in this research study. The information collected may not benefit you directly.

Please take 10 - 15 minutes to complete the survey. Your

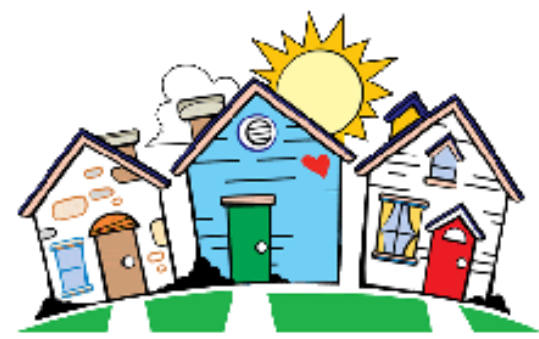
completed survey will be stored in a locked office and on an encrypted, password-protected computer at the Department of Criminal Justice. You do not have to answer any questions that make you uncomfortable. You may choose not to take part at all. Your participation, though, is vital in aiding our understanding of residents' perceptions regarding their neighborhood, as well as to give every resident an opportunity to express his/her opinions and concerns about their neighborhood. If you would like to, please respond to the survey (must be at least 18 years old and a homeowner of the home address), and return the survey within two weeks of its receipt in the business reply envelope supplied. By returning this survey, you agree to participate voluntarily in this research study, with the information learned in this study possibly helpful to others.

Individuals from the Department of Criminal Justice, the Institutional Review Board (IRB), the Human Subjects Protection Program Office (HSPPO), and other regulatory agencies may inspect these records. In all other respects, however, the data will be held in confidence to the extent permitted by law. Your identity will not be disclosed should the data be published. The IRB is an independent committee made up of people from the University community, the staff of the institutions, as well as people from the community not connected with these institutions. If you have questions about your rights as a research subject, you may call the HSPPO at 502-852-5188. You may also call this number if you have other questions about the research, and you cannot reach the research staff, or want to talk to someone else. If you have concerns or complaints about the research or research staff and you do not wish to give your name, you may call 1-877-852-1167; a 24-hour hotline answered by people not affiliated with the University of Louisville.

Please contact Dr. Richard Tewksbury (502-852-0379) or John Navarro (630-280-9930) if you have any questions, concerns, or complaints about the research study.

At the conclusion of the study, a brief summary of the results of the study will be posted at: http-//louisville.edu/justice/community-study

Thank you!

Richard Tewksbury, Ph.D.

John C. Navarro, M.S. 


\section{APPENDIX B}

Please help us to understand the quality of life in your neighborhood better by answering the following questions. For each question, place an " $X$ " in the box or write in the blank that corresponds to the correct response. Participation is voluntary, and all of your responses will be confidential.

FRIENDSHIP NETWORK

\begin{tabular}{|l|l|l|l|c|c|}
\hline \multicolumn{1}{|c|}{ FRIENDSHIP NETWORK } & None & A little & About half & A lot & All \\
\hline How many of your neighbors do you feel you could recognize? & & & & & \\
\hline How many of your neighbors do you consider friends? & & & & & \\
\hline
\end{tabular}

ORGANIZATIONAL PARTICIPATION

\begin{tabular}{|c|c|c|c|}
\hline In the past 2 months, have you or a member of your household participated in the following activities? & Yes & No & Unsure \\
\hline Attendance of a church/religious event & & & \\
\hline Block club meeting & & & \\
\hline Neighborhood watch & & & \\
\hline School groups/organizations & & & \\
\hline Volunteering in the neighborhood & & & \\
\hline
\end{tabular}

CRIME POLICIES

\begin{tabular}{|l|l|l|l|l|}
\hline How familiar are you with the following crime-related policies? & Never heard of & Slightly familiar & Familiar & Very familiar \\
\hline Amber Alert & & & & \\
\hline Benjamin's Act & & & & \\
\hline DARE Program & & & & \\
\hline Megan's Law & & & & \\
\hline Sex offender registries/registration & & & & \\
\hline Violence Against Women Act & & & \\
\hline
\end{tabular}

NEIGHBORHOOD STRUCTURAL VARIABLES

\begin{tabular}{|l|lll|l|ll|}
\hline \multicolumn{7}{|c|}{ Are you familiar with any of the following in your immediate neighborhood? } \\
\hline Abandoned car & $\square$ Yes & $\square$ No & $\square$ Unsure & Park & Yes & $\square$ No \\
\hline Bar & $\square$ Yes & $\square$ No & $\square$ Unsure & Police station & $\square$ Unsure \\
\hline Church & $\square$ Yes & $\square$ No & $\square$ Unsure & Registered sex offender & $\square$ Yes & $\square$ No \\
\hline Litter & $\square$ Yes & $\square$ No & $\square$ Unsure & Run down property & $\square$ Unsure \\
\hline Liquor store & $\square$ Yes & $\square$ No & $\square$ Unsure & School & $\square$ No & $\square$ Unsure \\
\hline
\end{tabular}


CONDITIONS IN YOUR NEIGHBORHOOD

\begin{tabular}{|l|l|l|l|l|}
\hline Please indicate how much you agree or disagree with the following statements. & Strongly disagree & Disagree & Agree & Strongly agree \\
\hline
\end{tabular}

There is a lot of graffiti in my neighborhood.

My neighborhood is noisy.

Vandalism is common in my neighborhood

There are a lot of abandoned buildings in my neighborhood.

My neighborhood is clean.

People in my neighborhood take good care of their houses and apartments.

There are too many people hanging around on the streets near my home.

There is too much drug use in my neighborhood.

There is too much alcohol use in my neighborhood.

I often have trouble with my neighbors.

There is a lot of crime in my neighborhood.

In my neighborhood, people watch out for each other.

The police protection in my neighborhood is adequate.

My neighborhood is safe.

I can trust most people in my neighborhood.

\begin{tabular}{|l|l|l|l|l|}
\hline & & & & \\
\hline & & & & \\
\hline & & & & \\
\hline & & & & \\
\hline & & & & \\
\hline & & & & \\
\hline & & & & \\
\hline & & & & \\
\hline & & & & \\
\hline
\end{tabular}

CRIME VICTIMIZATION

Have you been a victim of a property crime (e.g., auto theft, home burglary, vandalism) in the past 12 months?

Have you been a victim of a sexual crime in the past 12 months?

Have you been a victim of a violent crime (e.g., assault) in the past 12 months?

Has someone in the house been a victim of a property crime in the past 12 months?

Has someone in the house been a victim of a sexual crime in the past 12 months?

Has someone in the house been a victim of a violent crime in the past 12 months?

Have you ever accessed the online sex offender registry?

\section{FUTURE RESIDENTIAL PLANS}

\begin{tabular}{|c|l|l|}
\hline \multicolumn{2}{|l|}{ Are you planning to move in the next year? } & $\square$ Yes \\
\hline If "yes", list the 3 main reasons. If "no" leave blank. & 1. & No \\
\hline & 2. \\
\hline & 3. \\
\hline
\end{tabular}


FEAR OF CRIME

\begin{tabular}{|l|l|l|l|c|}
\hline $\begin{array}{l}\text { How worried are you that the following crimes could happen to you or your } \\
\text { family in your neighborhood? }\end{array}$ & $\begin{array}{c}\text { Not worried } \\
\text { at all }\end{array}$ & $\begin{array}{c}\text { Somewhat } \\
\text { worried }\end{array}$ & $\begin{array}{c}\text { Worried } \\
\text { worried }\end{array}$ \\
\hline Your home being broken into and/or having something stolen? & & & & \\
\hline Being mugged or robbed? & & & & \\
\hline Being physically attacked by strangers? & & & \\
\hline
\end{tabular}

NEIGHBORHOOD ENVIRONMENT

\begin{tabular}{|l|l|l|l|l|c|}
\hline \begin{tabular}{|l|l|} 
Please indicate how much you agree or disagree with the \\
following statements.
\end{tabular} & $\begin{array}{c}\text { Strongly } \\
\text { disagree }\end{array}$ & Disagree & $\begin{array}{c}\text { Neither disagree } \\
\text { nor agree }\end{array}$ & Agree & $\begin{array}{c}\text { Strongly } \\
\text { agree }\end{array}$ \\
\hline People in this neighborhood do not share the same values. & & & & & \\
\hline People in this neighborhood generally do not get along. & & & & & \\
\hline People in this neighborhood can be trusted. & & & & & \\
\hline People around here are willing to help their neighbors. & & & & & \\
\hline This is a close-knit neighborhood. & & & & \\
\hline
\end{tabular}

NEIGHBORHOOD MANAGEMENT

\begin{tabular}{|l|l|l|l|l|}
\hline $\begin{array}{l}\text { Would you say it is very likely, likely, unlikely or very unlikely that people } \\
\text { in your neighborhood would act in the following manner? }\end{array}$ & $\begin{array}{c}\text { Very } \\
\text { likely }\end{array}$ & Likely & $\begin{array}{c}\text { Neither likely } \\
\text { nor unlikely }\end{array}$ & $\begin{array}{c}\text { Unlikely } \\
\text { unlikely }\end{array}$ \\
\hline $\begin{array}{l}\text { If a group of neighborhood children were skipping school and hanging out on a } \\
\text { street corner, how likely is it that your neighbors would do something about it? }\end{array}$ & & & & \\
\hline $\begin{array}{l}\text { If some children were spray-painting graffiti on a local building, how likely is it } \\
\text { that your neighbors would do something about it? }\end{array}$ & & & & \\
\hline $\begin{array}{l}\text { If a child was showing disrespect to an adult, how likely is it that people in your } \\
\text { neighborhood would scold that child? }\end{array}$ & & & & \\
\hline $\begin{array}{l}\text { If there was a fight in front of your house and someone was being beaten or } \\
\text { threatened, how likely is it that your neighbors would break it up? }\end{array}$ & & & & \\
\hline $\begin{array}{l}\text { Suppose that because of budget cuts the fire station closest to your home was } \\
\text { going to be closed down by the city. How likely is it that neighborhood } \\
\text { residents would organize to try to do something to keep the fire station open? }\end{array}$ & & & & \\
\hline
\end{tabular}




\begin{tabular}{|c|c|c|c|c|c|c|}
\hline \multicolumn{7}{|c|}{ DEMOGRAPHIC INFORMATION } \\
\hline Age: & Gender: & $\square$ Male & \multicolumn{4}{|l|}{$\square$ Female } \\
\hline \multicolumn{2}{|c|}{ Are you Hispanic or Latino? } & $\square$ Yes & $\square$ No & & & \\
\hline \multicolumn{7}{|c|}{ If yes, write down the Hispanic or Latino culture/origin: } \\
\hline \multicolumn{7}{|c|}{ With which of the following race/ethnicities do you most identify? } \\
\hline$\square$ White & & $\square$ Pacific Islander & & American Indian & \multirow{2}{*}{\multicolumn{2}{|c|}{ Other: }} \\
\hline$\square$ Black & & $\square$ Asian & & $\square$ Multiple races & & \\
\hline \multicolumn{7}{|c|}{ What is your highest level of completed education? } \\
\hline \multicolumn{2}{|c|}{$\square$ Less than high school } & $\square$ High school/GED & $\square$ Some college & $\square$ Bachelor's degree & \multicolumn{2}{|c|}{$\square$ Graduate/Professional degree } \\
\hline \multicolumn{7}{|c|}{ What is your employment status? } \\
\hline$\square$ Full-time & & $\square$ Full-time student & $\square$ Part-time & $\square$ Unemployed & \multicolumn{2}{|l|}{ Other: } \\
\hline \multicolumn{7}{|c|}{ What is your marital status? } \\
\hline$\square$ Married & $\square$ Cohabitating & \multicolumn{2}{|c|}{$\square$ Divorced/Separated/Widowed } & $\square$ Never married/Single & \multicolumn{2}{|l|}{ Other: } \\
\hline \multicolumn{7}{|c|}{ How many children less than or equal to five years old are currently living in your household? } \\
\hline \multicolumn{7}{|c|}{ How many children between the ages of 6 to 18 are currently living in your household? } \\
\hline \multicolumn{3}{|c|}{ Do you currently rent or own your current residence? } & $\square$ Rent & $\square$ Own & \multicolumn{2}{|l|}{ Other: } \\
\hline \multicolumn{5}{|c|}{ How long have you lived at your current residence? } & years & months \\
\hline \multicolumn{5}{|c|}{ Do you have Internet access at your current residence? } & $\square$ Yes & $\square$ No \\
\hline
\end{tabular}

This is the end of the survey. Thank you for your participation! Please return the survey in the provided self-addressed stamped envelope to: Department of Criminal Justice

$$
2301 \text { S. } 3^{\text {rd }} \text { St. }
$$

University of Louisville

Louisville, KY 40292

Page 4 of 4 


\section{Don't Forget to Send in Your Survey!}

You should have recently received a letter inviting you to participate in a University study that only requires you to complete and mail back the survey you received. We know you are busy and may have just forgotten. The survey is also accessible online (and by smartphone) in the link provided below in order to make the completion of the survey as easy as possible.

\section{www.surveymonkey.com/r/louisville 3}

For more information contact:

John Navarro (MS.): (630) 280-9930 | jcnava03 @louisville.edu

Dr. Richard Tewksbury: (502) 852-0379 | ratewk01@louisville.edu

We would really love to hear from you! 


\section{CURRICULUM VITAE}

John C. Navarro

Department of Criminal Justice

2301 S. $3^{\text {rd }}$ Street

University of Louisville

Louisville, KY 40292
Cell Phone: (630) 280-9930

E-mail: jcnava03@cardmail.louisville.edu

Office Phone: (502) 852-6086

\section{EDUCATION}

Expected Ph.D. - Criminal Justice, University of Louisville

June

2017

Dissertation: A cross-sectional exploration of household financial reactions and homebuyer awareness of registered sex offenders in a rural, suburban, and urban county

Chair: Dr. Richard Tewksbury

Committee: Drs. Jill Adelson, Justin Nix, \& Kristin

Swartz

2014 M.S. - Criminal Justice Sciences, Illinois State University

Thesis Paper: Location, location, location, the impact of registered sex offenders on home sale prices: $A$ case study of McLean County, Illinois

Chair: Dr. Cara Rabe-Hemp

Committee: Drs. Shelly Clevenger \& Jason Ingram

2011 B.S. - Psychology; Minor: Criminal Justice Sciences, Illinois State University

FINANCIAL AWARDS

2016 Ruth D. Peterson Fellowship for Racial and Ethnic $\$ 6,000$ Diversity - American Society of Criminology

2016 Graduate Student Council (GSC) Travel Scholarship - $\$ 350$ University of Louisville

$2016 \quad$ Graduate Network in Arts and Sciences (GNAS) - $\quad \$ 100$ (each) University of Louisville (Spring and Fall of 2016) 
2015 James L. Fisher Outstanding Thesis Award - College of

Applied Sciences and Technology, Illinois State

University

2014- Graduate Assistantship - Department of Criminal Justice,

Present University of Louisville

2011- Graduate Assistantship - Department of Criminal Justice

$2014 \quad$ Sciences, Illinois State University

\section{RESEARCH INTERESTS}

Victimization

Social Ecology

Communities
Public Policy

Spatial Analyses

Criminal Justice
Identity Theft

Sex Offenders

\section{PEER-REVIEWED MANUSCRIPTS}

Accepted Navarro, John C., \& Richard Tewksbury. National comparisons of rape myth acceptance predictors between non-athletes and athletes from multi-institutional settings. Sexual Abuse.

2017 Navarro, John C., \& Richard Tewksbury. Mythbusters: Examining rape myth acceptance amongst U.S. Division I university students. Journal of Student Affairs Research and Practice. Advance online publication. doi: 10.1080/19496591.2017.1289094

2017 Navarro, John C., \& George E. Higgins. Familial identity theft. American Journal of Criminal Justice, 42(1), 218-230. doi: $10.1007 / \mathrm{s} 12103-016-9357-3$

2016 Navarro, John C., \& Richard Tewksbury. Deconstructing the associations of religiosity, Christian denominations, and nonreligions to rape myth acceptance among university students. Deviant Behavior. Advance online publication. doi: 10.1080/01639625.2016.1260386

2015 Navarro, John C., \& Richard Tewksbury. Bestiality: An overview and analytic discussion. Sociology Compass, 9(10), 864875. doi: $10.1111 /$ soc4.12306 


\section{BOOK CHAPTERS}

In Richard Tewksbury, \& John C. Navarro. Sexuality in Prisons. In H. press Griffin \& V. Woodward (Eds.), Handbook of Corrections in the United States. New York, NY: Taylor \& Francis/Routledge.

2016 Navarro, John C., Jacqueline L. Schneider, \& Egan K. Green. Animal cruelty for sport and profit. In M. P. Brewster \& C. L. Reyes (Eds.), Animal cruelty: A multidisciplinary approach to understanding (2 ${ }^{\text {nd }}$ ed., pp. 159-197). Durham, NC: Carolina Academic Press.

2016 Rabe-Hemp, Cara, John Navarro, \& Cayla Comens. Corruption. In N. S. Lind, E. T. Rankin, \& G. Harris (Eds.), Today's economic issues: Democrats versus Republicans (pp. 20-27). Santa Barbara, CA: ABC-CLIO.

2015 Navarro, John C., \& Cara Rabe-Hemp. Identity theft in the $21^{\text {st }}$ century. In N. S. Lind \& E. Rankin (Eds.), Privacy in the digital

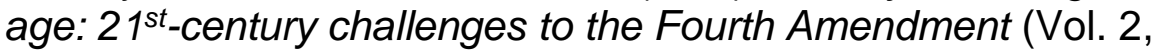
pp. 519-541). Santa Barbara, CA: ABC-CLIO.

2013 Navarro, John, \& Jacqueline L. Schneider. Animal cruelty for profit. In M. P. Brewster \& C. L. Reyes (Eds.), Animal cruelty: A multidisciplinary approach to understanding (pp. 127-155). Durham, NC: Carolina Academic Press.

\section{ENCYCLOPEDIA ENTRIES}

In Tewksbury, Richard \& John C. Navarro. Prison rape. In K. R. Kerley, press H. Copes, S. De Li, J. Lane, \& S. F. Sharp (Eds.), The Encyclopedia of Corrections. Hoboken, NJ: Wiley-Blackwell.

In Tewksbury, Richard \& John C. Navarro. Prison Rape Elimination Act press (2003). In K. R. Kerley, H. Copes, S. De Li, J. Lane, \& S. F. Sharp (Eds.), The Encyclopedia of Corrections. Hoboken, NJ: Wiley-Blackwell.

2016 Rabe-Hemp, Cara E., \& John C. Navarro. Experimental design in the study of crime, media, and popular culture. In N. Rafter and M. Brown (Eds.), The Oxford encyclopedia of crime, media, and popular culture. New York, NY: Oxford University Press. (9,579 words; peer-reviewed). Retrieved from http://criminology.oxfordre.com/view/10.1093/acrefore/978019 0264079.001.0001/acrefore-9780190264079-e-54 
2014 Navarro, John. Corporate Crime. In J. Albanese (Ed.), The Encyclopedia of Criminology and Criminal Justice (1 ${ }^{\text {st }}$ ed., Vol. 1, pp. 1-5). Hoboken, NJ: Wiley-Blackwell. doi:

10.1002/9781118517383.wbeccj328

\section{BOOK REVIEWS}

2016 Rabe-Hemp, Cara, \& John Navarro. A history of police and masculinities 1700-2010. [Review of the book $A$ history of police and masculinities, 1700-2010, by D. G. Barrie and S. Broomhall]. Policing \& Society, 26, 245-247. doi: 10.1080/10439463.2016.1120976

2015 John C. Navarro. The stick-up kids. [Review of the book The stickup kids: Race, drugs, violence, and the American Dream, by R. Contreras]. Criminal Justice Review, 40, 235-237. doi: $10.1177 / 0734016815571202$

\section{MANUSCRIPTS UNDER REVIEW}

Under Navarro, John C., \& Matthew Ruther. Sex offenders in your review neighborhood. (Submitted January 13, 2017 at Urban Studies; $\mathrm{R} \& \mathrm{R}$ April 28, 2017)

\section{MANUSCRIPTS IN PROGRESS}

In Navarro, John C., \& Richard Tewksbury. Rape myth acceptance progress pathways from high school onto university cultures.

In Navarro, John C. Intercity associations of young adult robbery progress amidst economic eras and rapid population change.

\section{TEACHING EXPERIENCE}

University of Louisville, Department of Criminal Justice Instructor of Record (Taught independently)

Organized Crime [Online]

Research Design

Crime \& Justice in the United States
Spring 2016

Fall 2015, Fall 2016

Summer 2015, Fall 2015

Courses Assisted (On-Line; Co-facilitated and taught with Drs. Ronald Holmes and Deborah Keeling)

Serial Murder

Spring 2015

Profiling Violent Crimes

Sex Crimes

Spring 2015

Fall 2014 
Illinois State University, Department of Criminal Justice Sciences

Teaching Assistant

Crime and Behavior [Criminological

Spring 2014

Theory]

Sex Offenders and the Criminal

Spring 2013

Justice System

Victimology

Terrorism and Counterterrorism

Spring 2013

Contemporary Policing in American

Society

Individuals, Society, and Justice

Summer 2013

Fall, 2011, Spring 2013, Fall 2013

Fall 2011 - Fall 2012, Fall 2013 -

Spring 2014

\section{ACADEMIC/RESEARCH EXPERIENCE}

University of Louisville, Department of Criminal Justice

Graduate Research and Teaching Assistant

Supervisor: Dr. Deborah G. Keeling Fall 2014 - Spring 2015

Illinois State University, Department of Criminal Justice Sciences

Graduate Research Assistant

Supervisors: Dr. Shelly Clevenger

Fall 2013 - Spring 2014

Dr. Jacqueline L. Schneider

Dr. Cara Rabe-Hemp

Fall 2011 - Spring 2012

Fall 2011 - Spring 2014

\section{Graduate Teaching Assistant}

Supervisors: Dr. Shelly Clevenger

Spring 2013

Dr. Cara Rabe-Hemp

Fall 2011 - Spring 2014

Illinois State University, Department of Psychology

Undergraduate Advanced Research Apprentice

Supervisor: Dr. Glenn Reeder

Fall 2010 - Spring 2011

\section{REVIEWER OF SCHOLARLY WORK}

Journal Articles

Criminal Justice Studies

Journal of Criminal Justice Education

Journal of Interpersonal Violence $\frac{\text { Book }}{\text { Oxford University Press }}$ 


\section{SERVICE}

March 2017

Ambassador for the Academy of

Criminal Justice Sciences

Graduate Student Summit

Spring 2013-Summer Normal Theater

6-12 hours/month

2014

Spring 2013-Fall

2013

Student Advisory Board - Illinois State University

6 hours/month

Fall 2009-Spring

2011

P.A.T.H. (Providing Access to Help)

20 hours/month

\section{MEDIA}

February Study: Religiosity is not associated with rape myth acceptance. $2017 \quad$ PsyPost.

September Study: Home prices may suffer in areas near offenders.

2014 Pantagraph.

RESEARCH PRESENTATIONS

\section{INTERNATIONAL AND NATIONAL}

2017 Navarro, John. (November). "Hiding" in plain sight. Effect of homebuyer awareness of sex offenders onto home selling prices. Paper to be presented at the $73^{\text {rd }}$ annual meeting of the American Society of Criminology, Philadelphia, PA.

2017 Navarro, John, \& Richard Tewksbury. (March). Deconstructing the associations of religiosity, Christian denominations, and nonreligions to rape myth acceptance among university students. Paper presented at the $54^{\text {th }}$ annual meeting of the Academy of Criminal Justice Sciences, Kansas City, MO.

2016 Navarro, John, \& Richard Tewksbury. (November). High school and university athletic participation and its influences on rape myth acceptance among students. Paper presented at the $72^{\text {nd }}$ annual meeting of the American Society of Criminology, New Orleans, LA.

2016 Navarro, John, \& Richard Tewksbury. (March). Division I college/university students' and student athletes' beliefs about sexual assaults. Paper presented at the $53^{\text {rd }}$ annual meeting of 
the Academy of Criminal Justice Sciences, Denver, CO.

2015 Navarro, John, \& Richard Tewksbury. (November). College students' beliefs about sexual assaults. Paper presented at the $71^{\text {st }}$ annual meeting of the American Society of Criminology, Washington, DC.

2015 Navarro, John, \& Cara Rabe-Hemp. (March). The concentration effect of registered sex offenders on home sale prices: A case study of McLean County, Illinois. Poster presented at the $52^{\text {nd }}$ annual meeting of the Academy of Criminal Justice Sciences, Orlando, FL.

2014 Navarro, John, \& Cara Rabe-Hemp. (November). Location, location, location, the impact of registered sex offenders on home sale prices: A case study of McLean County, Illinois. Paper presented at the $70^{\text {th }}$ annual meeting of the American Society of Criminology, San Francisco, CA.

2013 Navarro, John, \& Cara Rabe-Hemp. (November). The impact of sex offenders: A neighborhood context. Poster presented at the $69^{\text {th }}$ annual meeting of the American Society of Criminology, Atlanta, GA.

2013 Navarro, John, \& Shelly Clevenger. (November). The legality of bestiality in the United States. Paper presented at the $69^{\text {th }}$ annual meeting of the American Society of Criminology, Atlanta, GA.

2012 Navarro, John, \& Cara Rabe-Hemp. (November). Treatment, re-entry, and management of sex offenders. Paper presented at the $68^{\text {th }}$ annual meeting of the American Society of Criminology, Chicago, IL.

\section{REGIONAL}

2016 Navarro, John, \& Matthew Ruther. (September). Sex Offenders in Your Neighborhood. Paper presented at the $44^{\text {th }}$ annual meeting of the Southern Criminal Justice Association, Savannah, GA.

2015 Navarro, John, \& George Higgins. (September). Familial identity theft. Paper presented at the $43^{\text {rd }}$ annual meeting of the Southern Criminal Justice Association, Charleston, SC.

2014 Tewksbury, Richard \& John Navarro. (October). Sex Offender Registration Notification (SORN): Summaries of research. 
Presented at the meeting of the $10^{\text {th }}$ annual meeting of the National Juvenile Defender Leadership Summit, Louisville, KY.

2012 Navarro, John. (September). Corporate crime. Paper presented at the $35^{\text {th }}$ annual meeting of the Midwest Criminal Justice Association, Chicago, IL.

2012 Treger, Stanislav, \& John Navarro. (May). Moving to the music:

Rhythm tempo influences walking speed. Poster presented at the $83^{\text {rd }}$ annual meeting of the Midwest Psychological Association, Chicago, IL.

\section{PROFESSIONAL AFFILIATIONS}

2015- $\quad$ Academy of Criminal Justice Sciences (ACJS)

Present

2014-

Present

2012-

Present

Southern Criminal Justice Association (SCJA)

American Society of Criminology (ASC)

\section{PROFESSIONAL DEVELOPMENT}

University of Louisville PLAN Workshops (varies from 1 hour to a semester in length):

Delphi U Online (Semester long workshop)

Be Searchable

iClicker Training (3-hour workshop)

There's a Student with a disability in My Class...What Do I do

Now?

Blackboard Grade Center Basics and Beyond

Teaching Toolbox (3-hour workshop)

Transitioning into Faculty Life

Writing a Literature Review

Basics of Human Subjects Research Issues

Academic Job Search

Technology for Effective Teaching

More Than a Discussion Board: Best Practices and Effective

Applications for Teaching Online

Workshopping the CV

What GTAs Need to Know About Blackboard

Blackboard Basics

Spring 2017

Spring 2017

Fall 2016

Fall 2016

Fall 2016

Fall 2016

Spring 2016

Spring 2016

Spring 2016

Fall 2015

Spring 2015

Spring 2015

Fall 2014

Fall 2014

Fall 2014

CERTIFICATIONS

University of Louisville:

Delphi U: Principles of Online Course Design 
Delphi Center for Teaching \& Learning: Principles of Online Course Design Certification

Grant Writing Academy

Fall 2016

Fall 2015

Illinois State University:

ArcGIS I: Introduction to GIS

Spring 2014

ArcGIS II: Essential Workflows

Spring 2014

ArcGIS III: Performing Analysis

Spring 2014

Future Professors

Spring 2014

\section{COMPUTER AND TECHNICAL SKILLS}

Learning Management

Systems:

Mapping Software:

Office:

Statistical Software:

Technical:
Blackboard

Learn+

ArcGIS

Excel

HLM

Big Data

Analytics
Panopto

GeoDa

PowerPoint

SPSS

Qualitative

research
SoftChalk

GeoDa Space

Word

Quantitative

research

\section{ACADEMIC HONORS \& AWARDS}

2016 Academy of Criminal Justice Sciences Doctoral Graduate Student Summit Scholarship

2015-2016 Delphi Center for Teaching and Learning Faculty Favorite Nominee

2013 Outstanding Graduate Student Award - Criminal Justice Sciences Department, Illinois State University

2012 Doug Collins Male Scholar-Athlete of the Year Nominee - Illinois State University

2011 Anderson Financial Network, Inc (AFNI) Athletic Honor Roll 4.0 GPA - Illinois State University

2011 Missouri Valley Conference Cross Country Scholar Athlete

2010 State Farm Impact Award Recipient

2010-2011 Missouri Valley Conference State Farm Good Neighbor Award Recipient

2008-2011 Missouri Valley Conference Track \& Field Scholar Athlete 
2007-2012 Anderson Financial Network, Inc (AFNI) Athletic Honor Roll Illinois State University 